CRISTIANE LIONÇO ZEFERINO

\title{
Estudo do máximo carregamento em sistemas de energia elétrica via método da barreira modificada
}

Dissertação apresentada à Escola de Engenharia de São Carlos, da Universidade de São Paulo, como parte dos requisitos para a obtenção do Título de Mestre em Engenharia Elétrica.

Área de Concentração: Sistemas Elétricos de Potência.

Orientador: Prof. Dr. Geraldo Roberto Martins da Costa

São Carlos 


\section{DEDICATÓRIA}

Dedico este trabalho aos meus pais, a minha tia Vânia, à minha avó Alice, à minha irmã Gabriela e ao Alexandre, pessoas fundamentais na minha trajetória profissional e na minha vida, as quais eu amo muito. 


\section{AGRADECIMENTOS}

Ao meu orientador Geraldo Roberto Martins da Costa, o qual merece um agradecimento especial pela sua grande orientação e principalmente por sua amizade durante estes anos de convívio.

Ao professor Dílson Amâncio Alves pelas sugestões ao trabalho.

A todos os amigos e colegas do LOSEP pelos momentos agradáveis de convivência dentro e fora da USP, Fernando, Cristiane, Edmárcio, Marcus e Marcus e em especial a Vanusa que muito me auxílio neste trabalho.

A minha amiga Jaqueline por todos os momentos que passamos juntas, desde nossa graduação. Pelo seu incentivo, auxílio e disposição sempre quando precisei.

A minha amiga Elis, pela recepção, carinho e companhia quando aqui cheguei e pela grande amizade que temos hoje.

Ao CNPQ pelo suporte financeiro, sem o qual a realização deste trabalho não seria possível.

A Deus, que tornou possível todas estas coisas.

E a todos que, de alguma forma, contribuíram para o desenvolvimento deste trabalho. 


\section{RESUMO}

ZEFERINO, C. L. (2006). Estudo do máximo carregamento em sistemas de energia elétrica via método da barreira modificada. São Carlos, 2006. 45p. Dissertação (Mestrado) - Escola de Engenharia de São Carlos, Universidade de São Paulo.

Nesta dissertação é aplicado o método da Função Lagrangiana Barreira Modificada (FLBM), uma variante do método de pontos interiores, para determinação do máximo carregamento em sistemas de energia elétrica. A formulação do problema tem como restrições de igualdade as equações de balanço de potência do sistema, em sua forma parametrizada, e como restrições de desigualdade os limites de tensões nas barras e os limites de geração de potência reativa nas barras com controle de reativo.

Os resultados encontrados com a técnica de otimização estática utilizada neste estudo são confrontados com os resultados obtidos com o método Primal-Dual Barreira Logarítmica.

Para realização dos testes de desempenho da metodologia proposta, utilizou-se como padrão os sistemas do IEEE de 14, 57 e 118 barras. Os testes demonstraram a robustez e a eficiência do algoritmo proposto.

Palavras-chave: Colapso de Tensão, Máximo Carregamento, Método da Função Lagrangiana Barreira Modificada. 


\section{ABSTRACT}

ZEFERINO, C. L. (2006). Study of the maximum loadability on power systems via Modified Barrier method. São Carlos, 2006. 45p. M.Sc Dissertation - Escola de Engenharia de São Carlos, Universidade de São Paulo.

In this work the Modified Barrier Lagrangian Function (MBLF) method, a variant of the Interior Point Method, is applied for determination of the maximum loadability point in power systems. The formulation of the problem will have as constraints of equality the power system swinging equations, in a parametrized form, and as inequality constraints the voltage limits in the buses and the reactive generation limits in the buses with reactive control.

The results found with the static optimization technique used in this study are confronted with the results obtained with the Primal-dual Barrier Logarithmic method. The performance of the method is illustrated using as pattern the systems IEEE 14 , 57 and 118 bars. The tests demonstrated the robustness and the efficiency of the proposed algorithm.

Keywords: Maximum Loadability, Modified Barrier Lagrangian Function Method, Voltage Collapse. 


\section{LISTA DE FIGURAS}

Figura 1. Comportamento da carga ativa .................................................. 13

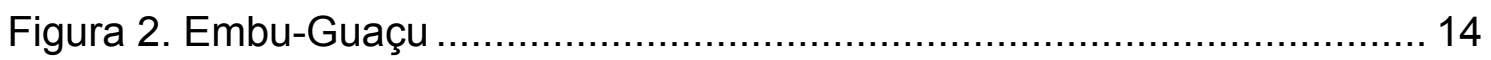

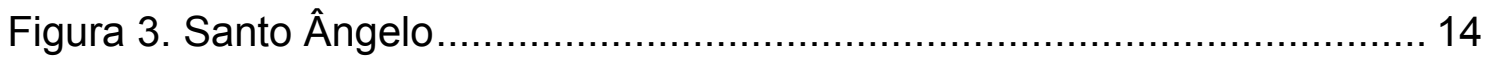

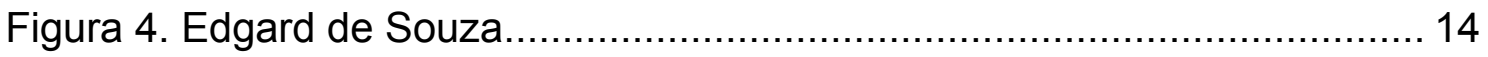

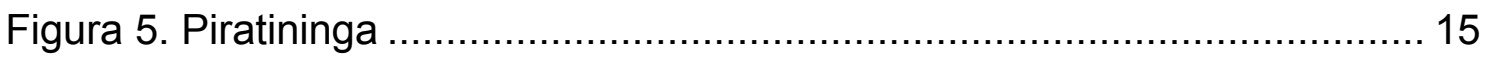

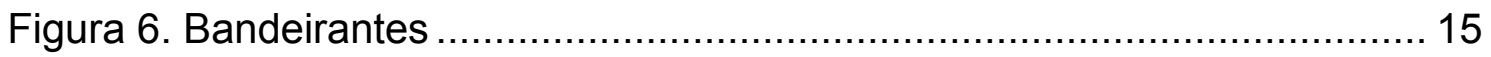

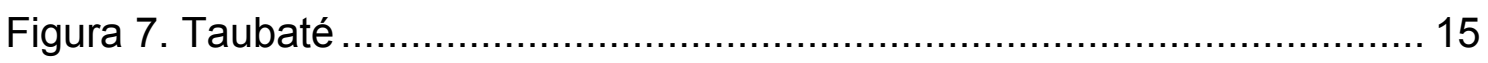

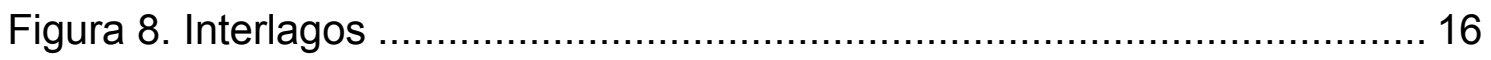

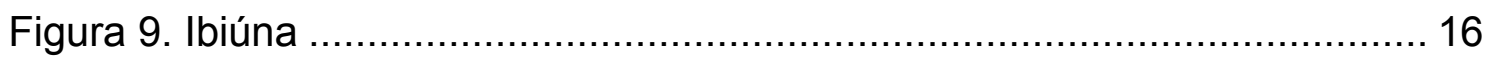

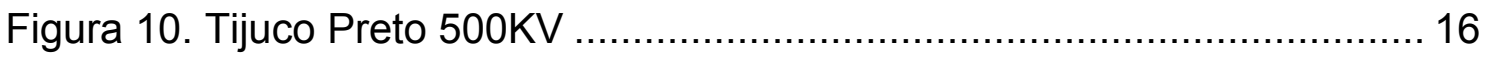

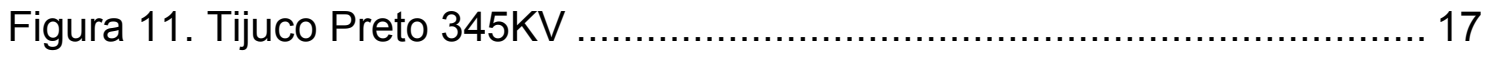

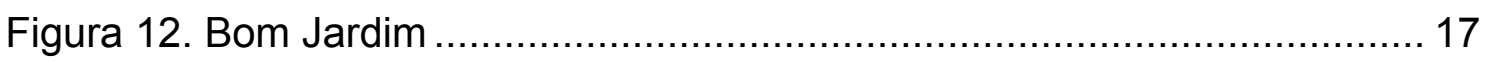

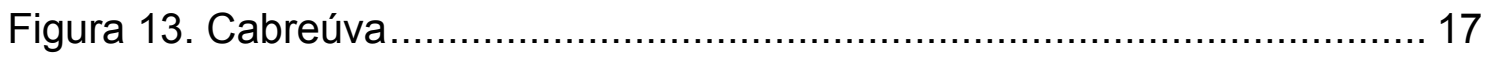

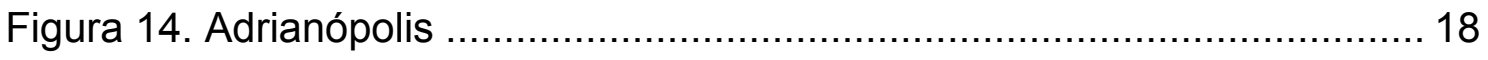

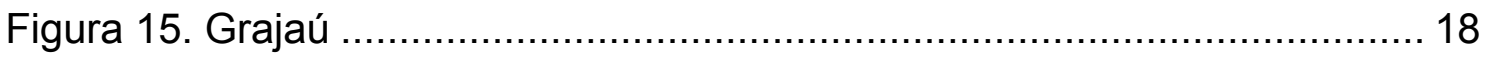

Figura 16. Geração Total do Sistema Sudeste.............................................. 18

Figura 17. Geração Total do Sistema Sul ................................................... 19

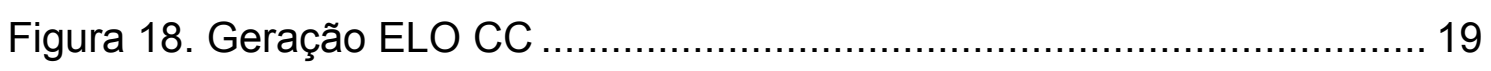

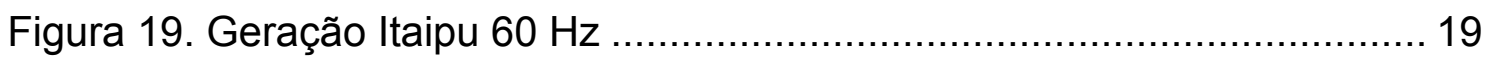

Figura 20. Geração Paranaíba .................................................................. 20

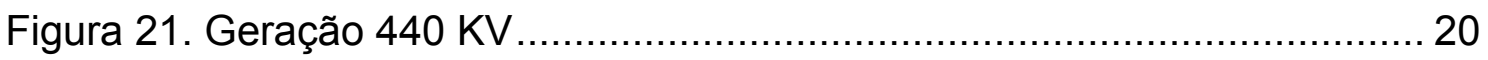


Figura 22. Potência Recebida pelo Sudeste ………….............................. 20

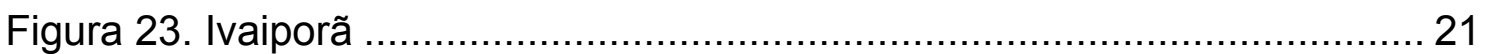

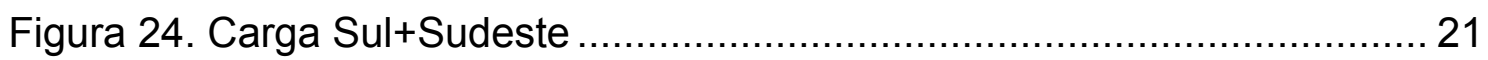

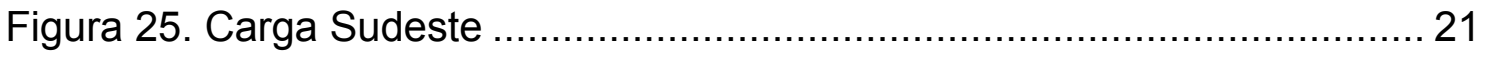

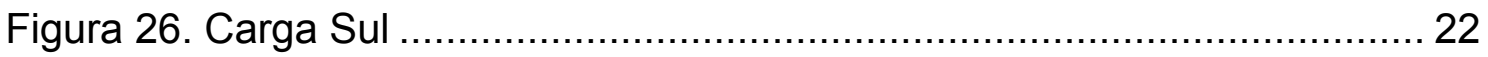

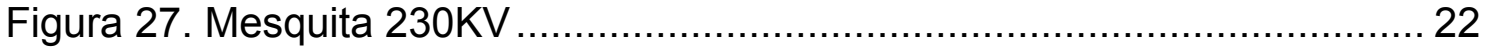

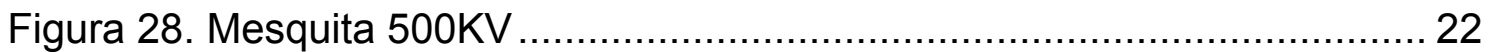

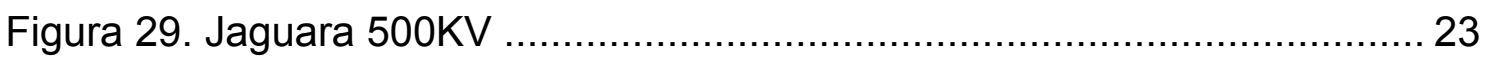

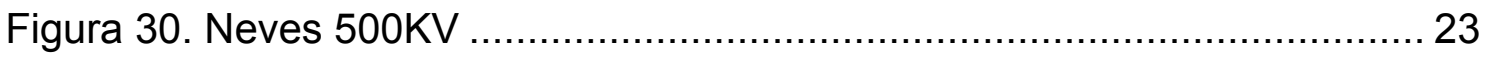

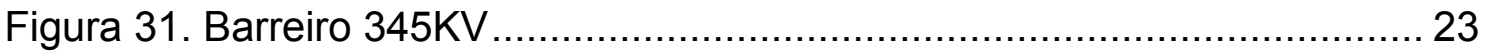

Figura 32. Compensador Síncrono de Ibiúna .............................................. 24

Figura 33. Compensador Síncrono Santo Ângelo ......................................... 24

Figura 34. Compensador Síncrono Embu ................................................. 24

Figura 35. Compensador Síncrono Grajaú.................................................. 25

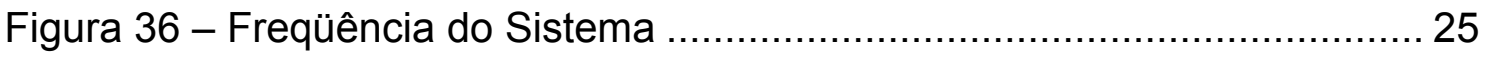

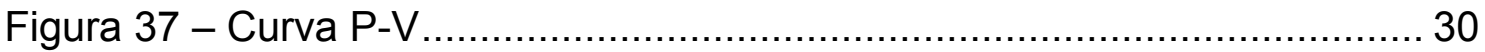

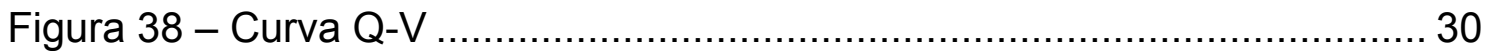

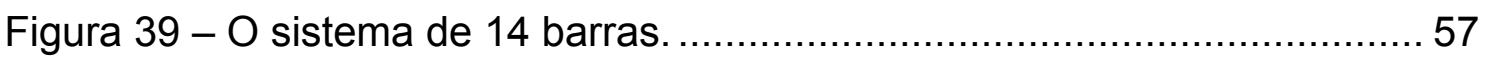

Figura 40 - Perfis de tensões para o sistema de 14 barras............................ 59

Figura 41 - Perfis de tensões para o sistema de 14 barras. ............................. 61

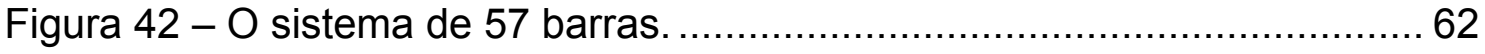

Figura 43. Perfis de tensões para o sistema de 57 barras .............................. 64

Figura 44. Perfis de tensões para o sistema de 57 barras .............................. 65

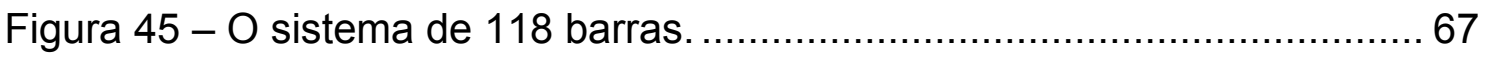

Figura 46. Perfis de tensões para o sistema de 118 barras .............................. 69 
Figura 47. Perfis de tensões para o sistema de 118 barras .......................... 71 


\section{LISTA DE TABELAS}

Tabela 1 - Comparativo entre o Método PDBL e o Método da FBM para o sistema de 14 barras 58

Tabela 2 - Comparativo entre o Método PDBL e o Método da FBM para o sistema de 14 barras 60

Tabela 3 - Comparativo entre o Método PDBL e o Método da FBM para o sistema de 57 barras 63

Tabela 4 - Comparativo entre o Método PDBL e o Método da FBM para o sistema de 57 barras 65

Tabela 5 - Comparativo entre o Método PDBL e o Método da FBM para o sistema de 118 barras 68

Tabela 6 - Comparativo entre o Método PDBL e o Método da FBM para o sistema de 118 barras 70 


\section{SUMÁRIO}

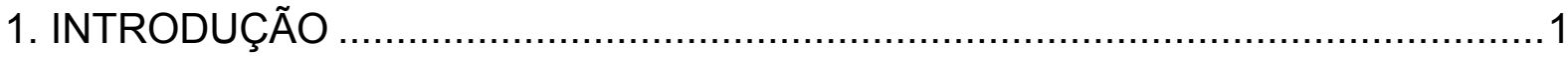

2. ALGUNS CONCEITOS BÁSICOS DE INSTABILIDADE DE TENSÃO ..................4

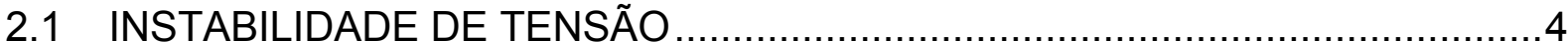

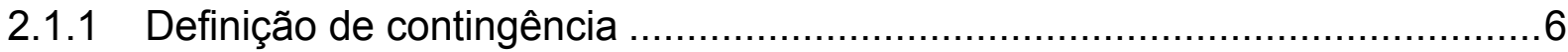

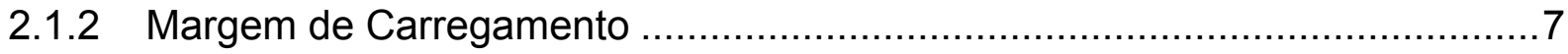

2.1.3 Descrição do Fenômeno Físico do Colapso de Tensão ..................................9

2.1.4 Colapso de tensão ocorrido em abril de 1997 no Sistema Interligado

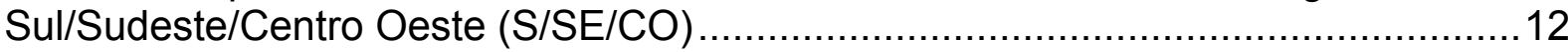

2.1.4.1 Descrição das Ocorrências do Dia 24/04/97 ……………….....................13

2.2 SUBDIVISÃO DA ANÁLISE DE ESTABILIDADE DE TENSÃO …..................26

2.2.1 Estabilidade a Grandes Perturbações .....................................................27

2.2.2 Estabilidade a Pequenas Perturbações..................................................27

2.3 MÉTODOS DE ANÁLISE DE ESTABILIDADE DE TENSÃO ….....................28

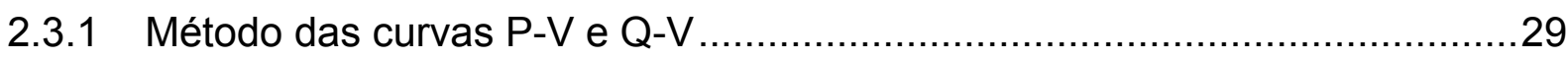

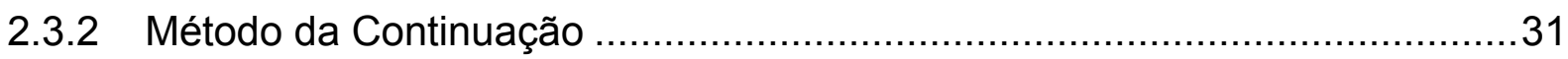

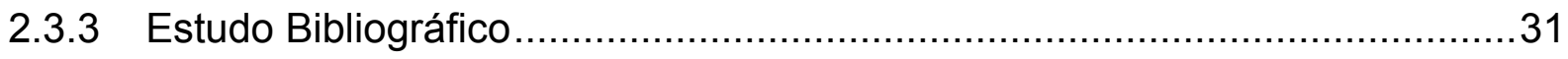

3.MÉTODO DA FUNÇÃO LAGRANGIANA BARREIRA MODIFICADA ….................37

3.1 O MÉTODO DA FUNÇÃO LAGRANGIANA BARREIRA MODIFICADA ….......37

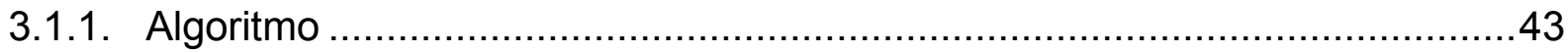

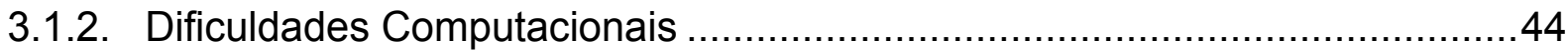

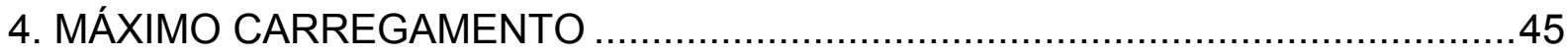

4.1 O PROBLEMA DE MÁXIMO CARREGAMENTO ......................................45 
4.1.1 Método da Função Lagrangiana Barreira Modificada Aplicado ao Problema de Máximo Carregamento

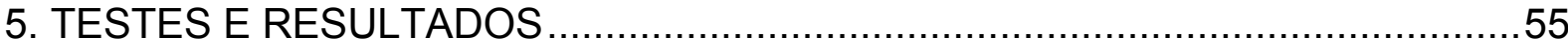

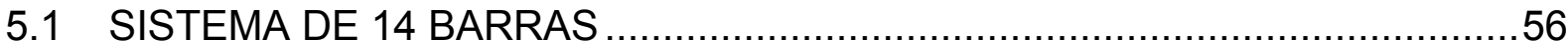

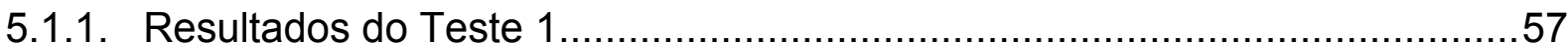

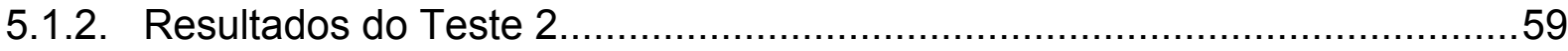

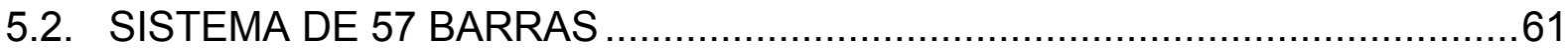

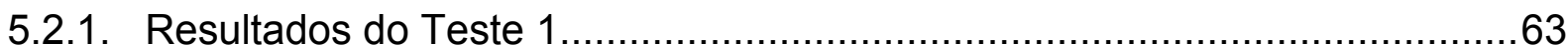

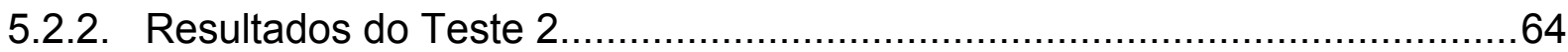

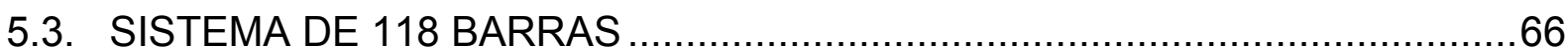

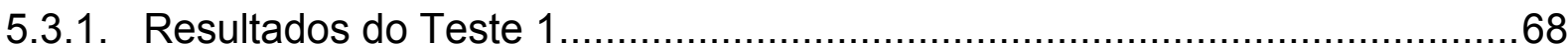

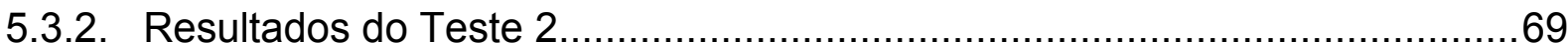

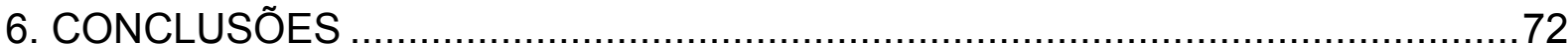

6.1. PERSPECTIVA PARA A CONTINUIDADE DESTE TRABALHO .....................73

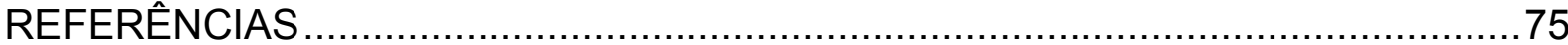

ANEXO A - O MÉTODO DOS PONTOS INTERIORES ….................................78 


\section{Capítulo 1}

\section{INTRODUÇÃO}

O crescente aumento da demanda dos sistemas de energia elétrica, associado à falta de investimentos na expansão e manutenção do setor, tem levado os sistemas a operar próximo de seus limites de carregamento, dificultando com isso, o atendimento da demanda. As restrições ambientais e/ou econômicas associadas à tendência de maximizar a utilização dos recursos e equipamentos dos sistemas de potência também contribuem, de forma decisiva, na consolidação deste cenário. Além do mais, com o advento de um ambiente desregulamentado, a malha de transmissão, interconectada e extremamente complexa, passa a ser utilizada para fins os quais esta não foi, a princípio, projetada. Surgem, portanto, dificuldades no seu monitoramento e controle devido à existência de contratos bilaterais entre geração e distribuição.

Pequenas variações de tensão entre os extremos de uma linha de transmissão, associadas às grandes diferenças angulares, podem causar o aumento das perdas série de potência reativa. A redução das reservas de reativos nas barras com controle de reativos, na tentativa de manter-se um perfil adequado de tensão, 
tem como conseqüência a perda de controle da tensão por parte dos geradores, resultando na queda contínua da tensão e no aumento da diferença angular entre os extremos da linha de transmissão, a fim de manter a transmissão de potência ativa. O aumento da diferença angular, somado à queda de tensão e conseqüente redução do suporte de reativos por parte dos bancos de capacitores, causará um novo aumento nas perdas reativas das linhas de transmissão, bem como na taxa de perdas com relação à queda de tensão. Esta queda gradual das magnitudes de tensão é o estágio inicial de um colapso de tensão (ALVES, 2000).

Esta dissertação de mestrado tem como objetivo estudar o fenômeno da instabilidade e determinar o ponto de máximo carregamento em sistemas elétricos de potência aplicando o método da Função Lagrangiana Barreira Modificada (FLBM). Este método é uma variante do método de pontos interiores.

A estrutura desta dissertação de mestrado apresenta a seguinte organização.

O capítulo 2 introduz os conceitos fundamentais relacionados à instabilidade de tensão, bem como algumas técnicas importantes utilizadas para a sua análise e apresenta trabalhos que tratam dos problemas relacionados à instabilidade de tensão e determinação do ponto de máximo carregamento de sistemas de energia elétrica.

O capítulo 3 apresenta a metodologia proposta para a solução do problema de máximo carregamento. A formulação do método da Função Lagrangiana Barreira Modificada é discutida.

O capítulo 4 descreve a aplicação da metodologia proposta para a solução do problema de máximo carregamento. 
No capítulo 5 são discutidos os resultados obtidos com a aplicação do método da Função Lagrangiana Barreira Modificada. Os testes são aplicados aos seguintes sistemas: IEEE 14, 57 e 118 barras.

Finalmente, o capítulo 6 apresenta as conclusões desta pesquisa, bem como as perspectivas de continuidade deste trabalho. 


\section{Capítulo 2}

\section{ALGUNS CONCEITOS BÁSICOS DE}

INSTABILIDADE DE TENSÃO

Este capítulo introduz os conceitos fundamentais relacionados ao fenômeno de instabilidade de tensão, imprescindíveis para análise do mesmo. E apresenta também trabalhos que tratam do problema de máximo carregamento em sistemas de energia elétrica.

\subsection{INSTABILIDADE DE TENSÃO}

O fenômeno da instabilidade de tensão é um processo iniciado por um carregamento desordenado, pela ocorrência de contingências no sistema de potência ou quando o sistema é incapaz de atender à demanda de potência reativa e é caracterizado pela depreciação da magnitude do valor da tensão em uma ou mais barras do sistema após a ocorrência do distúrbio, seja este um simples 
aumento de carga ou mudanças significativas na topologia do sistema, isto é, perda de grandes blocos de geração, perda de linhas de transmissão com grandes carregamentos.

No sistema altamente estressado, quando a magnitude dos valores de tensão atinge valores inaceitáveis, o sistema apresenta um comportamento instável e então é caracterizado o fenômeno do colapso de tensão, neste momento o suprimento de energia aos consumidores de um sistema ou de uma região é interrompido causando os mais diversos prejuízos econômicos e sociais (KUNDUR, 1994a; TAYLOR, 1994a; PAL, 1992).

O mecanismo do colapso de tensão é dirigido pela característica particular das cargas de potência constante de tender à recuperação de sua demanda de potência pré-falta. Quando ocorre queda de tensão por uma perturbação qualquer, esse tipo de carga compensa-a exigindo uma corrente maior do sistema. Esse acréscimo de corrente aumenta as perdas nos elementos série do sistema, reduzindo ainda mais as tensões das barras com suprimento deficiente de reativo, o que, conseqüentemente, aumenta a exigência de corrente pela carga. Esse processo realimentado ocasiona o colapso de tensão (PAL, 1992; HONG e GAU, 1994).

O colapso de tensão é um fenômeno essencialmente local, mas sua ocorrência pode acarretar blecaute parcial ou total do sistema. Como exemplo, no Brasil, pode-se citar a ocorrência de um grande blecaute na região Sul e Sudeste em 1997, associado a um problema de instabilidade de tensão na rede de distribuição que se estendeu para o sistema de transmissão correspondente (Análise das Perturbações dos Dias 24 E 25/04/97 no Sistema Interligado S/SE/CO, 1997), o 
qual é mostrado nesta dissertação; no mundo, destacam-se os colapsos de tensão no sistema da Suécia em 1983 e no Japão em 1987 (KUNDUR, 1993).

\subsubsection{Definição de contingência}

Por contingência entende-se a saída de equipamentos tais como geradores, linhas de transmissão, transformadores, etc..., algumas vezes vitais ao bom funcionamento do sistema. Freqüentes são os casos em que a saída inesperada de uma linha de transmissão causa sobrecarga em outra(s) linha(s). Não raro são também os casos em que há violação dos limites de tensão nas barras por efeito da saída de transformadores e/ou outros equipamentos de controle de tensão.

Quando somente um equipamento sai de operação, tem-se uma contingência simples. Quando dois ou mais equipamentos saem de operação tem-se uma contingência múltipla.

É preciso, mesmo quando componentes do sistema falham, manter sua segurança, por isso muitos equipamentos são protegidos por dispositivos automáticos ou manuais, que são desativados quando seus limites forem violados. Se um sistema continua operando com limites violados, quando ocorre um evento, este pode ser seguido de uma série de ações futuras contingência em cascata, que pode ocasionar a saída de vários outros 
equipamentos; este processo continuado é conhecido como efeito cascata e pode levar todo o sistema ou grande parte dele ao colapso de tensão.

\subsubsection{Margem de Carregamento}

A margem de carregamento é fundamental para se quantificar a proximidade de um colapso de tensão. Uma questão freqüentemente levantada na utilização de algoritmos para a determinação da margem de carregamento é saber o quanto esta mudará a partir de uma perturbação no sistema. Basicamente, as perturbações podem ser: variações nas cargas e/ou gerações ou mesmo uma contingência.

Para um ponto de operação particular, o montante de carga adicional utilizando um modelo específico de aumento de carga, que causaria o colapso de tensão é chamado de margem de carregamento para o colapso de tensão. A margem de carregamento é o mais básico e abrangente índice de colapso de tensão.

Quando a carga do sistema é escolhida como parâmetro de carregamento, uma curva PV pode ser traçada; neste caso, a margem de carregamento para o colapso de tensão é a variação no carregamento entre o ponto de operação e o "nariz" da curva para a barra crítica.

Vantagens da margem de carregamento como índice de colapso de tensão: 
- fácil aceitação e entendimento;

- não é baseada em um modelo de sistema particular; requer, apenas, um modelo estático do sistema de potência;

- é um índice preciso que considera a não linearidade do sistema e seus limites de potência reativa, atingidos com o acréscimo de carga;

Desvantagens da margem de carregamento como índice de colapso de tensão:

- necessita o cálculo de pontos além do ponto de operação atual e, conseqüentemente, apresenta um maior custo computacional do que índices que usam apenas informações do ponto de operação. Sendo esta a maior desvantagem da margem de carregamento;

- requer a suposição de uma direção de aumento de carga, porém algumas vezes esta informação não esta disponível.

A margem de carregamento pode, em princípio, ser calculada iniciando no ponto de operação atual, fazendo pequenos incrementos no carregamento e recalculando os fluxos de carga para cada incremento até que o "nariz" da curva seja atingido. A margem de carregamento é então o total incrementado no carregamento. 


\subsubsection{Descrição do Fenômeno Físico do Colapso de Tensão}

A instabilidade de tensão é caracterizada pela queda progressiva da tensão e é causada pela falta de suporte local de potência reativa. Há várias situações que podem contribuir para que a demanda de reativos não seja atendida, agravando desta forma o quadro de instabilidade de tensão:

- quando os limites de reativos dos geradores, dos compensadores síncronos e estáticos são atingidos, devido à redução da potência reativa produzida pelos capacitores na ocorrência de tensões baixas.

- quando há redução da capacidade de transmissão, ocasionando altas perdas de potência reativa devido às linhas de transmissão sobrecarregadas, possíveis saídas de linhas ou geradores, aumento de carga, ação de transformadores LTC.

O sistema entra em colapso quando atinge o ponto crítico, ou seja, a potência adicional necessária para o suprimento do aumento de carga não pode mais ser transmitida. Para a carga modelada como injeção de potência constante, quando a demanda de potência da carga aumenta, as perdas nos elementos série das linhas de transmissão causam uma sensível queda de tensão nas barras, a qual provoca um aumento das correntes nas linhas, implicando em maiores perdas. Este processo repetitivo resulta no colapso de tensão. Quanto mais próximo o dispositivo de controle estiver da área mais fraca, maior o efeito das ações corretivas. 
De acordo com Mohamed e Jasmon (1996) o colapso de tensão não é exclusivamente resultado final da instabilidade de tensão, podendo também ocorrer devido ao aumento na demanda de potência ativa e não necessariamente devido à alta demanda de potência reativa. Conforme apresentado em Nema e Castro (1996), não há necessariamente uma relação entre a proximidade ao colapso e a magnitude da tensão para uma barra, não sendo correto tomar as magnitudes das tensões nas barras como indicadores de susceptibilidade ao colapso, ou seja, embora uma barra seja mais fraca com relação ao colapso de tensão, a tensão nesta barra pode ser maior do que em uma barra mais forte. As tensões nos barramentos de um ramo podem estar dentro dos limites aceitáveis, mas com a margem pós-contingência do ramo pequena, neste caso, o ponto de colapso está muito próximo e fazer uma análise pelos valores de tensão resultaria em uma análise incorreta.

Para prevenir o colapso de tensão, informam esses autores, pode-se tomar medidas corretivas, tais como: aplicação de dispositivos de compensação de potência reativa; controle das tensões da rede e de saída reativa de geradores; redespacho de geração; controle de mudança de tap de transformadores; corte de carga na subtensão; manutenção adequada da margem de estabilidade de tensão; manutenção de reserva girante de potência reativa na operação de geradores. A escolha apropriada das ações corretivas pode ser tomada pelos operadores do sistema de potência tendo com base índices relacionados com a estabilidade de tensão.

As tensões nas barras devem estar dentro de uma faixa específica, em torno do seu valor nominal. Para sistemas de transmissão o nível é regulado dentro de $5 \%$ do valor nominal. Para controlar o nível de tensão são utilizados dispositivos de 
controle de reativos estáticos, geradores, transformadores com mudança de tap sob carga, bancos de capacitores e reatores estáticos.

O critério da estabilidade de tensão define qual margem é considerada suficiente para a segurança de tensão do sistema, especifica que as tensões dos barramentos devem permanecer dentro de certa porcentagem do valor nominal (précontingência) e determina que as reservas de potência reativa devem permanecer em um determinado valor percentual acima da potência de saída reativa e deve ser selecionado de forma a fornecer segurança adequada sem restringir a operação do sistema desnecessariamente.

O problema de instabilidade de tensão tem se tornado cada vez mais evidente por diversas razões, o que pode ser constatado pela maior ocorrência de blecautes em muitos países nos últimos tempos. Estes incidentes são um claro indicativo de que os sistemas elétricos de potência estão operando cada vez mais próximos do limite de sua capacidade de transferência de energia. No Brasil, podese citar como exemplo a ocorrência de um grande blecaute na região Sul e Sudeste em 1997, associado a um problema de instabilidade de tensão na rede de distribuição que se estendeu para o sistema de transmissão correspondente, levando a falha e abertura do elo DC (Análise das Perturbações dos Dias 24 E 25/04/97 no Sistema Interligado S/SE/CO, 1997). Este exemplo de colapso de tensão é descrito na seção seguinte. 


\subsubsection{Colapso de tensão ocorrido em abril de 1997 no Sistema Interligado Sul/Sudeste/Centro Oeste (S/SE/CO)}

Nos dias 24 , às 18:21h, e 25 de abril de 1997, às 18:17h, ocorreram perturbações no sistema S/SE/CO, que não levaram o sistema ao colapso total, graças à ação do Esquema Regional de Alívio de Carga (ERAC) e aos cortes de carga realizados manualmente (ECAM). Permanecendo em serviço cerca de $85 \%$ da carga total em ambos distúrbios.

As análises constataram um afundamento da tensão na região da grande São Paulo, compatível com um colapso parcial de tensão, mesmo sem o registro de qualquer perturbação ou anormalidade que desse origem ao fenômeno. As ocorrências evidenciaram a utilização total dos recursos disponíveis de controle de tensão no sistema interligado S/SE/CO.

Pode-se observar, na figura 1, o comportamento da carga ativa dos dias 24 e 25 de abril, minutos antes dos desligamentos. Caso essas cargas mantivessem a mesma tendência, os valores da carga ativa seriam da mesma ordem do dia 15 de abril. 


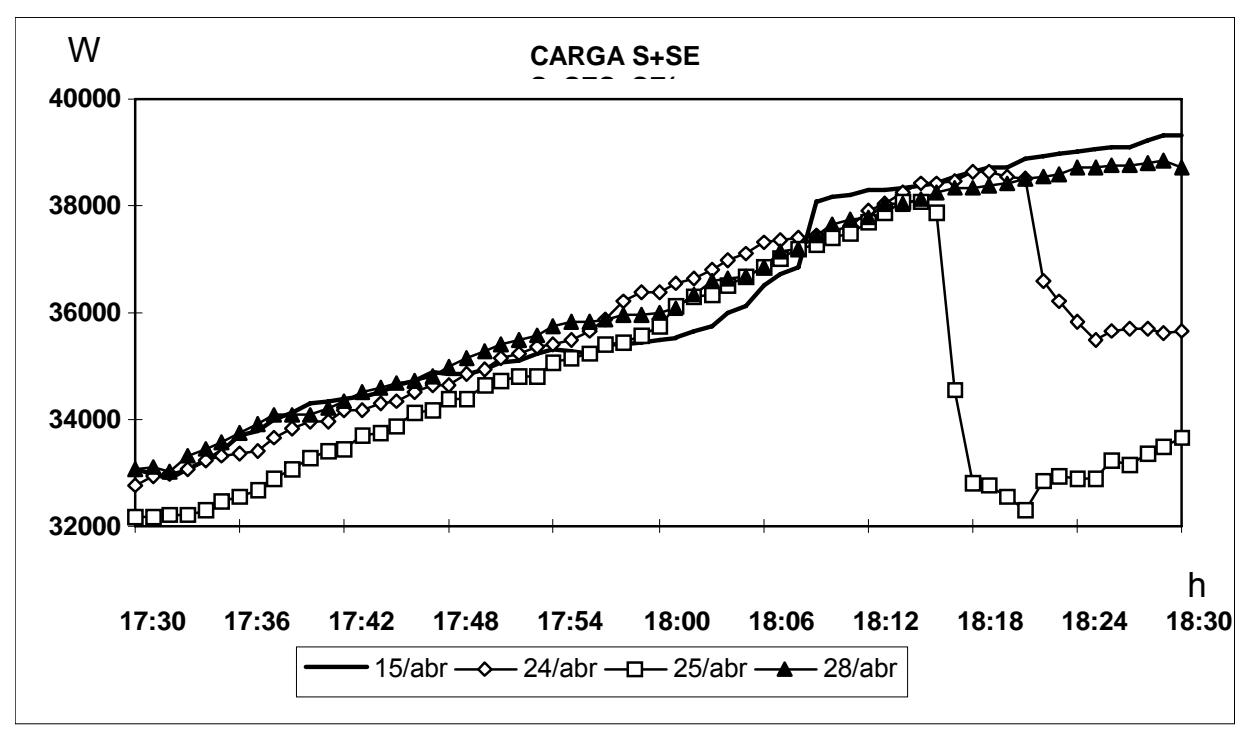

Figura 1. Comportamento da carga ativa

\subsubsection{Descrição das Ocorrências do Dia 24/04/97}

O afundamento de tensão na região da grande São Paulo, compatível com um colapso parcial de tensão, ocorrido no dia 24/04/97 será descrito e ilustrado por meio de gráficos. As ocorrências desta data foram escolhidas devido ao maior número de dados disponíveis em relação ao ocorrido no dia 25/04/97.

Às 18h00min as tensões de alguns barramentos da área São Paulo e Minas Gerais já estavam abaixo das faixas operativas, conforme figuras 2 a 7. 


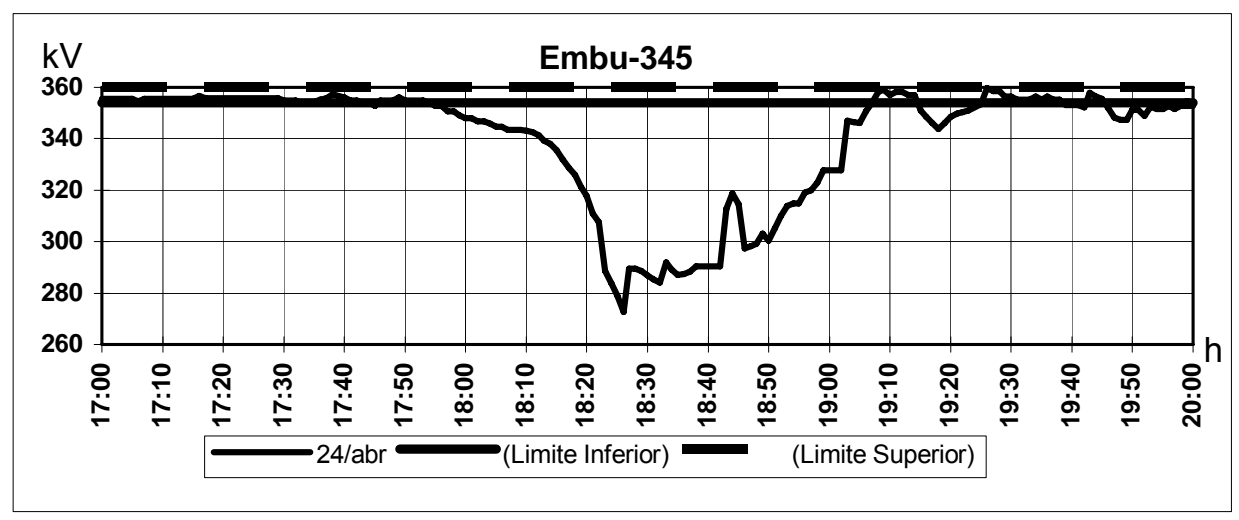

Figura 2. Embu-Guaçu

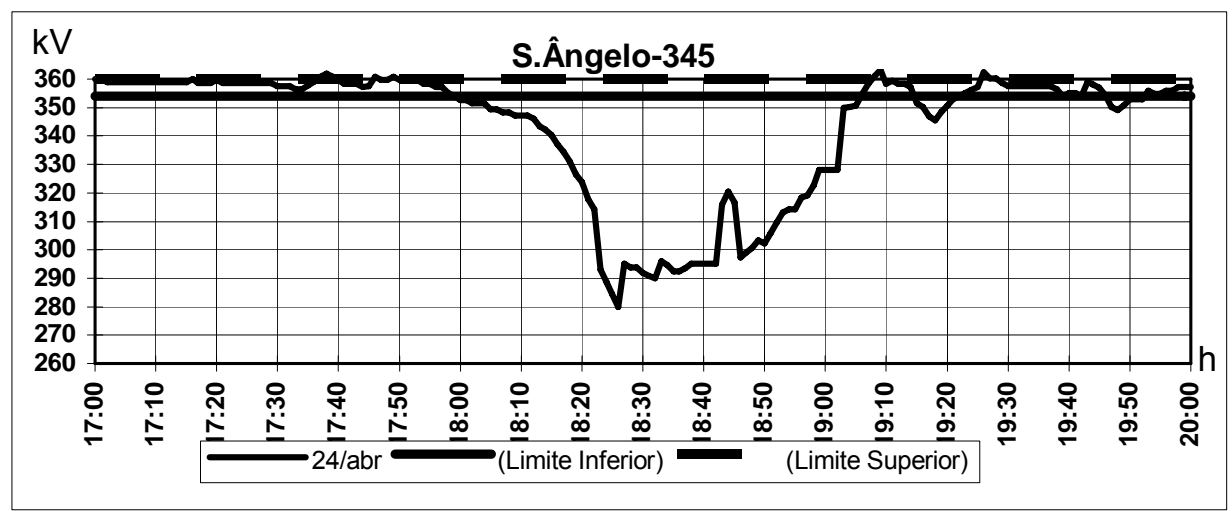

Figura 3. Santo Ângelo

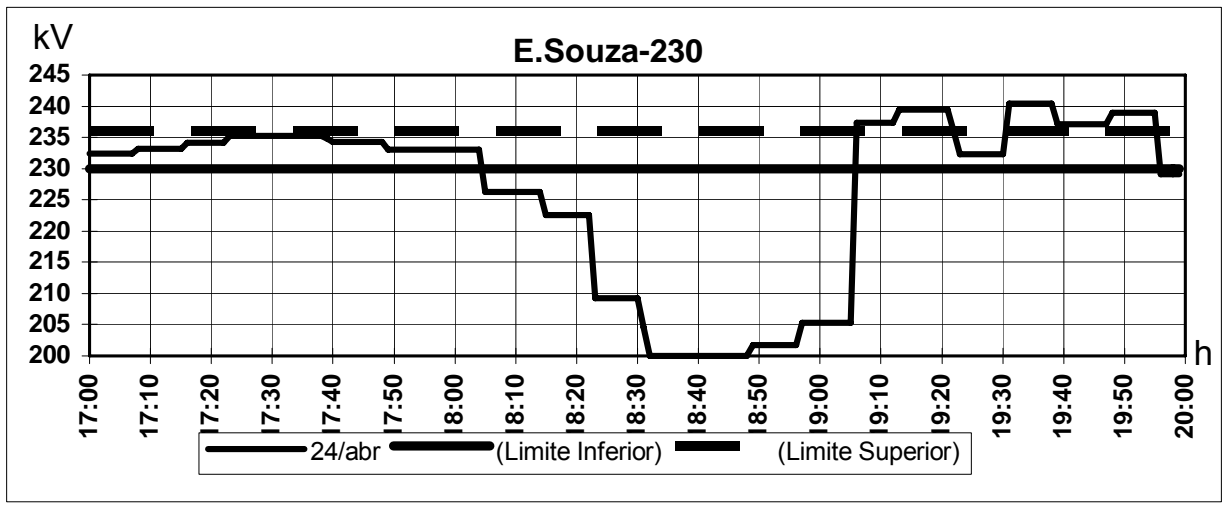

Figura 4. Edgard de Souza 


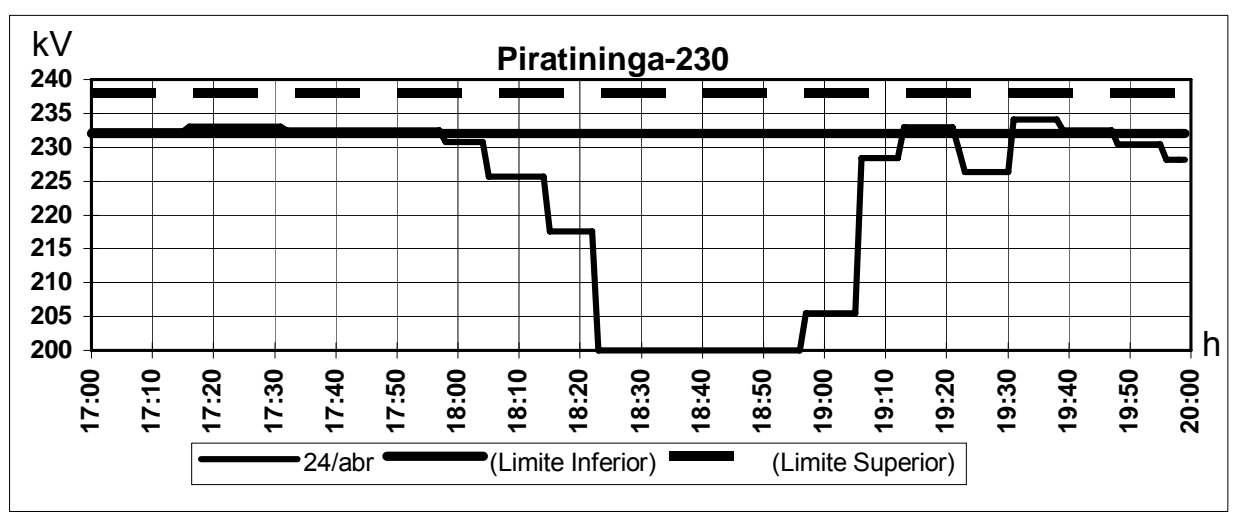

Figura 5. Piratininga

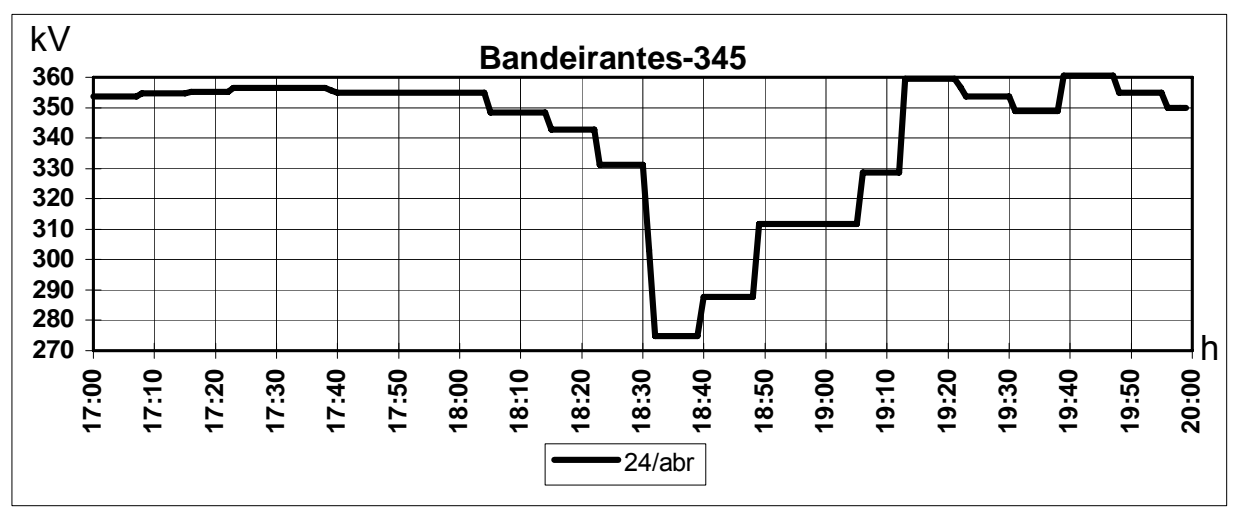

Figura 6. Bandeirantes

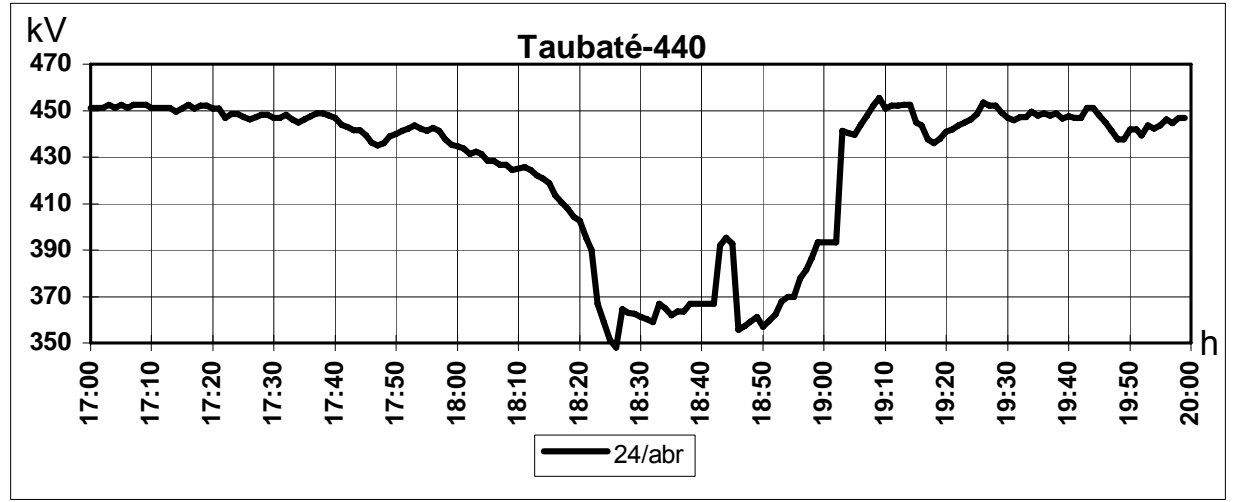

Figura 7. Taubaté

A partir das 18:05h, foi observada uma tendência de queda de tensão no sistema Sudeste, conforme figuras 2 a 7 mostrados anteriormente e 8 a 15, mostrados a seguir. Ressalta-se que se encontrava em andamento o processo de 
rampeamento da geração do sistema e adequação da utilização dos recursos de controle de tensão, figuras 16 a 22 .

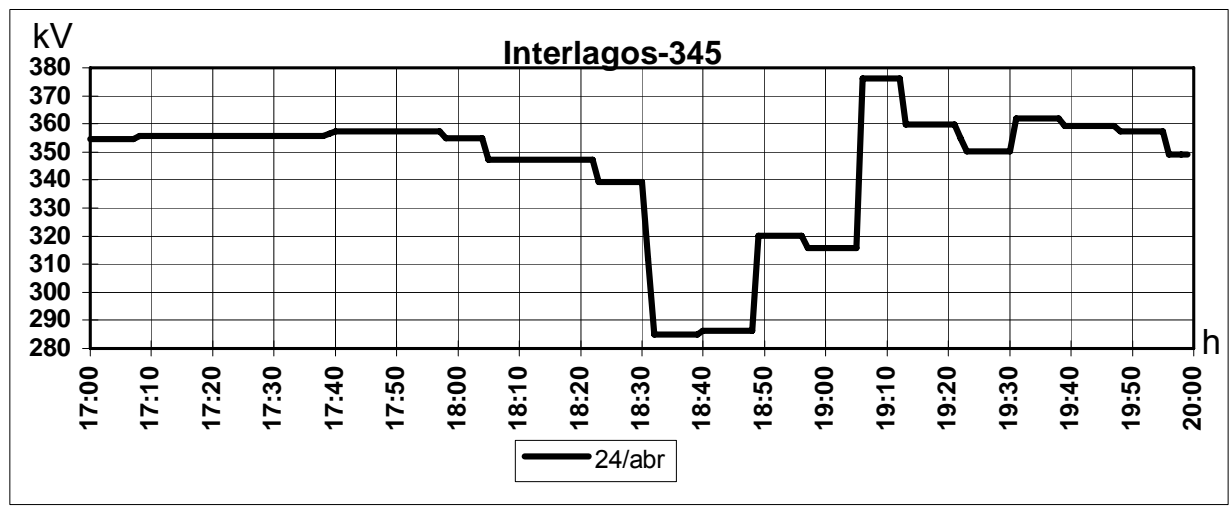

Figura 8. Interlagos

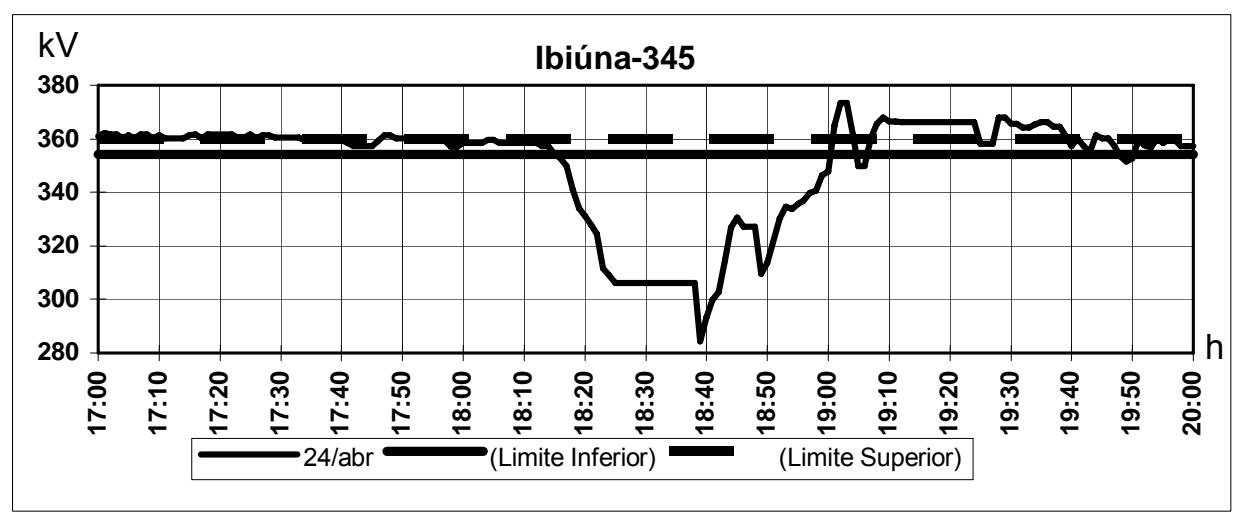

Figura 9. Ibiúna

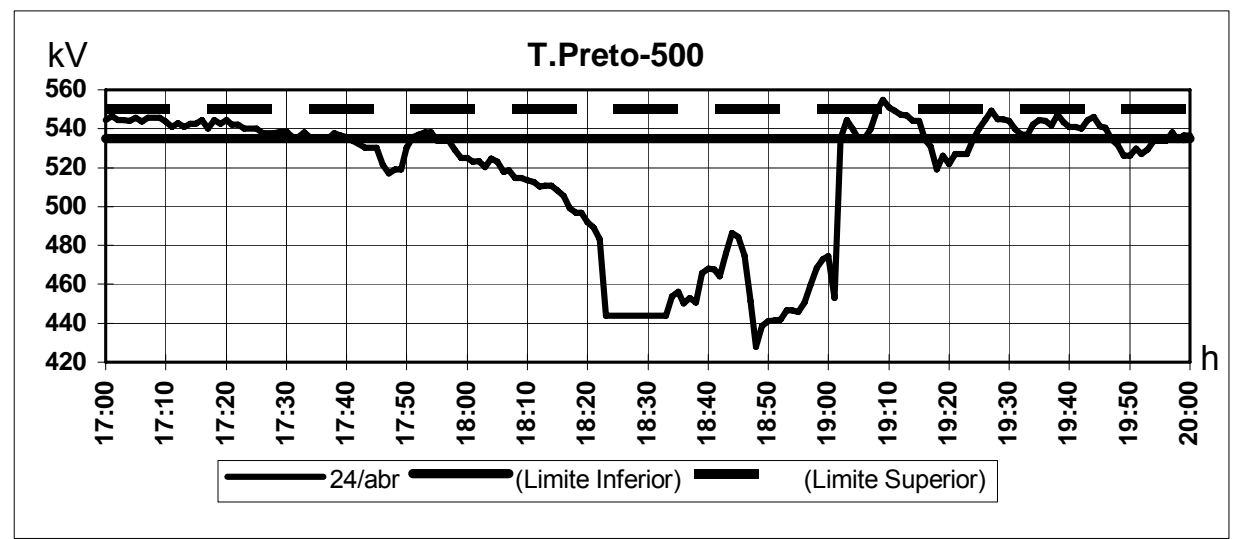

Figura 10. Tijuco Preto 500KV 


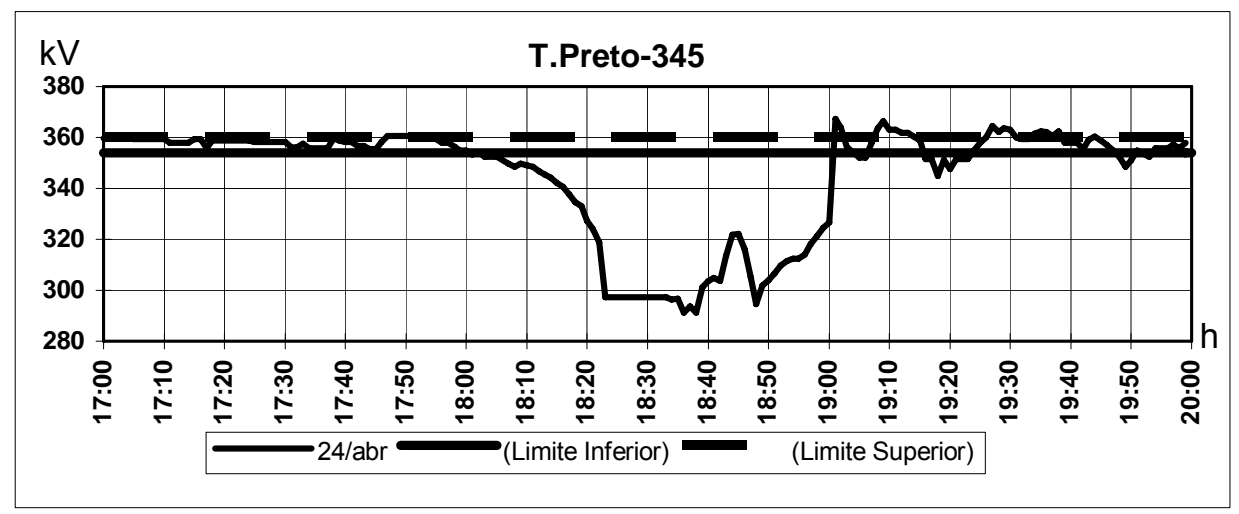

Figura 11. Tijuco Preto 345KV

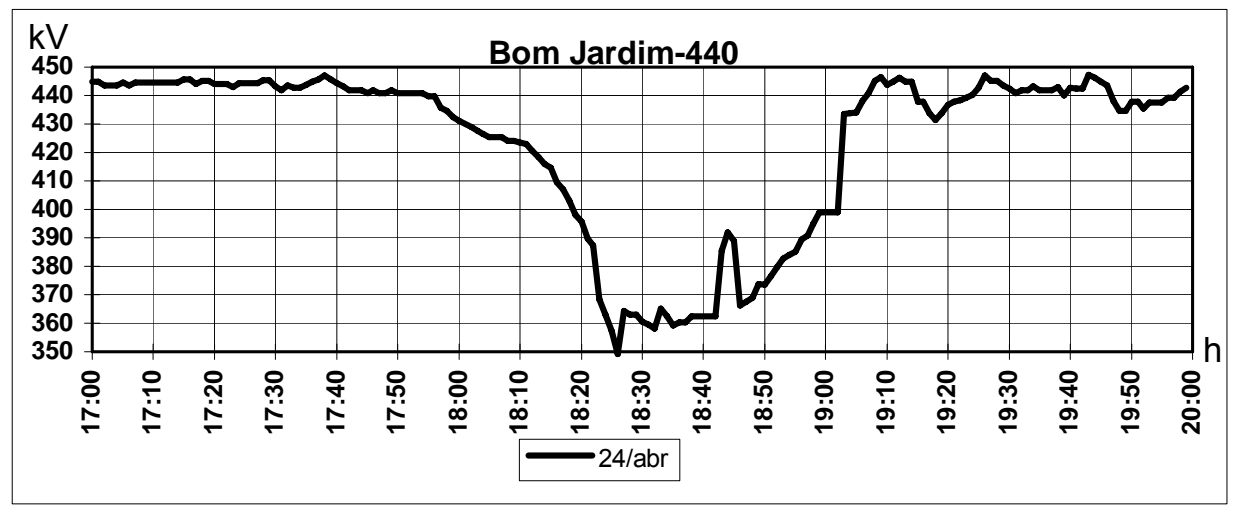

Figura 12. Bom Jardim

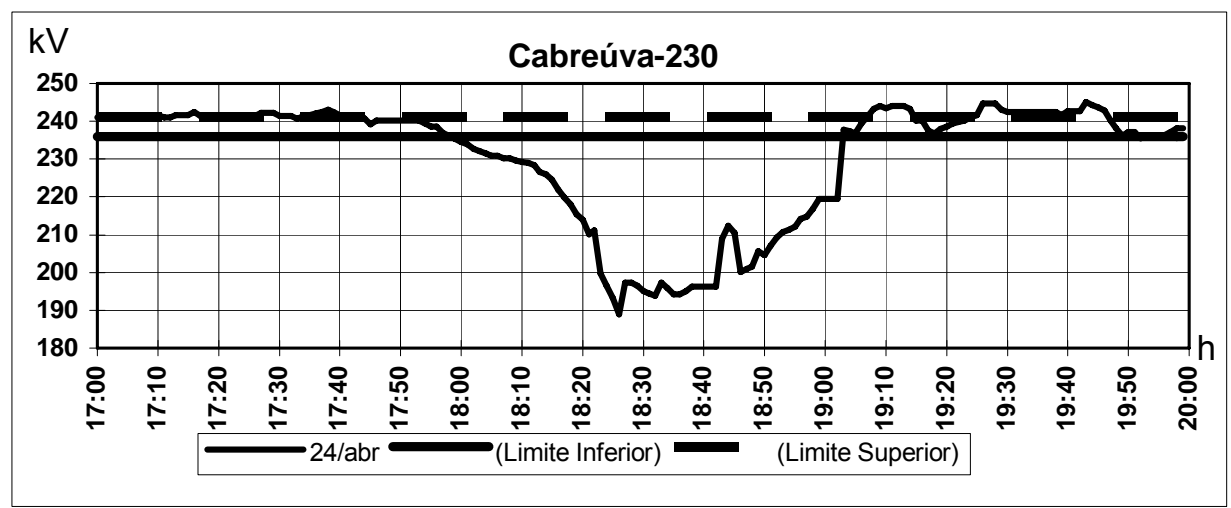

Figura 13. Cabreúva 


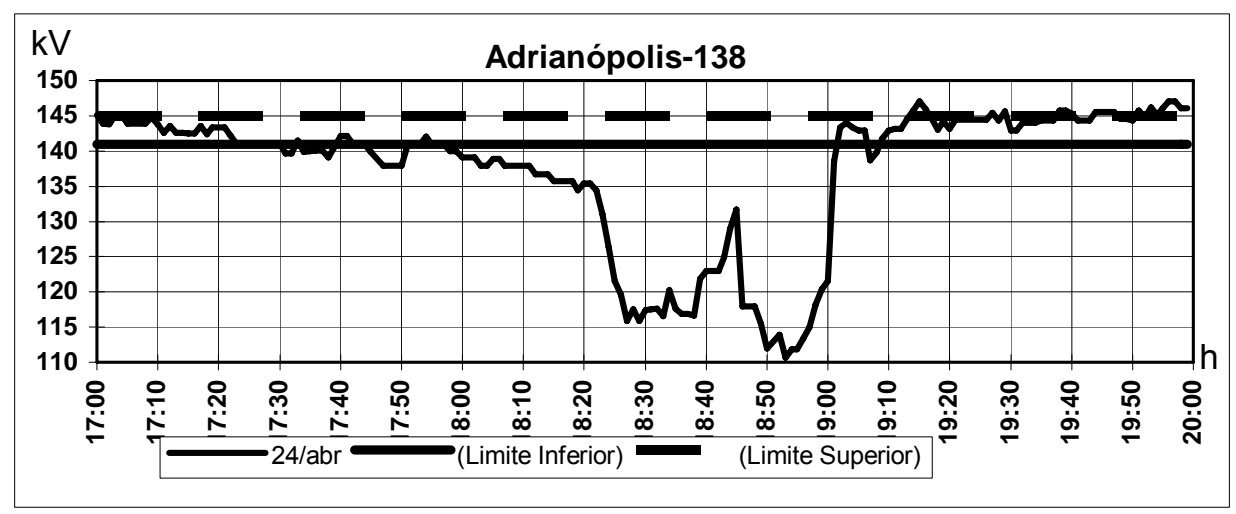

Figura 14. Adrianópolis

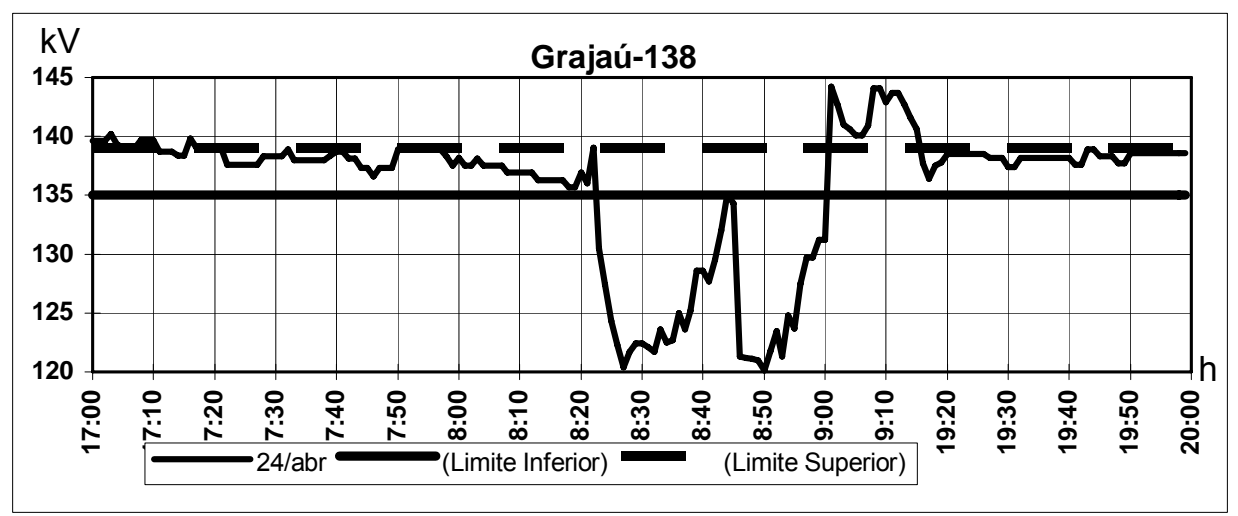

Figura 15. Grajaú

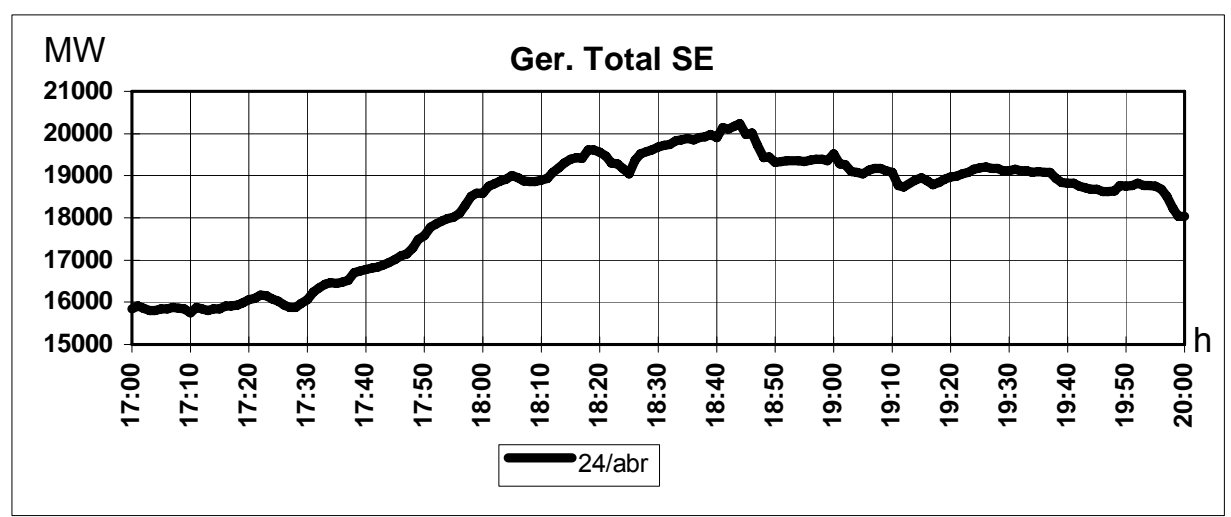

Figura 16. Geração Total do Sistema Sudeste 


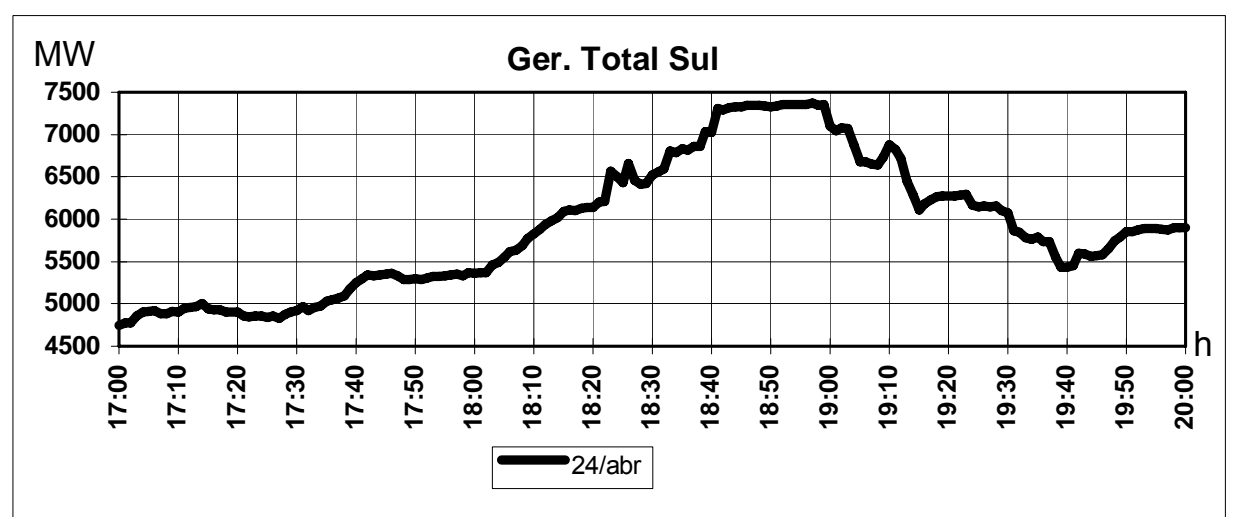

Figura 17. Geração Total do Sistema Sul

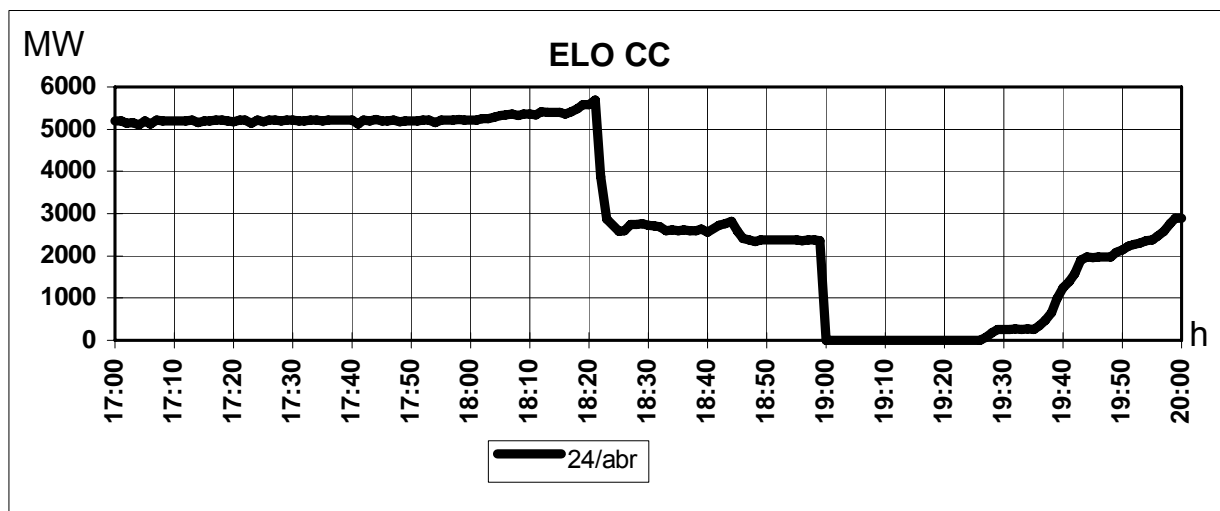

Figura 18. Geração ELO CC

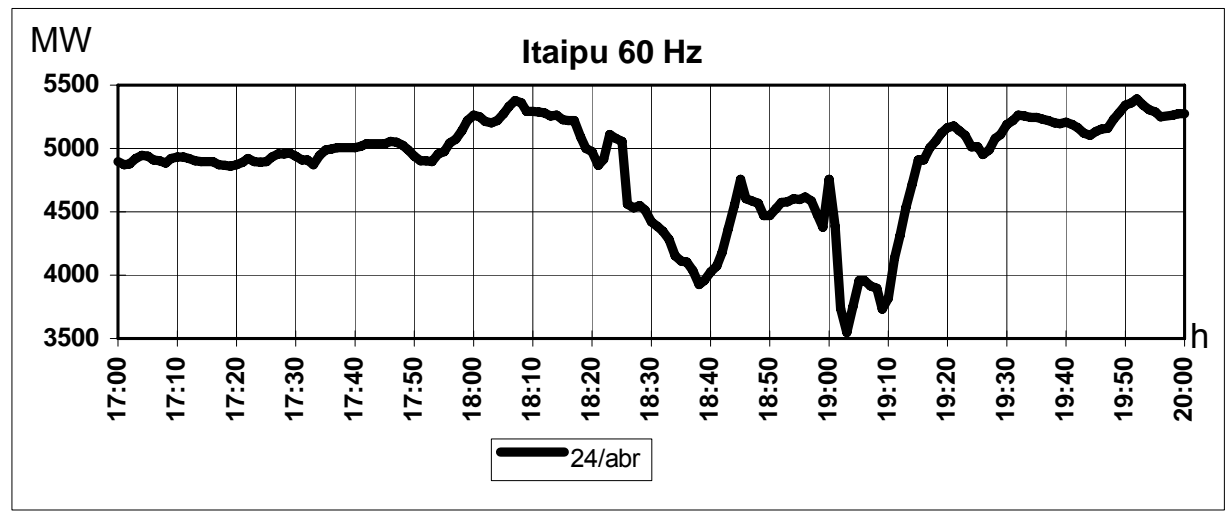

Figura 19. Geração Itaipu $60 \mathrm{~Hz}$ 


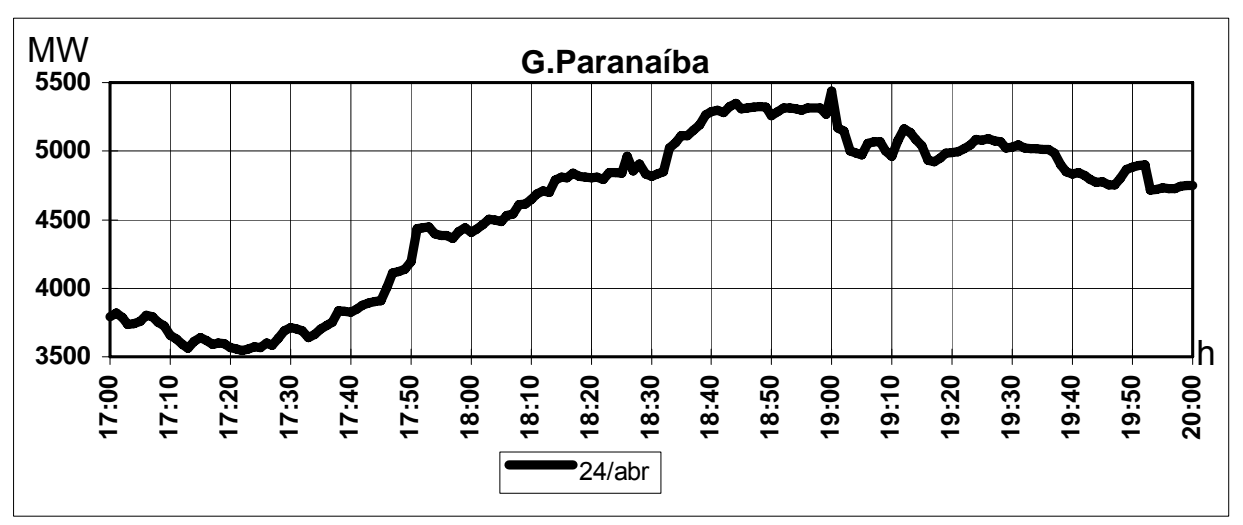

Figura 20. Geração Paranaíba

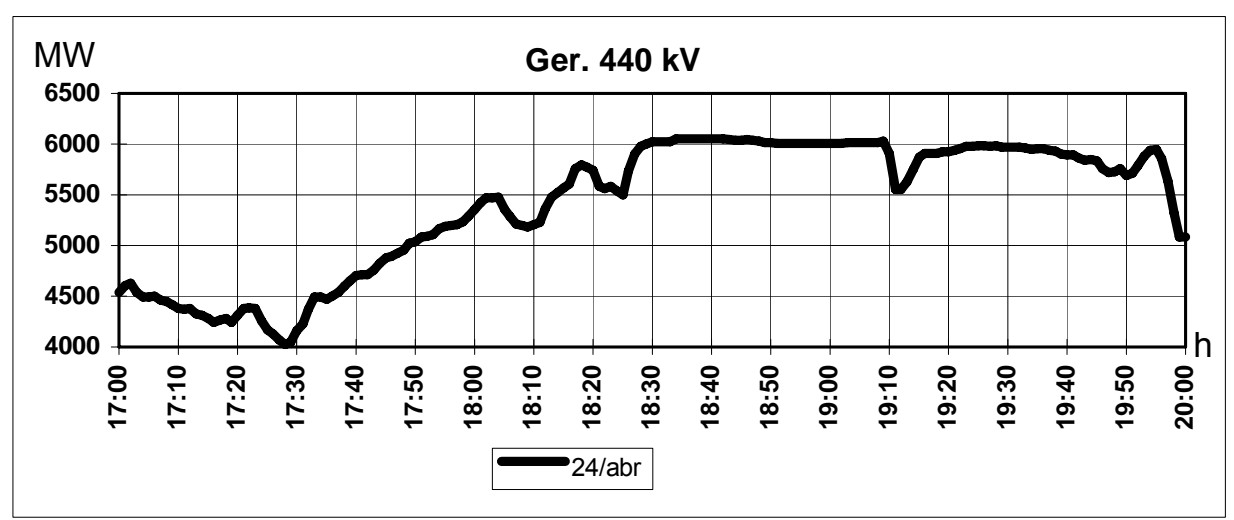

Figura 21. Geração 440 KV

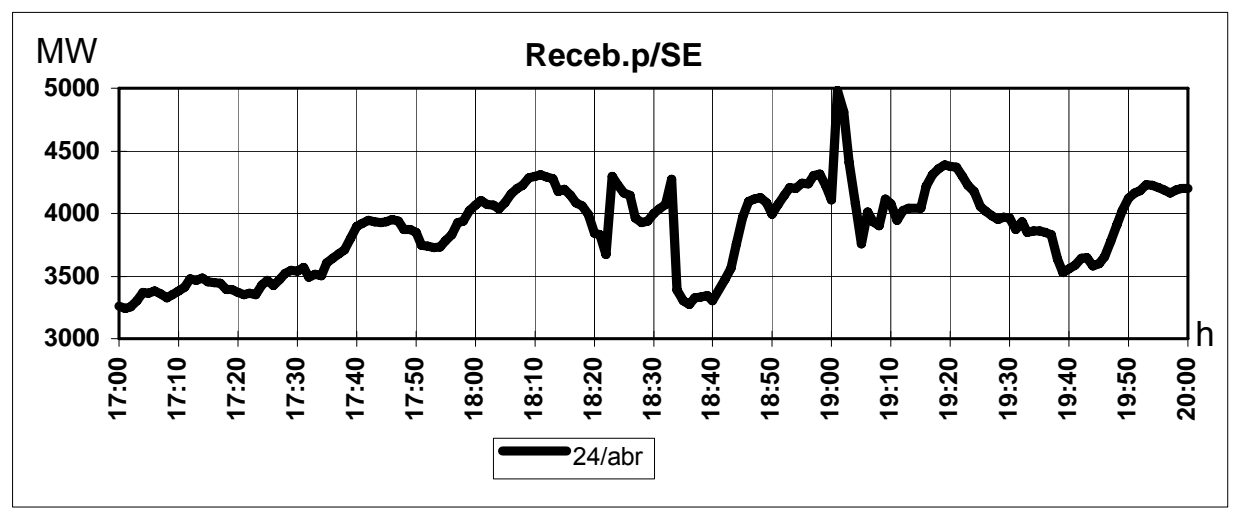

Figura 22. Potência Recebida pelo Sudeste

As 18:07h a Usina de ITAIPU-60Hz do CAG-FURNAS com $5350 \mathrm{MW}$, foi desligada para evitar elevação de sua geração em função de rampa de carga do sistema e, consequentemente, evitar a degradação de tensão no $750 \mathrm{kV}$ (793kV às 18:05h), conforme figura 23 a seguir. 


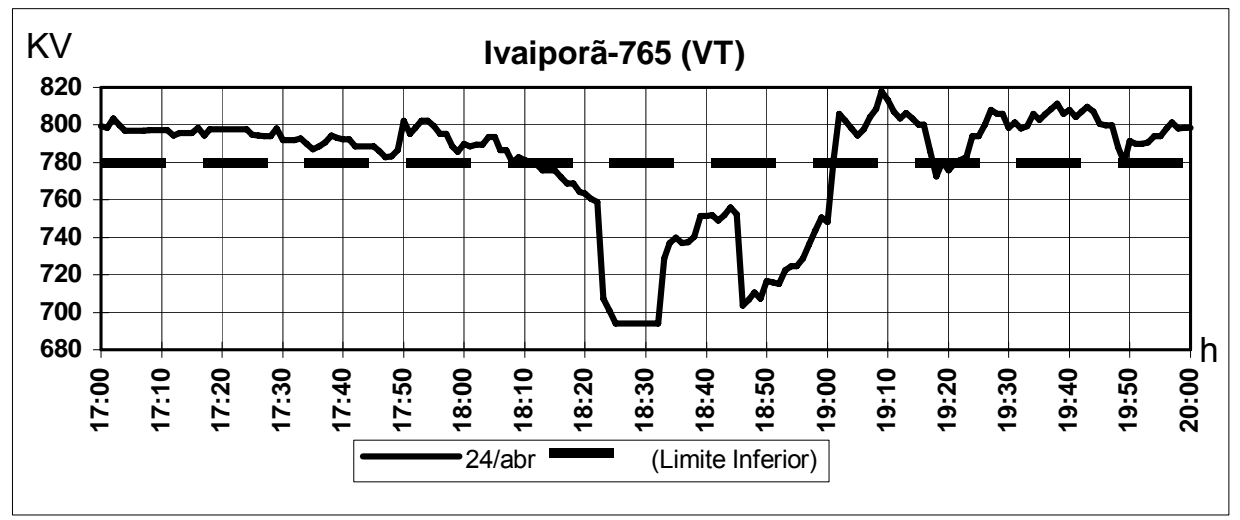

Figura 23. Ivaiporã

As figuras 24 a 26, mostram o carregamento do sistema:

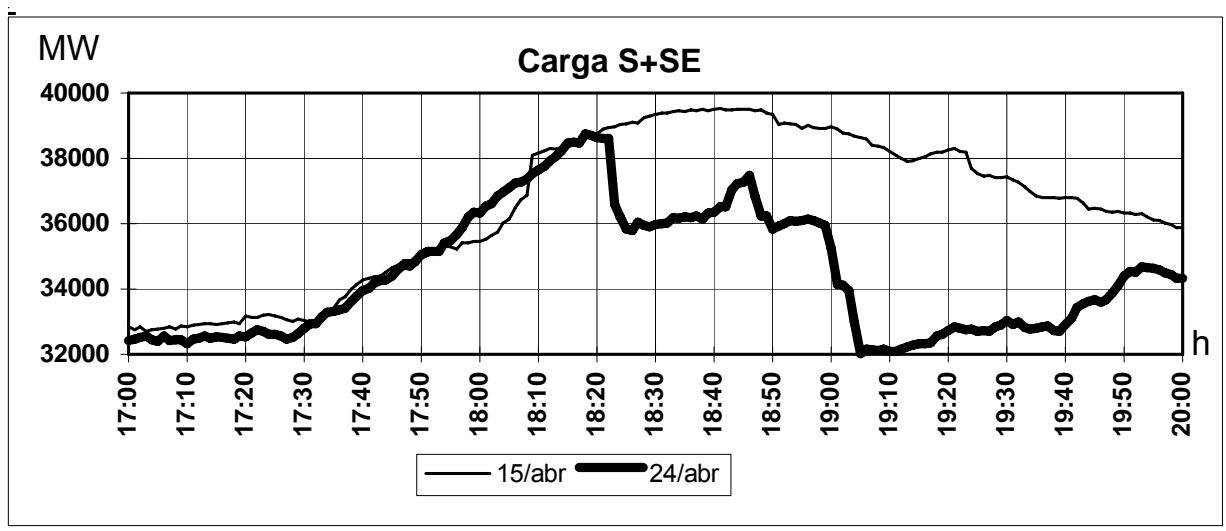

Figura 24. Carga Sul+Sudeste

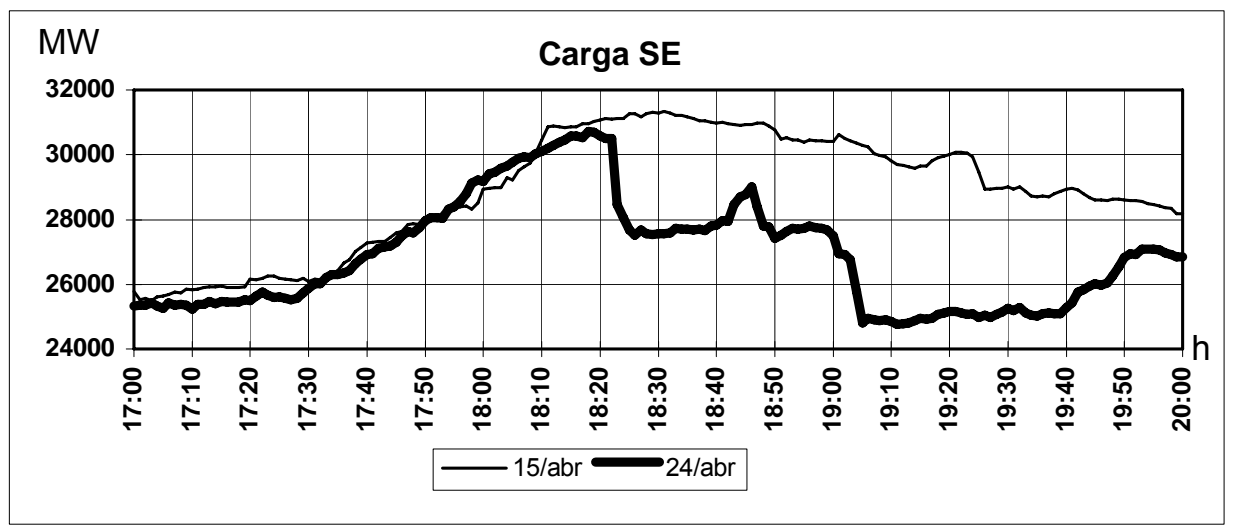

Figura 25. Carga Sudeste 


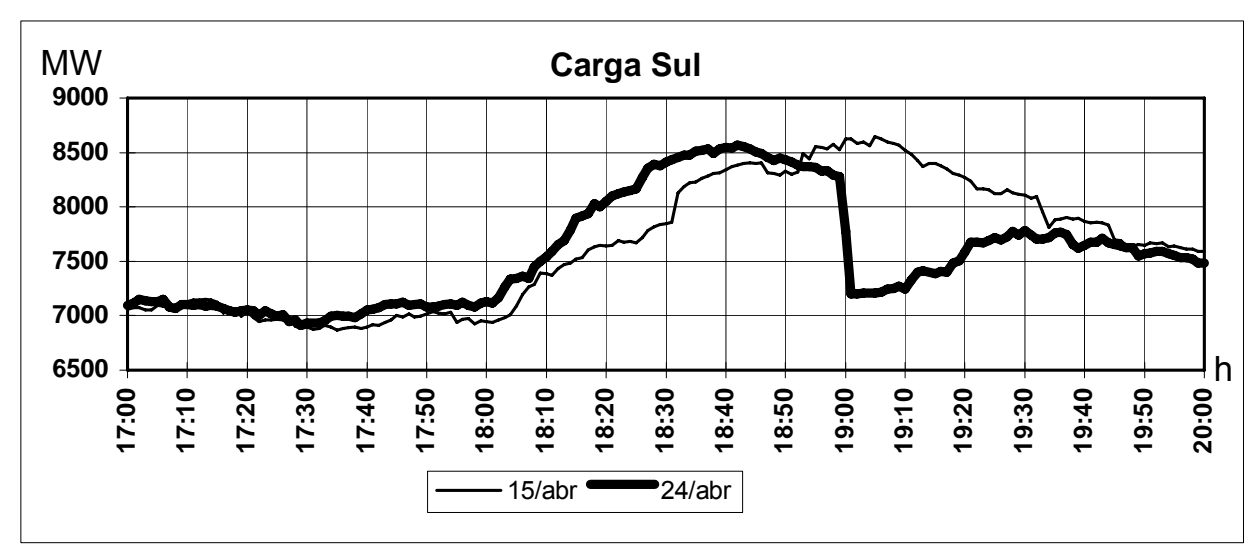

Figura 26. Carga Sul

A partir das 18:10h, a CEMIG solicitou corte de carga num total de 33MW em função de baixos níveis de tensão nos barramentos de Mesquita (517/232kV), Jaguara (515kV), Neves (526kV) e Barreiro (343kV), conforme figuras 27 a 29.

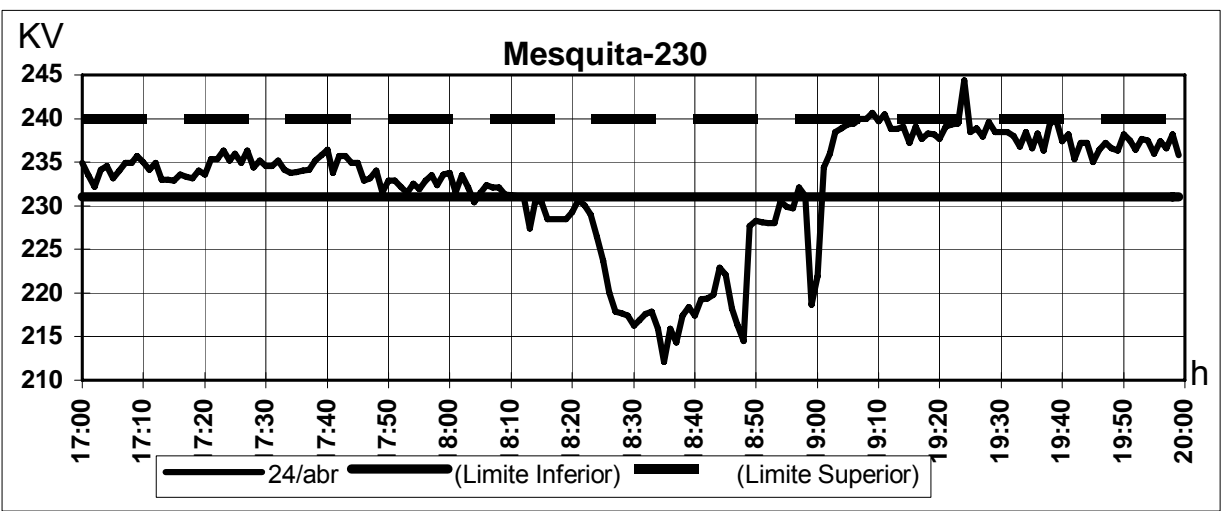

Figura 27. Mesquita 230KV

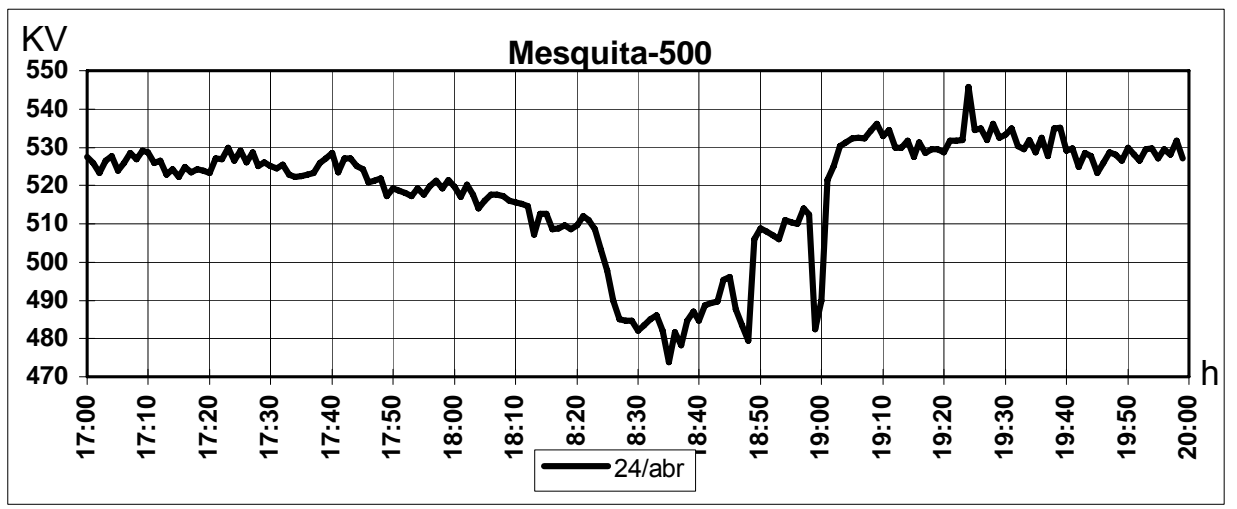

Figura 28. Mesquita 500KV 


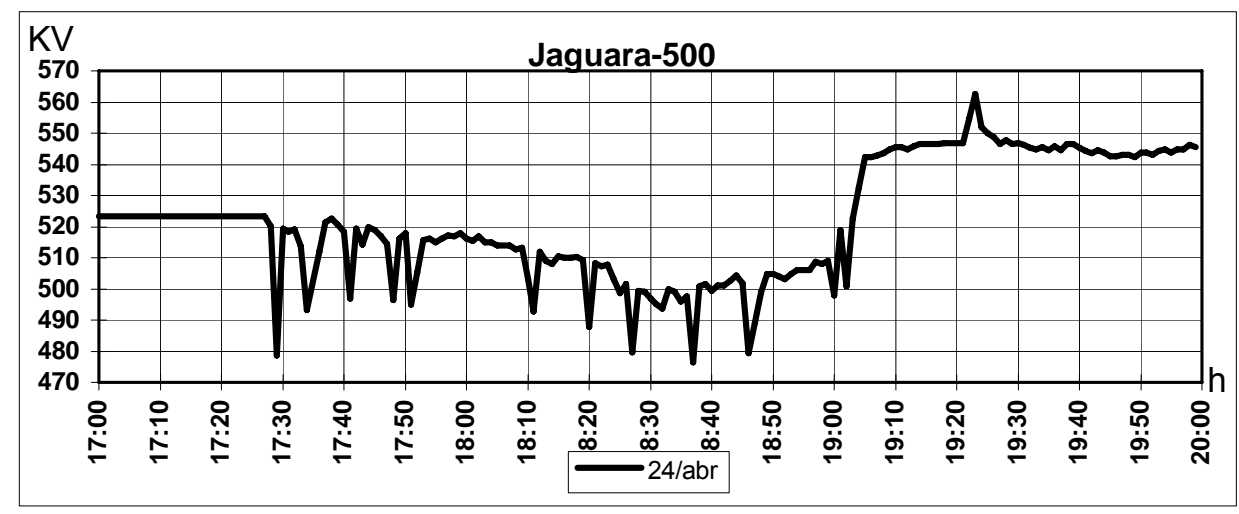

Figura 29. Jaguara 500KV

Às 18:18h os recursos de controle de tensão da área São Paulo encontravam-se esgotados, figuras 30 a 35.

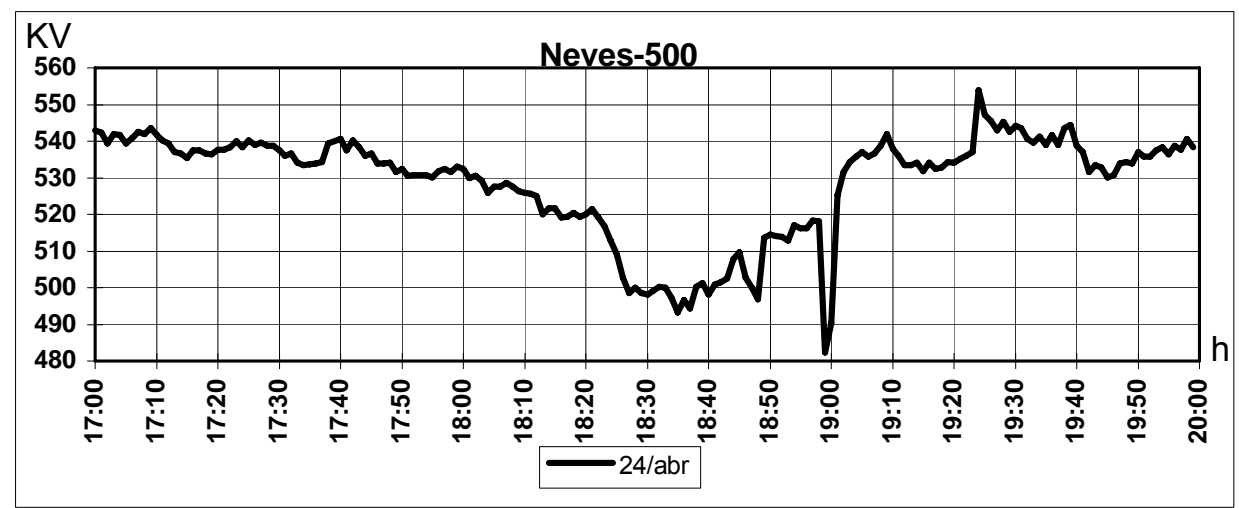

Figura 30. Neves 500KV

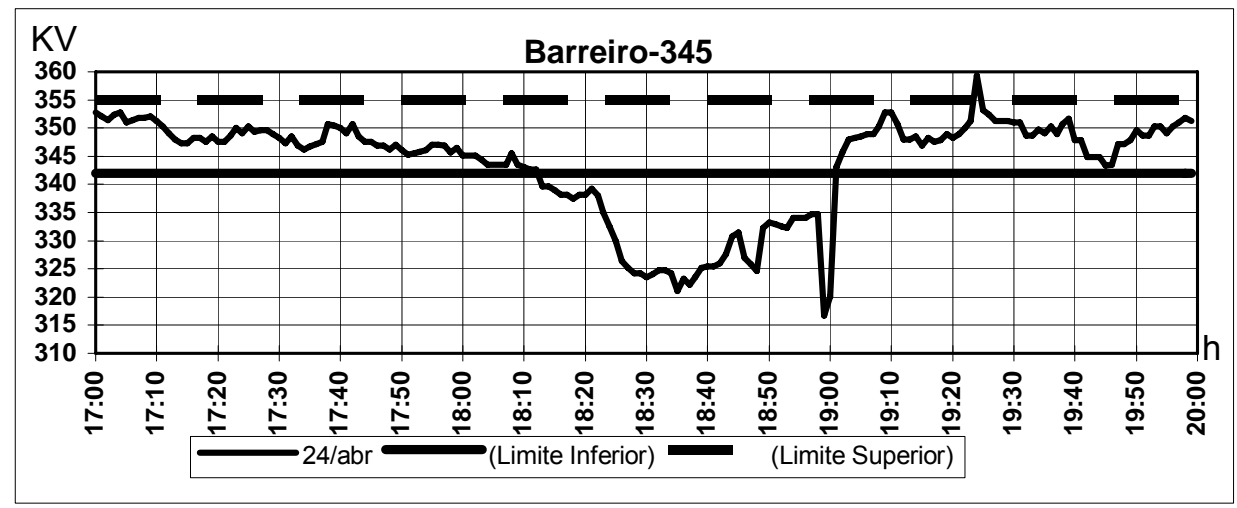

Figura 31. Barreiro 345KV 


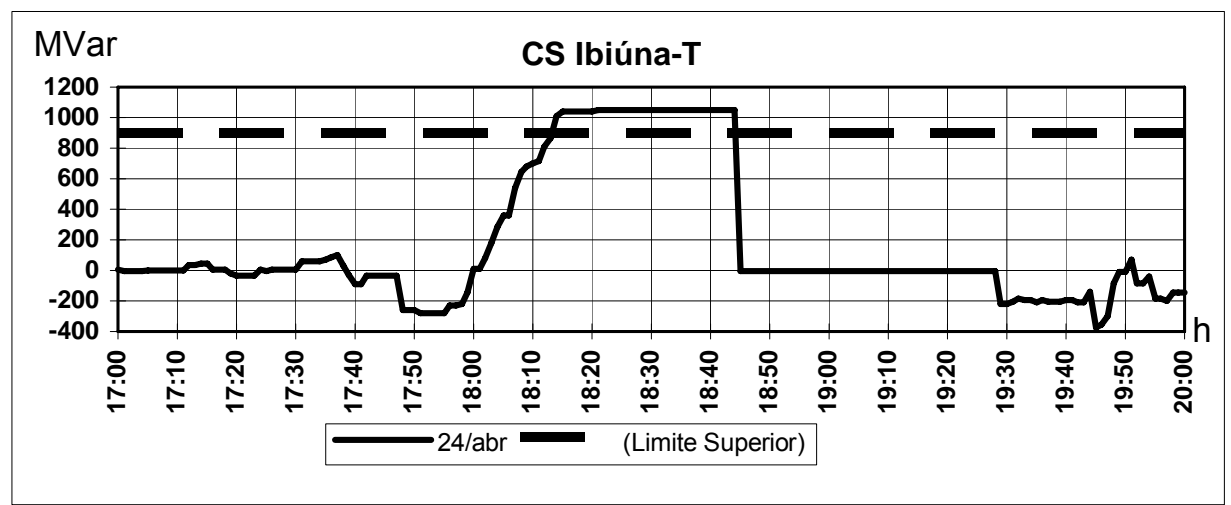

Figura 32. Compensador Síncrono de Ibiúna

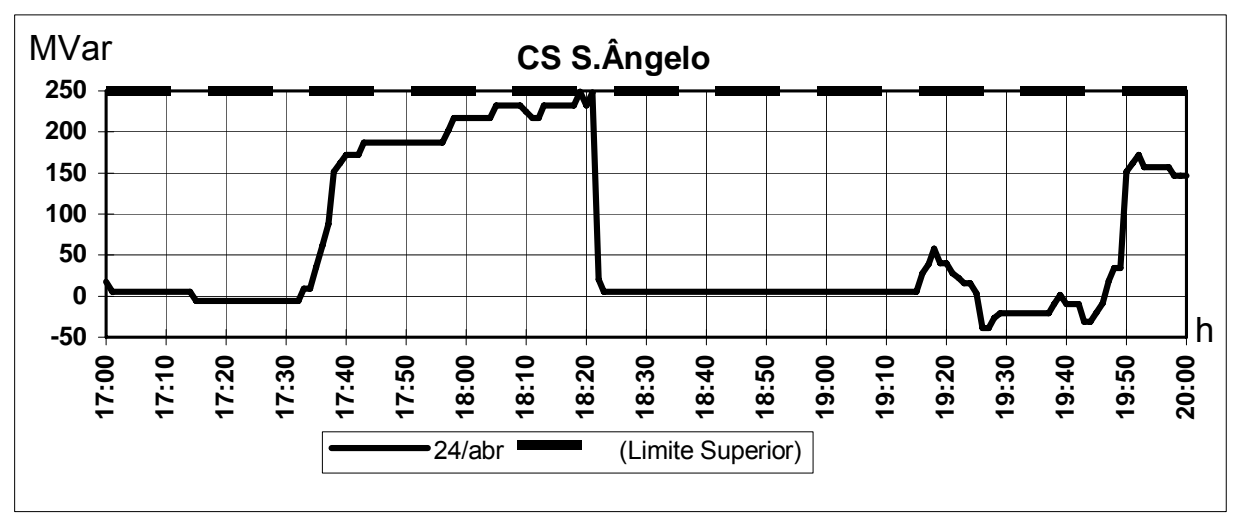

Figura 33. Compensador Síncrono Santo Ângelo

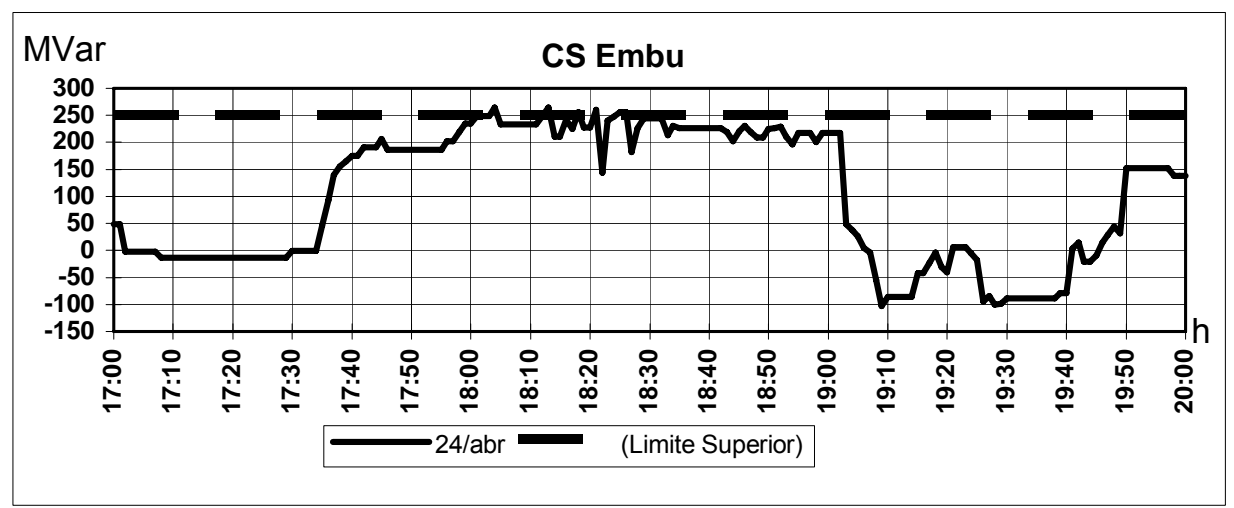

Figura 34. Compensador Síncrono Embu 


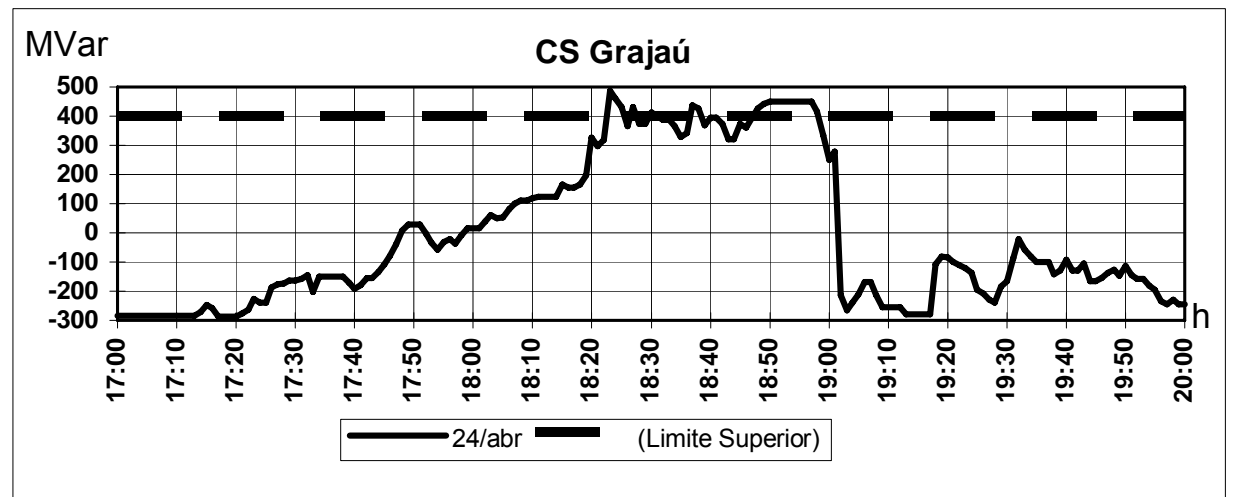

Figura 35. Compensador Síncrono Grajaú

Às 18:19h ocorreu uma ligeira elevação da freqüência atingindo $60,50 \mathrm{~Hz}$, provavelmente devido ao desligamento automático de cargas de consumidores por subtensão, figura 36.

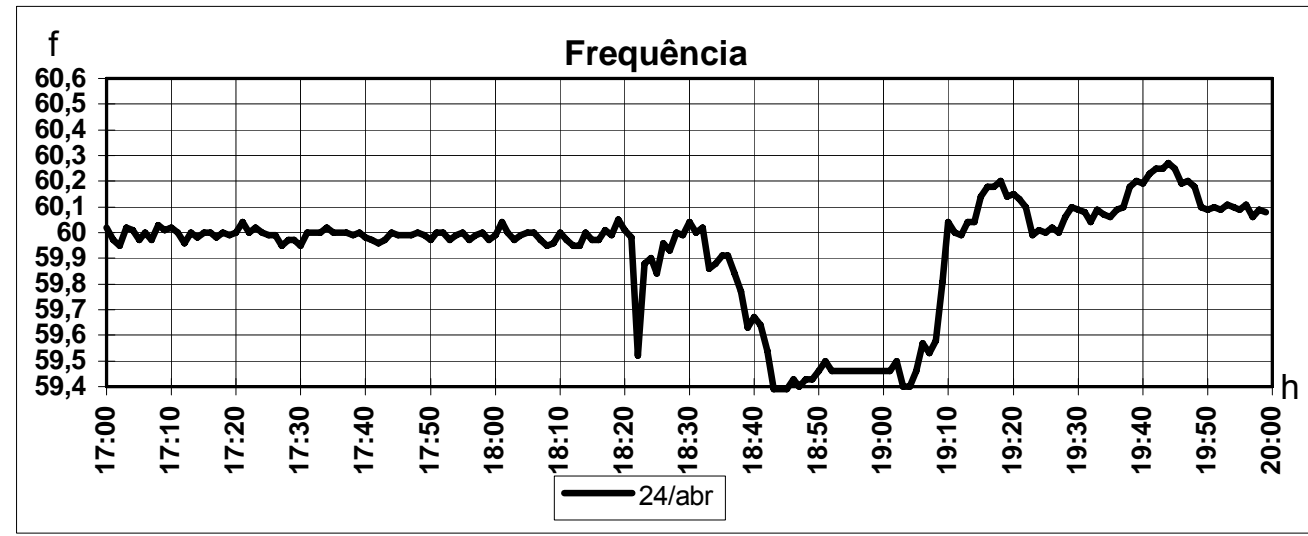

Figura 36 - Freqüência do Sistema

Nesse instante, foram registrados os valores críticos de tensão, conforme figuras 2 a 15 e 23. A freqüência retorna ao valor de $60,0 \mathrm{~Hz}$, caindo logo a seguir.

Às 18:45h há nova queda de tensão generalizada em todo o sistema e também da freqüência (conforme gráficos anteriores).

Às 19:03h a freqüência atingiu $58,10 \mathrm{~Hz}$, levando a atuação do Esquema Regional de Alívio de Carga (ERAC), $1^{\circ}$ e $2^{\circ}$ Estágios. A atuação do ERAC, não foi suficiente, pois muitas cargas do ERAC já haviam sido desligadas anteriormente 
para recuperação da freqüência. Desse modo, houve solicitação, para que fossem realizados cortes adicionais, o que foi feito recuperando a freqüência ao patamar de 60,00 Hz em menos de 10 minutos, quando se iniciou a liberação cautelosa e gradual do religamento das cargas.

Às 19:11h houve o início do restabelecimento das cargas e às 19:27h, todas as cargas foram liberadas para serem religadas, normalizando o Sistema Interligado S/SE/CO.

Com base na análise dos gráficos apresentados, constatou-se um afundamento da tensão na região da grande São Paulo, compatível com um colapso parcial de tensão.

O panorama do Sistema Interligado das $18: 21 \mathrm{~h}$ às $18: 59 \mathrm{~h}$ era de subfreqüência e subtensão, onde as ações eram tomadas durante um período de carga ainda crescente, o que dificultou o pronto restabelecimento das condições normais.

\subsection{SUBDIVISÃO DA ANÁLISE DE ESTABILIDADE DE TENSÃO}

A análise de estabilidade de tensão pode ser subdividida em duas categorias: estabilidade a grandes perturbações e estabilidade a pequenas perturbações. 


\subsubsection{Estabilidade a Grandes Perturbações}

A estabilidade a grandes perturbações é a resposta do sistema quando submetido a distúrbios significativos, tais como a ocorrência de uma falta na rede de transmissão, perdas de grandes blocos de geração ou de carga. Tal fato é observado também nos casos apresentados por Kundur (1994a), Taylor (1994a) e Morison e Gao (1993), geralmente produzidos a partir do uso de simulações no domínio do tempo, e exigem uma modelagem dinâmica completa dos componentes do sistema.

\subsubsection{Estabilidade a Pequenas Perturbações}

A Estabilidade a Pequenas Perturbações é a resposta do sistema quando submetido a pequenas e graduais variações na carga, ou a perda de elementos pouco significativos. Esses casos permitem uma modelagem simplificada, onde a dinâmica dos componentes do sistema pode ser representada por modelos linearizados em torno do ponto de equilíbrio (KUNDUR, 1994a, TAYLOR, 1994a, MORISON E GAO, 1993). 


\subsection{MÉTODOS DE ANÁLISE DE ESTABILIDADE DE TENSÃO}

A estabilidade de tensão, antigamente associada somente a sistemas fracos e linhas de transmissão longas, hoje é uma preocupação para sistemas em geral, devido a altos carregamentos. Os estudos sobre estabilidade de tensão podem ser realizados através de análises dinâmicas em quaisquer circunstâncias, ou através de análises estáticas quando o problema trata de fenômenos com resposta dinâmica lenta.

Os métodos estáticos fornecem resultados mais conservadores do ponto de equilíbrio representado por uma condição de operação específica do sistema de potência do que os métodos dinâmicos, visto que muitos fatores que têm considerável efeito sobre a estabilidade de tensão são ignorados no cálculo do fluxo de carga, sendo amplamente usados por serem rápidos do ponto de vista computacional podendo propiciar uma rápida e simples avaliação das condições críticas do sistema, e estão associados à singularidade da matriz Jacobiana do fluxo de carga. Muitos métodos estáticos buscam a definição de índices de proximidade ao colapso de tensão para a comparação entre diferentes pontos de operação, de modo a se obter uma classificação das condições críticas (CORTEZ, 2001; KUNDUR, 1994a; TAYLORa, 1994; WSCC,1998). 


\subsubsection{Método das curvas P-V e Q-V}

As metodologias mais utilizadas para o traçado das curvas $\mathrm{P}-\mathrm{V}$, figura 37, e Q-V, figura 38, para o estudo e análise da estabilidade de tensão em regime permanente, são as propostas por Kundur (1994b) e Taylor (1994b) e Overbye et al., (1994) e Chowdhury e Taylor, (2000).

Através da curva $Q-V$ se obtém a variação da magnitude da tensão em uma determinada barra em função da injeção de potência reativa. A obtenção desta curva é feita adicionando-se um condensador síncrono hipotético à barra escolhida para análise. Diminui-se gradativamente a sua tensão à medida que se calcula a injeção de reativos através da solução de sucessivos fluxos de potência (TAYLOR, 1994a).

As curvas P-V representam a relação entre o crescimento de carga e a variação de tensão e são obtidas através da solução de uma série de fluxos de potência considerando incrementos sucessivos de carga, de acordo com uma direção pré-esbabelecida. O método das curvas $\mathrm{P}-\mathrm{V}$ é normalmente usado para avaliar a margem de estabilidade de tensão do sistema como um todo, indicando a região em que o sistema pode encontrar um ponto de operação estável, sendo que, a margem de estabilidade de tensão do sistema é dada pela distância de um dado ponto de operação até o "nariz" das curvas P-V e QV (DA SILVA, 2001).

Porém, o método das curvas P-V apresenta problemas de convergência à medida que a matriz Jacobiana se aproxima da singularidade, tornando necessário o uso de metodologias complementares para que se obtenham 
curvas P-V completas. Esse problema é resolvido através do Método da Continuação alterando-se a formulação do fluxo de potência de modo a evitar a singularidade da matriz Jacobiana, alcançando um ponto de equilíbrio independentemente do nível de carregamento do sistema.

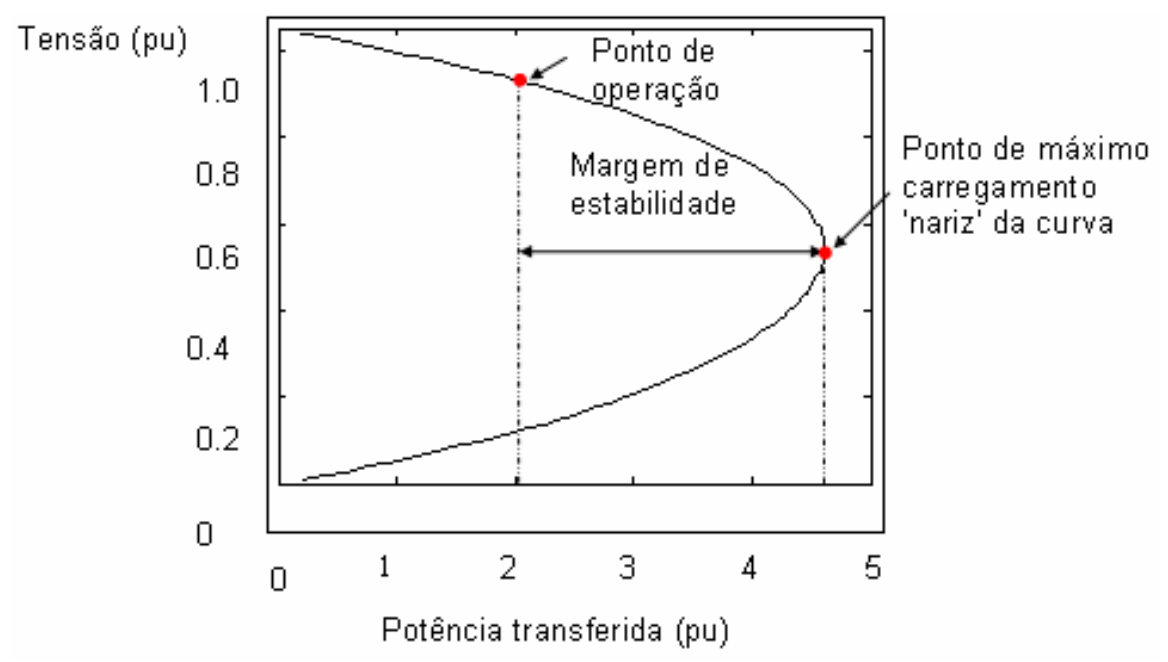

Figura 37 - Curva P-V

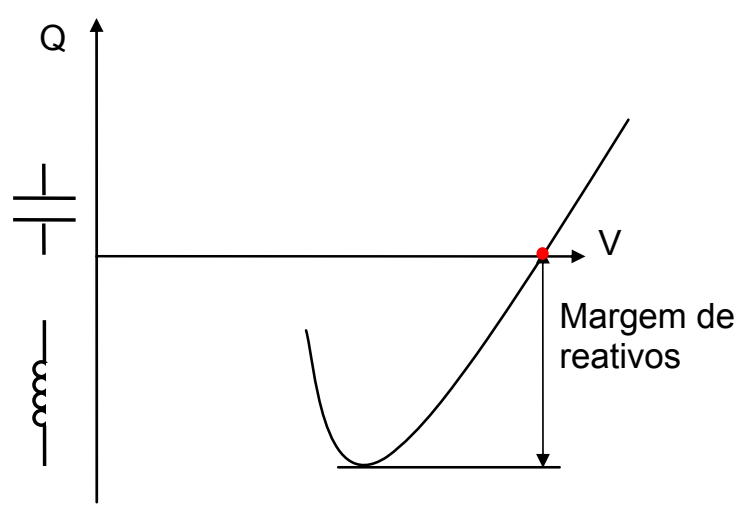

Figura 38 - Curva Q-V 


\subsubsection{Método da Continuação}

O método da continuação, apresentado por Ajjarapu (1992) tem sido empregado na análise de estabilidade de tensão para o cálculo da trajetória das soluções. Através deste método são obtidas sucessivas soluções do fluxo de carga, e, a partir de um caso base são traçadas as curvas PxV até o ponto de máximo carregamento. Neste método o nível de carregamento do sistema é acrescentado como uma nova variável no conjunto de equações não-lineares que representam os balanços de potência ativa e reativa das barras do sistema no modelo de fluxo de carga convencional.

A singularidade da matriz Jacobiana pode ser evitada pela ligeira reformulação das equações de fluxo de potência e aplicando uma técnica local de continuação parametrizada, possibilitando o traçado completo do perfil de tensão a partir da variação do parâmetro $\lambda$ (parâmetro associado à carga do sistema).

\subsubsection{Estudo Bibliográfico}

Muitos trabalhos foram publicados com propostas para resolver o problema de máximo carregamento em sistemas de energia elétrica. A seguir é apresentado o estudo bibliográfico realizado nesta dissertação. 
Destaca-se o método de otimização não linear de Pontos Interiores (PI) apresentado por Irisarri et al (1997) para determinação do máximo carregamento em sistemas de potência, os autores apresentam a resolução do algoritmo de PI nãolinear, nas suas versões Primal-Dual (PIPD) Pura e Preditor-Corretor (PIPC). Na implementação deste trabalho não são incluídas restrições de contingências diretamente no método. Em alguns dos testes realizados pelos autores o máximo carregamento obtido através Fluxo de Carga (FC) é usado como referência. Os modelos de transformadores com mudança de tape e transformadores com defasador de ângulo de fase são modelados completamente na implementação. É feita também comparação entre o modelo de carga constante e o modelo de carga não linear dependente de tensão. O uso do modelo de carga não-linear, como esperado, resulta em considerável aumento de margem em relação ao modelo de carga constante $P Q$.

Outro importante trabalho sobre a abordagem não-linear do método dos Pontos Interiores em suas versões Pura e Preditor-Corretor aplicada ao problema de Fluxo de Potência Ótimo (FPO) é apresentado por Barbosa, Salgado e Almeida (1998). Nesta proposta, o problema de máximo carregamento de um sistema de energia elétrica é analisados levando-se em conta suas limitações, tanto operacionais, como de equipamentos. Os resultados foram obtidos modelando-se as cargas como injeções de potências ativa e reativa e mantendo-se seus fatores de potência constantes. Conforme indicam Barbosa, Salgado e Almeida (1998) foram analisados dois aspectos: (i) a influência das restrições operacionais na solução, sendo que os resultados da aplicação do algoritmo de otimização são confrontados com aqueles obtidos através do Método da Continuação (AJJARAPU e CHRISTY, 1992) e foram consideradas as condições de: presença de restrições apenas na 
potência reativa gerada e ausência completa de restrições operativas; (ii) a eficiência em termos de número de iterações e tempo de CPU das duas versões do algoritmo de pontos interiores, foram estudadas neste aspecto as condições de: consideração de todas as restrições operativas (geração de potencias ativa e reativa, magnitude de tensões, tapes dos transformadores com comutação sob carga e fluxos de potência nas linhas) e semelhante a anterior, porém sem restrições de fluxos de potência nas linhas. Os resultados do máximo carregamento total e das margens totais de potência ativa e reativa obtidas levando em consideração o aspecto (i) mostra que os valores das quantidades obtidas pelas duas abordagens são semelhantes. A diferença entre estes valores é atribuída à ausência de um controle mais refinado sobre o crescimento da carga. Do ponto de vista computacional a versão Preditor-Corretor apresenta um desempenho superior à versão Primal-Dual Pura, reiteram Barbosa, Salgado e Almeida (1998). Embora na primeira versão tenha-se que resolver dois sistemas lineares de porte razoável a cada iteração, a mesma matriz fatorada é utilizada. Fazendo com que o tempo por iteração seja maior para a versão Preditor-Corretor. Mesmo assim, o processo iterativo converge mais rapidamente sendo, portanto mais atrativo em termos de rapidez.

Almeida e Salgado (2000) desenvolveram uma metodologia para calcular uma seqüência de solução do FPO sob condições de variação de carga. O objetivo é obter um conjunto de pontos ótimos de operação na vizinhança da fronteira da região definida pelas equações do fluxo de potência e um conjunto de limites de operação. Para isto, apresenta-se um algoritmo baseado no método da continuação e no método de pontos interiores primal-dual. Tal algoritmo consiste em dois passos principais: o passo preditor, que usa uma aproximação linear das condições de KKT para estimar um novo ponto de operação para um aumento na carga do sistema; e 
um passo corretor, que calcula o correspondente ótimo para o novo nível de carga via um método não-linear de pontos interiores primal-dual. Uma análise de sensibilidade é feita para calcular a compensação total de reativo que permite um aumento pré-especificado na carga do sistema. São apresentados resultados para sistemas testes reais.

No trabalho proposto por Rider et al. (2004) os problemas de minimização das perdas ativas, de mínimo corte de carga e de máximo carregamento são formulados como um problema de FPO que é resolvido utilizando uma combinação de métodos de Pontos Interiores preditor com múltiplas correções e múltiplas correções centralizadas (ambas pertencendo à família dos métodos de pontos interiores de alta ordem). Os resultados mostram que o método proposto é capaz de resolver os problemas de médio e grande porte com um número reduzido de iterações e em alguns casos com menor tempo de CPU que outros métodos.

Finalmente, Zambroni et al. (2004) apresentaram uma abordagem usando modelos de otimização para o problema do aumento do carregamento de sistemas de potência. O trabalho enfoca a localização dos impactos das ações de controle local no carregamento do sistema. O estudo é realizado em dois passos. Primeiro, usando a técnica do vetor tangente, onde duas áreas importantes do sistema de potência são identificadas: a área crítica sob o ponto de vista do colapso de tensão, e as áreas mais sensíveis à redução das perdas de potência ativa. Segundo, uma vez que essas duas áreas são identificadas, uma técnica de otimização visa otimizar a compensação de potência reativa ótima que deve estar disponível em cada barra. Segundo os autores os resultados obtidos usando os dois sistemas testes do IEEE 14 e 118 barras são consistentes com a robustez esperada para essa ferramenta computacional. 
Echavarren et al (2006) apresentam um algoritmo de otimização de Programação Linear (PL) que busca melhorar a margem de estabilidade através da rejeição de carga, obtendo a localização ótima tanto da geração quanto da barra de carga, e a sua correspondente redução de potência. A função objetivo consiste em minimizar a diminuição da demanda total do sistema. São consideradas sensibilidades de primeira ordem da margem de estabilidade com relação à carga que será rejeitada. O desempenho do método é ilustrado utilizando o sistema de potência espanhol. A problema é formulado incluindo como restrições a equação de balanço e os limites de geração e de demanda.

A melhoria da margem de estabilidade é aproximada através de uma restrição linear baseada nas sensibilidades com respeito à carga a ser rejeitada. Estas sensibilidades são calculadas através dos multiplicadores de Lagrange do problema de otimização não linear cuja solução é ponto de bifurcação sela-nó do sistema. O principal problema da formulação linear da margem de estabilidade é a perda de precisão para grandes variações de geração e demanda. Para superar esta dificuldade, o processo iterativo do algoritmo impõe uma restrição adicional de redução de demanda total a cada iteração (ECHAVARREN et al, 2006).

A margem de estabilidade crítica é obtida neste artigo resolvendo-se o método de otimização, a partir da solução obtida com o método de continuação e a estimação dos multiplicadores de Lagrange. Sendo, a estimação dos multiplicadores de Lagrange, obtida resolvendo-se o problema de minimização dos mínimos quadrados, usando a solução obtida através do método da continuação.

As principais vantagens do algoritmo apresentadas nesse trabalho de Echavarren et al (2006), com respeito a outros algoritmos na literatura, são: 
- A formulação PL permite considerar aspectos técnicos da rede, como o fator de potência das cargas ou os limites de geração de potência ativa dos geradores.

- O processo iterativo permite atualizar gradualmente as sensibilidades, evitando a perda de precisão da aproximação linear.

- A convergência do problema de otimização pela atualização da margem de estabilidade crítica é garantida devido ao fato que o redespacho da máxima demanda permitida em cada iteração é controlado.

- A minimização baseada no método dos mínimos quadrados baseada na estimação dos multiplicadores de Lagrange permite agregar as vantagens do método da continuação e dos métodos de otimização para cálculo da margem de estabilidade crítica. 


\section{Capítulo 3}

\section{MÉTODO DA FUNÇÃO LAGRANGIANA BARREIRA MODIFICADA}

Neste capítulo é apresentado o método da Função Lagrangiana Barreira Modificada, seu algoritmo e suas dificuldades computacionais.

\subsection{O MÉTODO DA FUNÇÃO LAGRANGIANA BARREIRA MODIFICADA}

O método da Função Lagrangiana Barreira Modificada (FLBM) foi desenvolvido por Sousa (2006). Nesta abordagem as restrições de desigualdade são tratadas pela associação dos métodos de Barreira Modificada e Primal-Dual Barreira Logarítmica (PDBL). As restrições de desigualdade são transformadas em igualdades introduzindo variáveis auxiliares positivas, as quais são relaxadas através do parâmetro de barreira. Uma função Lagrangiana é associada ao problema modificado. As condições necessárias de primeira ordem são aplicadas na 
função Lagrangiana gerando um sistema de equações não-linear o qual é resolvido pelo método de Newton. A relaxação das variáveis auxiliares resulta na expansão da região factível do problema original, permitindo que os limites das restrições de desigualdade sejam atingidos.

Com o objetivo de simplificar o modelo matemático o método da FLBM será apresentado partindo de um modelo geral de um problema de programação nãolinear.

Considere o seguinte problema de otimização generalizado:

$\min f(x)$

$$
\begin{array}{ll}
\text { s.a } & g_{j}(x)=0 \\
& h_{i}(x) \geq 0 \\
& \underline{x} \leq x \leq \bar{x}
\end{array}
$$

sendo: $x \in R^{n}, g(x) \in R^{m}, h(x) \in R^{P}$, e as funções são de classe $C_{2}$.

No problema (1) padroniza-se o sinal $\geq 0$ apenas por convenção, acrescentam-se as variáveis de excesso positivas às restrições de desigualdade transformando-as em igualdade como no problema (2).

$$
\begin{array}{ll}
\min & f(x) \\
\text { s.a } & g(x)=0 \\
& h(x)-s_{1}=0 \\
& -x-s_{2}+\bar{x}=0 \\
& x-s_{3}-\underline{x}=0 \\
& s_{1} \geq 0 \\
& s_{2} \geq 0 \\
& s_{3} \geq 0
\end{array}
$$


Sendo $s_{1} \in R^{P}, s_{2}$ e $s_{3} \in R^{n}$ o vetor das variáveis de excesso.

Em seguida, as variáveis de excesso são relaxadas usando o parâmetro de barreira $\mu$ e tratadas pela função barreira modificada (POLYAK, 1992), obtendo-se, assim, o seguinte problema modificado:

$\min f(x)$

$$
\begin{array}{ll}
\text { s.a } & g(x)=0 \\
& h(x)-s_{1}=0 \\
& -x-s_{2}+\bar{x}=0 \\
& x-s_{3}-\underline{x}=0 \\
& \mu \ln \left(\mu^{-1} s_{1}+1\right) \geq 0 \\
& \mu \ln \left(\mu^{-1} s_{2}+1\right) \geq 0 \\
& \mu \ln \left(\mu^{-1} s_{3}+1\right) \geq 0
\end{array}
$$

Associa-se ao problema (3) a seguinte função Lagrangiana:

$$
\begin{aligned}
& L=f(x)-\mu\left(\sum_{i=1}^{p} u_{1 i} \ln \left(\mu^{-1} s_{1 i}+1\right)+\sum_{r=1}^{n} u_{2 r} \ln \left(\mu^{-1} s_{2 r}+1\right)+\sum_{r=1}^{n} u_{3 r} \ln \left(\mu^{-1} s_{3 r}+1\right)+\right. \\
& -\sum_{j=1}^{m} \lambda_{j} g_{j}(x)-\sum_{i=1}^{p} \pi_{1 i}\left(h_{i}(x)-s_{1 i}\right)-\sum_{r=1}^{n} \pi_{2 r}\left(-x_{r}-s_{2 r}+\bar{x}_{r}\right)-\sum_{r=1}^{n} \pi_{3 r}\left(x_{r}-s_{3 r}-\underline{x}_{r}\right)
\end{aligned}
$$

sendo $\quad u_{1} \in R^{p}, \quad u_{2}$ e $u_{3} \in R^{n}, \quad \lambda \in R^{m}, \pi_{1} \in R^{p}, \pi_{2}$ e $\pi_{3} \in R^{n} \quad$ os vetores dos multiplicadores de Lagrange e $\mu$ é o parâmetro de barreira.

Aplicam-se às condições necessárias de primeira ordem à função Lagrangiana (4) e obtém-se o sistema não linear:

$\nabla_{\mathrm{d}} \mathrm{L}=0$ 
sendo: $d^{\top}=\left(x, s_{1}, s_{2}, s_{3}, \lambda, \pi_{1}, \pi_{2}, \pi_{3}\right)$ o vetor das variáveis.

$\nabla_{d} L=\left[\begin{array}{l}\nabla_{x} f(x)^{\top}-\lambda^{\top} J(x)-\pi^{\top} J_{1}(x)+\pi_{2}-\pi_{3} \\ -\frac{u_{1}}{\mu^{-1} s_{1}+1}+\pi_{1} \\ -\frac{u_{2}}{\mu^{-1} s_{2}+1}+\pi_{2} \\ -\frac{u_{3}}{\mu^{-1} s_{3}+1}+\pi_{3} \\ -g(x) \\ -\left(h(x)-s_{1}\right) \\ -\left(-x-s_{2}+\bar{x}\right) \\ -\left(x-s_{3}-\underline{x}\right)\end{array}\right]$

$J(x)^{T}=\left(\nabla_{x} g_{1}(x), \ldots, \nabla_{x} g_{m}(x)\right), \quad J_{1}(x)^{T}=\left(\nabla_{x} h_{1}(x), \nabla_{x} h_{2}(x), \ldots, \nabla_{x} h_{p}(x)\right) \quad$ são denominadas matrizes Jacobiana.

Através do método de Newton, obtém-se a solução do sistema não-linear (5). A aplicação do método de Newton resulta no sistema matricial, cuja, forma simplificada, é representada por:

$\mathrm{W} \Delta \mathrm{d}=-\nabla \mathrm{L}$

sendo, $\Delta d$ é o vetor de correção e $\nabla L$ é o vetor dado em (6). 


$$
W=\left(\begin{array}{cccccccc}
\nabla_{x x}^{2} \mathrm{~L} & 0 & 0 & 0 & -J(x) & -J_{1}(x) & I & -1 \\
0 & \frac{\mu \mathrm{u}_{1}}{\left(\mathrm{~s}_{1}+\mu\right)^{2}} & 0 & 0 & 0 & \mathrm{I} & 0 & 0 \\
0 & 0 & \frac{\mu \mathrm{u}_{2}}{\left(\mathrm{~s}_{2}+\mu\right)^{2}} & 0 & 0 & 0 & \mathrm{I} & 0 \\
0 & 0 & 0 & \frac{\mu \mathrm{u}_{3}}{\left(\mathrm{~s}_{3}+\mu\right)^{2}} & 0 & 0 & 0 & 1 \\
-\mathrm{J}(\mathrm{x}) & 0 & 0 & 0 & 0 & 0 & 0 & 0 \\
-\mathrm{J}_{1}(\mathrm{x}) & \mathrm{I} & 0 & 0 & 0 & 0 & 0 & 0 \\
\mathrm{I} & 0 & \mathrm{I} & 0 & 0 & 0 & 0 & 0 \\
-\mathrm{I} & 0 & 0 & \mathrm{I} & 0 & 0 & 0 & 0
\end{array}\right)
$$

W é a matriz Hessiana da função Lagrangiana

Atualiza-se o vetor d por:

$$
\mathrm{d}^{\mathrm{k}+1}=\mathrm{d}^{\mathrm{k}}+\alpha_{\mathrm{p}, \mathrm{d}} \Delta \mathrm{d}^{\mathrm{k}}
$$

sendo $\alpha_{p}$ e $\alpha_{d}$ o tamanho do passo utilizado na atualização das variáveis primais e duais, respectivamente. O cálculo do passo máximo é uma adaptação da estratégia utilizada por Granville (1994), Quintana et al. (1995), entre outros. O passo primal é determinado pelo menor valor entre os componentes das variáveis auxiliares positivas e o valor 1 . O objetivo do passo primal é garantir que as variáveis primais obedeçam seus limites na solução e é dado por:

$$
\alpha_{p}=\min \left\{\left(\min _{\Delta \mathrm{s}_{1}<0 \text { e } \mathrm{s}_{1}>0} \frac{\mathrm{s}_{1}}{\left|\Delta \mathrm{s}_{1}\right|}, \min _{\Delta \mathrm{s}_{2}<0 \text { e } \mathrm{s}_{2}>0} \frac{\mathrm{s}_{2}}{\left|\Delta \mathrm{s}_{2}\right|}, \min _{\Delta \mathrm{s}_{3}<0 \mathrm{e} \mathrm{s}_{3}>0} \frac{\mathrm{s}_{3}}{\left|\Delta \mathrm{s}_{3}\right|}\right), 1\right\}
$$

O passo dual é calculado de forma que cada componente dos vetores duais $\lambda, \pi_{1}, \pi_{2}$ e $\pi_{3}$ permaneçam com seus respectivos sinais, isto é: 


$$
\alpha_{d}=\min \left\{\left(\min _{\Delta \pi_{1}<0 \text { e } \pi_{1}>0} \frac{\pi_{1}}{\left|\Delta \pi_{1}\right|}, \min _{\Delta \pi_{2}>0 \text { e } \pi_{2}<0} \frac{-\pi_{2}}{\left|\Delta \pi_{2}\right|}, \min _{\Delta \pi_{3}<0 \text { e } \pi_{3}>0} \frac{\pi_{3}}{\left|\Delta \pi_{3}\right|}\right), 1\right\}
$$

Durante o processo iterativo o parâmetro de barreira $\mu$ deve decrescer, este é atualizado segundo Melman e Polyak (1996), como segue:

$\mu^{k+1}=\mu^{k}\left(1-\frac{\sigma}{\sqrt{r}}\right)$

em que r é o número de restrições de desigualdade do problema e

$$
\sigma=\max \left(\frac{1}{\mu^{-1} s_{j}+1}\right), \quad j=1, \ldots, r \text { para } s_{j}>0
$$

O vetor dos multiplicadores de Lagrange u é atualizado pela regra de Polyak (1992), da seguinte forma:

$$
u^{k+1}=\frac{u^{k} \mu^{k+1}}{s^{k+1}+\mu^{k+1}}
$$

O critério de parada é dado pelas restrições de igualdade, que devem ser menores do que uma tolerância de convergência $\xi$ pré-estabelecida, e pelas condições de KKT, que devem estar satisfeitas. 


\subsubsection{Algoritmo}

O problema (1), pode ser resolvido iterativamente através do algoritmo apresentado a seguir:

Passo 0: Faça $k=0$, dê uma estimativa inicial para $d^{k}=\left(x^{k}, s_{1}^{k}, s_{2}^{k}, s_{3}^{k}, \lambda^{k}, \pi_{1}^{k}, \pi_{2}^{k}, \pi_{3}^{k}\right)$, $u_{1}^{k}, u_{2}^{k}$ e $u_{3}^{k}>0$ e $\mu^{k}>0$

Passo 1: Determine o sistema (7) e resolva-o;

Passo 2: Atualize $d^{\mathrm{k}}$ utilizando (9);

Passo 3: Se o critério de parada está satisfeito então pare. Caso contrário vá para o passo 4;

Passo 4: Atualize $\mu$ utilizando (12) e os multiplicadores de Lagrange u usando (14). Faça $\mathrm{k}=\mathrm{k}+1$ e retorne ao passo 1 .

O ponto inicial pode ser infactível ao problema original, mas deve satisfazer a condição $s>-\mu$. Na solução as condições $s \geq 0$ e $\pi_{1}>0, \pi_{2}>0$ e $\pi_{3}>0$ devem ser satisfeitas.

Observa-se que o algoritmo apresentado é eficiente e a trajetória de otimização passa pelo interior da região factível relaxada. Em razão da estrutura esparsa da matriz W, do método de Newton, utilizam-se técnicas eficientes de esparsidade. 


\subsubsection{Dificuldades Computacionais}

As principais dificuldades encontradas no método da Função Lagrangiana Barreira Modificada são: o valor inicial do parâmetro de barreira, sua forma de atualização e os valores iniciais dos multiplicadores de Lagrange associados à função barreira modificada. 


\section{Capítulo 4}

\section{MÁXIMO CARREGAMENTO}

Neste capítulo será apresentado o desenvolvimento do método da Função Lagrangiana Barreira Modificada aplicado à solução problema de Máximo Carregamento.

\subsection{O PROBLEMA DE MÁXIMO CARREGAMENTO}

O máximo carregamento pode ser formulado como um problema de otimização estática não-linear. O objetivo deste problema é a determinação do máximo aumento de carga em um sistema de potência, isto é, a carga total do sistema, a carga em uma área específica do sistema, a carga em uma barra particular ou em um conjunto de barras, satisfazendo as restrições operacionais do sistema e de equipamentos. O problema pode ser apresentado sob a seguinte forma: 
$\operatorname{Max} \alpha$

sujeito a :

Equações de balanço do sistema elétrico:

$\Delta P_{i}=P_{G i}-P_{d 0 i}+\alpha\left(P_{G i}-P_{d 0 i}\right)-P_{i}^{\text {calc }}$

para $\mathrm{i}=1,2, \ldots, \mathrm{nb}-1$

$\Delta Q_{i}=Q_{G i}-Q_{d 0 i}+\alpha\left(Q_{G i}-Q_{d 0 i}\right)-Q_{i}^{\text {calc }}$

para $\mathrm{i}=1,2, \ldots, \mathrm{npq}$

Limite na geração de potência ativa :

$\mathrm{P}_{\mathrm{Gi}}^{\min } \leq \mathrm{P}_{\mathrm{Gi}} \leq \mathrm{P}_{\mathrm{Gi}}^{\max }$

para $\mathrm{i}=1,2, \ldots, \mathrm{npv}$

Limite de tensão nas barras:

$\mathrm{V}_{\mathrm{i}}^{\min } \leq \mathrm{V}_{\mathrm{i}} \leq \mathrm{V}_{\mathrm{i}}^{\max }$

para $\mathrm{i}=1,2, \ldots, \mathrm{nb}$

Limite de tap de transformador

$a_{i}^{\min } \leq a_{i} \leq a_{i}^{\max }$

para $\mathrm{i}=1,2, \ldots$, ntraf

Limite na geração de potência reativa:

$\mathrm{Q}_{\mathrm{Gi}}^{\min } \leq \mathrm{Q}_{\mathrm{Gi}} \leq \mathrm{Q}_{\mathrm{Gi}}^{\max }$

para $\mathrm{i}=1,2, \ldots, \mathrm{npv}$

Limite nos quadrados dos fluxos de potência aparente no circuito i: $\left(\mathrm{N}_{\mathrm{pq}}^{2}\right)_{\mathrm{i}} \leq\left(\mathrm{N}_{\mathrm{pq}}^{2}\right)_{\mathrm{i}}^{\max }$ para $i=1,2, \ldots$, nlt 
$\left(\mathrm{N}_{\mathrm{qp}}^{2}\right)_{\mathrm{i}} \leq\left(\mathrm{N}_{\mathrm{qp}}^{2}\right)_{\mathrm{i}}^{\max }$

$$
\text { para } \mathrm{i}=1,2, \ldots, \mathrm{nlt}
$$

onde, nb é o número de barras do sistema;

npq é o número de barras de carga do sistema;

npv é o número de barras de geração do sistema;

ntraf é o número de transformadores do sistema;

nlt é o número de circuitos monitorados no sistema;

$\alpha$ é o parâmetro de incremento de carga;

$P_{d 0 i}$ é a demanda ativa inicial na barra i;

$\mathrm{P}_{\mathrm{i}}^{\text {calc }}$ é a potência ativa injetada calculada na barra $\mathrm{i}$;

$Q_{d 0 i}$ é a demanda reativa inicial na barra i;

$Q_{i}^{\text {calc }}$ é a potência reativa injetada calculada na barra $i$;

$P_{G i}, P_{G i}^{\text {min }}$ e $P_{G i}^{\text {max }}$ é a geração de potência ativa na barra $i$, com seus limites mínimo e máximo, respectivamente, para todas as barras com controle de reativos;

$V_{i}, V_{i}^{\text {min }}$ e $V_{i}^{\max }$ é a magnitude de tensão na barra $i$, com seus limites mínimo e máximo, respectivamente, para todas as barras do sistema;

$a_{i}, a_{i}^{\min }$ e $a_{i}{ }^{\max }$ é o valor do tap do transformador com mudança de tap sob carga no circuito i, com seus limites mínimo e máximo, respectivamente, para todos os circuitos contendo transformadores LTC ;

$Q_{G i}, Q_{G i}{ }^{\min }$ e $Q_{G i}{ }^{\max }$ é a geração de potência reativa na barra $i$, com seus limites mínimo e máximo, respectivamente, para todas as barras com controle de tensão; 
O vetor $\mathrm{x}$ das variáveis de decisão, para este problema, pode ser dado como:

$\mathrm{d}=\left[\begin{array}{c}\mathrm{P}_{\mathrm{G}} \\ \mathrm{V} \\ \mathrm{a} \\ \delta \\ \alpha\end{array}\right]$

onde, $P_{G}$ é o vetor das gerações de potência ativa em todas as barras PV;

V é o vetor das magnitudes das tensões em todas as barras do sistema;

a é o vetor dos tapes dos transformadores LTC;

$\delta$ é o vetor dos ângulos de fase das tensões em todas as barras, exceto na barra de folga;

$\alpha$ é o parâmetro de incremento de carga;

\subsubsection{Método da Função Lagrangiana Barreira Modificada Aplicado ao Problema de Máximo Carregamento}

Neste trabalho, aplica-se o método da Função Lagrangiana Barreira Modificada ao problema de máximo carregamento considerando as equações (16) e 
(17), restrições de igualdade, e as equações (19) e (21), restrições de desigualdade. Logo, a formulação do problema torna-se:

$\operatorname{Max} \alpha$

sujeito a:

Equações de balanço do sistema elétrico: para $\mathrm{i}=1,2, \ldots, \mathrm{nb}$ $\Delta P_{i}=P_{G i}-P_{d 0 i}+\alpha\left(P_{G i}-P_{d 0 i}\right)-P_{i}^{\text {calc }}$

$\Delta Q_{i}=Q_{G i}-Q_{d 0 i}+\alpha\left(Q_{G i}-Q_{d 0 i}\right)-Q_{i}^{\text {calc }}$

para $\mathrm{i}=1,2, \ldots, \mathrm{npv}$

Limite de tensão nas barras:

$\mathrm{V}_{\mathrm{i}}^{\min } \leq \mathrm{V}_{\mathrm{i}} \leq \mathrm{V}_{\mathrm{i}}^{\max }$

para $\mathrm{i}=1,2, \ldots, \mathrm{nb}$

Limite na geração de potência reativa:

$\mathrm{Q}_{\mathrm{Gi}}^{\min } \leq \mathrm{Q}_{\mathrm{Gi}} \leq \mathrm{Q}_{\mathrm{Gi}}^{\max }$

para $\mathrm{i}=1,2, \ldots, \mathrm{npv}$

O vetor d das variáveis de decisão, no estudo apresentado neste trabalho é dado por: 


$$
d=\left[\begin{array}{l}
\mathrm{V} \\
\delta \\
\alpha
\end{array}\right]
$$

Para aplicar o método da Função Lagrangiana Barreira Modificada ao problema de máximo carregamento, primeiramente transformam-se todas as desigualdades em igualdades, utilizando variáveis de folga ou excesso. Em seguida, essas variáveis de folga ou excesso referentes às restrições das magnitudes de tensão e de geração de potência reativa são relaxadas usando o parâmetro de barreira. Desta forma, obtém-se a Função Lagrangiana Barreira Modificada associada:

$$
\begin{aligned}
L(\alpha, x, s, \lambda, \pi)=\alpha & -\mu \sum_{i=1}^{n b} u_{1 i} \ln \left(\mu^{-1} s_{1 i}+1\right)-\mu \sum_{i=1}^{n b} u_{2 i} \ln \left(\mu^{-1} s_{2 i}+1\right)- \\
& -\mu \sum_{j=1}^{n p v} u_{3 j} \ln \left(\mu^{-1} s_{3 j}+1\right)-\mu \sum_{j=1}^{n p v} u_{4 j} \ln \left(\mu^{-1} s_{4 j}+1\right)- \\
& -\sum_{k=1}^{n b-1} \lambda_{1 k}\left(P_{G k}-P_{d 0 k}+\alpha\left(P_{G k}-P_{d 0 k}\right)-P_{k}^{\text {calc }}\right)- \\
& -\sum_{i=1}^{n p q} \lambda_{2 l}\left(Q_{G l}-Q_{d 0 I}+\alpha\left(Q_{G l}-Q_{d 0 l}\right)-Q_{l}^{\text {calc }}\right)- \\
& -\sum_{i=1}^{n b} \pi_{1 i}\left(V_{i}^{\min }-V_{i}-s_{1 i}\right)-\sum_{i=1}^{n b} \pi_{2 i}\left(V_{i}^{\max }-V_{i}+s_{2 i}\right)- \\
& -\sum_{j=1}^{n p v} \pi_{3 j}\left(Q_{j}^{\min }-Q_{j}-s_{3 j}\right)-\sum_{j=1}^{n p v} \pi_{4 j}\left(Q_{j}^{\max }-Q_{j}+s_{4 j}\right)
\end{aligned}
$$

Sendo $u_{1}$ e $u_{2} \in R^{n b}, u_{3}$ e $u_{4} \in R^{n p v}, \lambda_{1} \in R^{n b-1}, \lambda_{2} \in R^{n p q}, \pi_{1}$ e $\pi_{2} \in R^{n b}$ $\pi_{3}$ e $\pi_{4} \in R^{n p v}$ os vetores dos multiplicadores de Lagrange, $s_{1} \in R^{n b}$ e $s_{3} \in R^{n p v} o$ vetor das variáveis de excesso, $s_{2} \in R^{n b}$ e $s_{4} \in R^{n p v}$ o vetor das variáveis de folga e $\mu$ é o parâmetro de barreira. 
As condições necessárias de primeira-ordem são aplicadas à Função Lagrangiana Barreira Modificada, gerando um sistema de equações não-lineares, como segue:

$\nabla \mathrm{L}\left(\alpha, \mathrm{X}, \mathrm{s}_{1}, \mathrm{~s}_{2}, \mathrm{~S}_{3}, \mathrm{~s}_{4}, \lambda_{1}, \lambda_{2}, \pi_{1}, \pi_{2}, \pi_{3}, \pi_{4}\right)=0$

sendo:

$$
\nabla_{d} L=\left[\begin{array}{c}
1-\left(P_{G}-P_{d 0}\right)-\left(Q_{G}-Q_{d 0}\right) \\
-\lambda_{1}^{\top} J_{p}(x)-\lambda_{2}^{\top} J_{q}(x)-\pi_{1}^{\top} J_{Q}(x)-\pi_{2}^{\top} J_{Q}(x)-\left(\pi_{3}\right)-\left(\pi_{4}\right) \\
-\frac{u_{1}}{\mu^{-1} s_{1}+1}+\pi_{1} \\
-\frac{u_{2}}{\mu^{-1} s_{2}+1}-\pi_{2} \\
-\frac{u_{3}}{\mu^{-1} s_{3}+1}+\pi_{3} \\
-\frac{u_{4}}{\mu^{-1} s_{4}+1}-\pi_{4} \\
g p \\
g q \\
\left(V^{\min }-V-s_{1}\right) \\
\left(V^{\max }-V+s_{2}\right) \\
\left(Q^{\min }-Q-s_{3}\right) \\
\left(Q^{\max }-Q+s_{4}\right) \\
\end{array}\right]
$$

com:

$g p=-\sum_{k=1}^{n b-1}\left(P_{G k}-P_{d 0 k}+\alpha\left(P_{G k}-P_{d 0 k}\right)-P_{k}^{c a l c}\right)$

$g q=-\sum_{l=1}^{n p q}\left(Q_{G l}-Q_{d 01}+\alpha\left(Q_{G l}-Q_{d 0 l}\right)-Q_{l}^{\text {calc }}\right)$

$J_{p}(x)=\left(\nabla_{x} \mathrm{gp}_{1}(x), \ldots, \nabla_{x} g p_{n b-1}(x)\right)$ e $J_{q}(x)=\left(\nabla_{x} g q_{1}(x), \ldots, \nabla_{x} g_{n b-1}(x)\right) \quad e$ 
$\mathrm{J}_{\mathrm{Q}}(\mathrm{x})=\left(\nabla_{\mathrm{x}} \mathrm{Q}_{1}(\mathrm{x}), \nabla_{\mathrm{x}} \mathrm{Q}_{2}(\mathrm{x}), \ldots, \nabla_{\mathrm{x}} \mathrm{Q}_{\mathrm{npv}}(\mathrm{x})\right)$, as quais são denominadas matrizes Jacobianas.

O sistema de equações não-lineares (3.24) é solucionado utilizando o método de Newton. A aplicação do método de Newton gera as direções de busca $\left(\Delta \alpha, \Delta \mathrm{x}, \Delta \mathrm{s}_{1}, \Delta \mathrm{s}_{2}, \Delta \mathrm{s}_{3}, \Delta \mathrm{s}_{4}, \Delta \lambda_{1}, \Delta \lambda_{2}, \Delta \pi_{1}, \Delta \pi_{2}, \Delta \pi_{3}, \Delta \pi_{4}\right)$, as quais serão usadas para a atualização das variáveis do sistema, e resulta num sistema matricial, que, pode ser representado de forma simplificada como:

$\mathrm{W} \Delta \mathrm{d}=-\nabla \mathrm{L}$

em que:

$\Delta \mathbf{d}^{\top}=\left(\Delta \alpha, \Delta \mathbf{x}, \Delta \mathbf{s}_{1}, \Delta \mathbf{s}_{2}, \Delta \mathbf{s}_{3}, \Delta \mathbf{s}_{4}, \Delta \lambda_{1}, \Delta \lambda_{2}, \Delta \pi_{1}, \Delta \pi_{2}, \Delta \pi_{3}, \Delta \pi_{4}\right)$ e $\nabla \mathrm{L}$ é dado em (33).

$W=\left[\begin{array}{cccccccccccc}0 & 0 & 0 & 0 & 0 & -P_{G}+P_{d 0} & -Q_{G}+Q_{d 0} & 0 & 0 & 0 & 0 & 0 \\ 0 & \nabla_{x x}^{2} \mathrm{~L} & 0 & 0 & 0 & 0 & -J_{p}(x) & -J_{q}(x) & -J_{Q}(x) & -J_{Q}(x) & -1 & -1 \\ 0 & 0 & \mu^{-1} S_{1} & 0 & 0 & 0 & 1 & 0 & 0 & 0 & 0 & 0 \\ 0 & 0 & 0 & \mu^{-1} S_{2} & 0 & 0 & 0 & -1 & 0 & 0 & 0 & 0 \\ 0 & 0 & 0 & 0 & \mu^{-1} S_{3} & 0 & 0 & 0 & 1 & 0 & 0 & 0 \\ -P_{G}+P_{d 0} & 0 & I & 0 & 0 & \mu^{-1} S_{4} & 0 & 0 & 0 & -1 & 0 & 0 \\ -Q_{G}+Q_{d 0} & -J_{p}(x) & 0 & -1 & 0 & 0 & 0 & 0 & 0 & 0 & 0 & 0 \\ 0 & -J_{q}(x) & 0 & 0 & 1 & 0 & 0 & 0 & 0 & 0 & 0 & 0 \\ 0 & -J_{Q}(x) & 0 & 0 & 0 & -1 & 0 & 0 & 0 & 0 & 0 & 0 \\ 0 & -J_{Q}(x) & 0 & 0 & 0 & 0 & 0 & 0 & 0 & 0 & 0 & 0 \\ 0 & -I & 0 & 0 & 0 & 0 & 0 & 0 & 0 & 0 & 0 & 0 \\ 0 & -1 & 0 & 0 & 0 & 0 & 0 & 0 & 0 & 0 & 0 & 0\end{array}\right]$

W é a matriz Hessiana da função Lagrangiana e as submatrizes $S_{1}, S_{2}, e S_{3}$ são dadas por: 


$$
\begin{aligned}
& S_{1}=\left(\begin{array}{ccc}
\frac{u_{11}}{\left(\mu^{-1} s_{11}+1\right)^{2}} & & 0 \\
0 & \ddots & \frac{u_{1 n b}}{\left(\mu^{-1} s_{1 n b}+1\right)^{2}}
\end{array}\right) \quad S_{2}=\left(\begin{array}{ccc}
\frac{u_{21}}{\left(\mu^{-1} s_{21}+1\right)^{2}} & & 0 \\
0 & & \frac{u_{2 n b}}{\left(\mu^{-1} s_{2 n b}+1\right)^{2}}
\end{array}\right) \\
& \mathrm{S}_{3}=\left(\begin{array}{ccc}
\frac{\mathrm{u}_{31}}{\left(\mu^{-1} \mathrm{~s}_{31}+1\right)^{2}} & & 0 \\
0 & \ddots & \frac{\mathrm{u}_{3 \mathrm{nnv}}}{\left(\mu^{-1} \mathrm{~s}_{3 \mathrm{npv}}+1\right)^{2}}
\end{array}\right) \quad \mathrm{S}_{4}=\left(\begin{array}{ccc}
\frac{\mathrm{u}_{41}}{\left(\mu^{-1} \mathrm{~s}_{41}+1\right)^{2}} & & 0 \\
0 & & \frac{\mathrm{u}_{4 n \mathrm{pv}}}{\left(\mu^{-1} \mathrm{~s}_{4 n \mathrm{vv}}+1\right)^{2}}
\end{array}\right)
\end{aligned}
$$

Definidos o vetor gradiente, $\nabla \mathrm{L}$, e a matriz Hessiana da função Lagrangiana, W, o sistema (34) é resolvido, e determina-se o vetor das direções de busca, $\Delta d$. Os vetores das variáveis $\alpha, x, s, \lambda$ e $\pi$ são atualizados utilizando o vetor $\Delta \mathrm{d}$ juntamente com os passos primais e duais da seguinte forma:

Os vetores das variáveis $\alpha, x, s, \lambda$ e $\pi$ são atualizados da seguinte forma:

$$
\begin{aligned}
& \alpha^{k+1}=\alpha^{k}+\alpha_{p} \Delta x^{k} \\
& x^{k+1}=x^{k}+\alpha_{p} \Delta x^{k} \\
& s_{1}^{k+1}=s_{1}^{k}+\alpha_{p} \Delta s_{1}^{k} \\
& s_{2}^{k+1}=s_{2}^{k}+\alpha_{p} \Delta s_{2}^{k} \\
& s_{3}^{k+1}=s_{3}^{k}+\alpha_{p} \Delta s_{3}^{k} \\
& s_{4}^{k+1}=s_{4}^{k}+\alpha_{p} \Delta s_{4} \\
& \lambda_{1}^{k+1}=\lambda_{1}^{k}+\alpha_{d} \Delta \lambda_{1}^{k} \\
& \lambda_{2}^{k+1}=\lambda_{2}^{k}+\alpha_{d} \Delta \lambda_{2}^{k} \\
& \pi_{1}^{k+1}=\pi_{1}^{k}+\alpha_{d} \Delta \pi_{1}^{k} \\
& \pi_{2}^{k+1}=\pi_{2}^{k}+\alpha_{d} \Delta \pi_{2}^{k}
\end{aligned}
$$


$\pi_{3}^{k+1}=\pi_{3}^{k}+\alpha_{d} \Delta \pi_{3}^{k}$

$\pi_{4}^{\mathrm{k}+1}=\pi_{4}^{\mathrm{k}}+\alpha_{\mathrm{d}} \Delta \pi_{4}^{\mathrm{k}}$

Finalmente, o parâmetro de barreira e os multiplicadores de Lagrange são atualizados pelas regras de Melman e Polyak (1996) e Polyak (1992), respectivamente. 


\section{Capítulo 5}

\section{TESTES E RESULTADOS}

Neste capítulo, são apresentados os resultados numéricos do método Função Lagrangiana Barreira Modificada para a resolução do problema de máximo carregamento e posteriormente um estudo comparativo com o método clássico Primal-Dual Barreira Logarítmica.

Para avaliar a metodologia proposta empregada na determinação do ponto de máximo carregamento, foram utilizados os seguintes sistemas-teste do IEEE:

- sistema de 14 barras;

- sistema de 57 barras;

- sistema de 118 barras.

Os testes realizados nos sistemas citados acima, utilizaram como critério de parada as condições de KKT com uma tolerância de $\xi<10^{-3} \mathrm{pu}$.

As implementações foram desenvolvidas em linguagem de programação Fortran, para esta finalidade foi utilizado um computador Pentium 4, 2 GHz, com 256 Mbytes de memória RAM. 
O estudo comparativo entre os métodos foi feito com base na realização dos seguintes testes:

- Teste 1: as magnitudes das tensões das barras foram liberadas, com exceção da barra de folga cuja tensão foi estipulada de acordo com o banco de dados para cada sistema; a potência ativa gerada na barra de folga foi liberada, enquanto que nas demais barras com controle de reativos foram especificadas de acordo com os valores dos bancos de dados; a potência reativa gerada na barra de folga foi liberada, enquanto que nas barras com controle de reativos foram especificados limites de acordo com os valores dos bancos de dados; os taps foram fixados nos mesmos valores dos bancos de dados.

- Teste 2: idem ao anterior, com exceção de que as potências reativas geradas nas barras com controle de reativos foram liberadas.

\subsection{SISTEMA DE 14 BARRAS}

O sistema de 14 barras, mostrado na Figura 39, tem as seguintes características:

- 1 barra de referência;

- 4 barras de controle de reativo;

- 9 barras de carga; 
- 17 linhas de transmissão;

- 3 transformadores com tap variável.

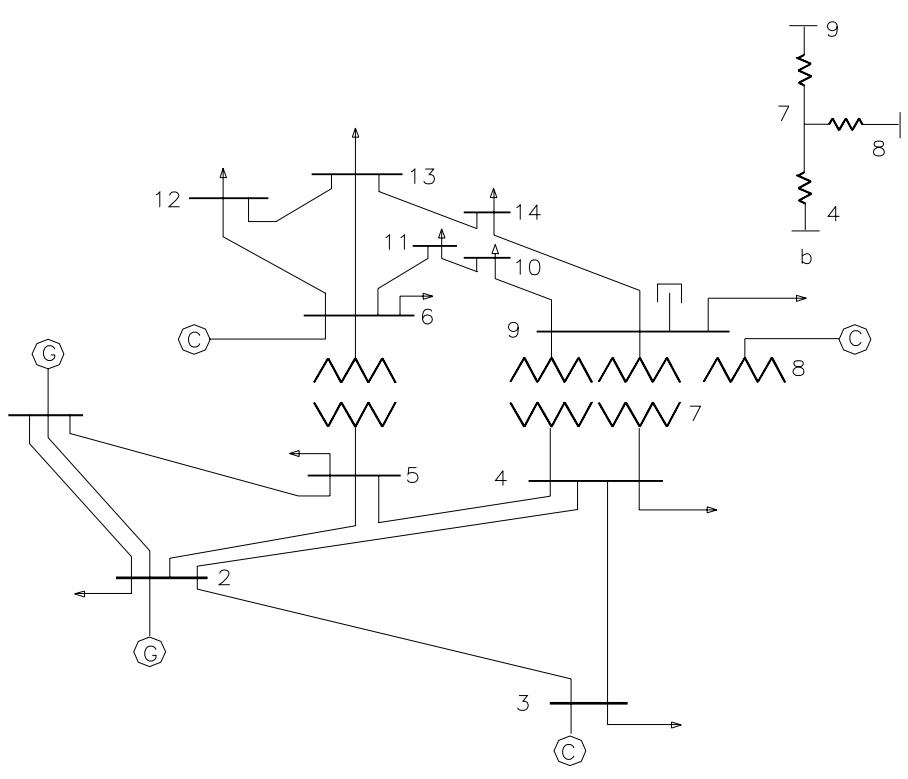

Figura 39 - O sistema de 14 barras.

\subsubsection{Resultados do Teste 1}

Os resultados obtidos no teste 1 para o sistema IEEE 14 barras são apresentados na Tabela 1, na qual verifica-se que as duas metodologias implementadas apresentaram resultados extremamente semelhantes em termos de ponto de máximo carregamento $(\alpha)$, como esperado. 
Tabela 1 - Comparativo entre o Método PDBL e o Método da FBM para o sistema de 14 barras

Método PDBL

$\alpha$

Iterações

Barra crítica

Tensão da Barra crítica
0,831 11

14

0,680
Método FBM

0,835

5

14

0,670

A Figura 40 mostra os perfis de tensões das barras do sistema. As linhas horizontais representam a faixa normalmente aceitável para as tensões de um sistema de energia elétrica, ou seja, entre 0,95 e 1,05 pu. Tais linhas permitem observar quão longe desta faixa encontram-se as tensões no sistema. Nesta figura, constata-se que a distribuição das tensões ao longo do sistema também são semelhantes para os dois métodos, resultando na proximidade entre os pontos de máximo carregamento. Sendo que o Método da Função Lagrangeana Barreira Modificada convergiu com um número de iterações menor do que o Método PrimalDual Barreira Logarítmica. 


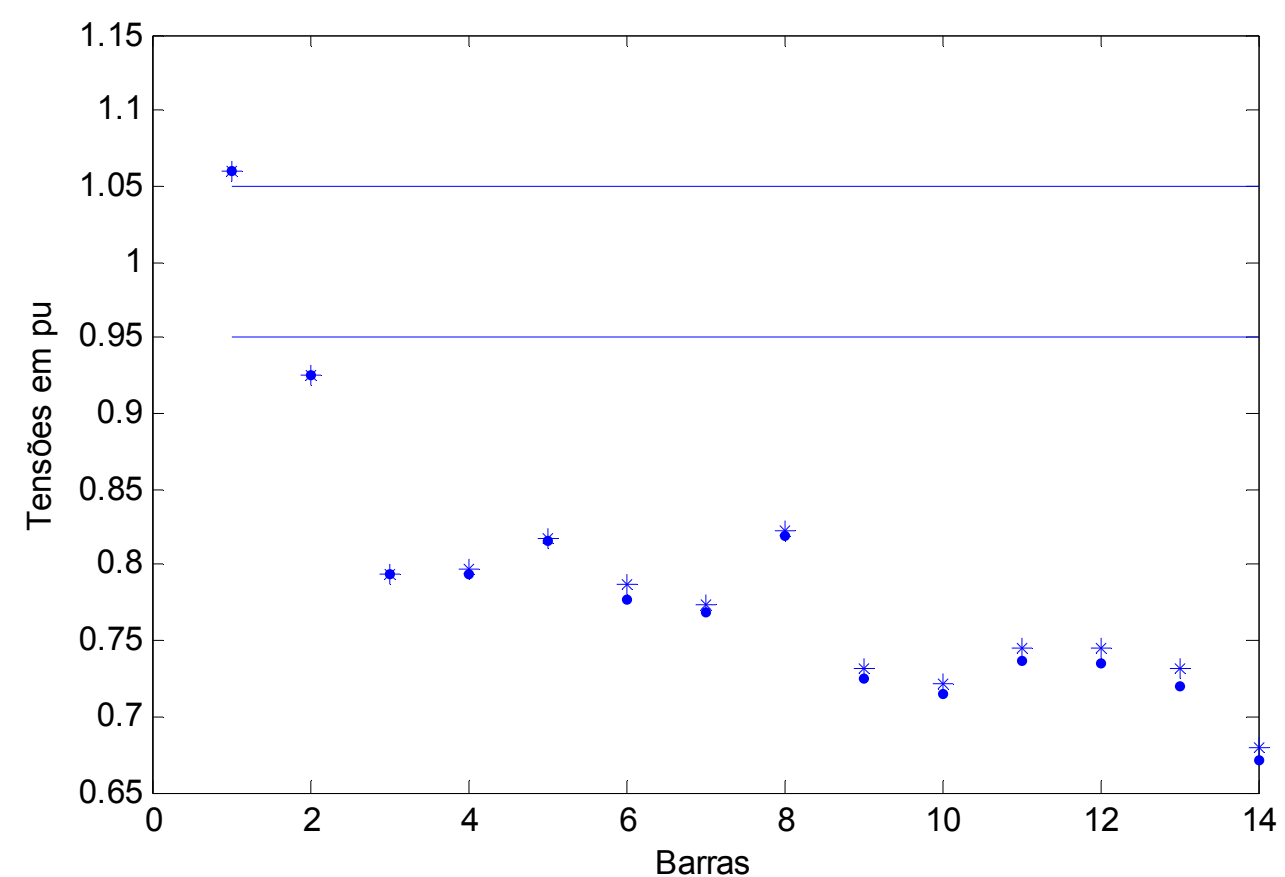

* Método PDBL
- Método FBM

Figura 40 - Perfis de tensões para o sistema de 14 barras.

Pode-se observar, tanto na Tabela 1 quanto na Figura 40, que a barra 14 apresentou a menor magnitude de tensão quando a geração de reativos foi limitada, ou seja, esta é a barra crítica do sistema.

\subsubsection{Resultados do Teste 2}

Com as potências reativas liberadas nas barras com controle de reativos, verifica-se nas Tabela 1 à Tabela 2 que há uma grande diferença entre os pontos de máximo carregamento, esta diferença entre os resultados obtidos com a aplicação 
dos Testes 1 e 2. Justifica-se observando que no Teste 2 toda a geração de potência reativa do sistema foi liberada, ampliando a oferta de reativos, e portanto os pontos de máximo carregamento foram ampliados.

Tabela 2 - Comparativo entre o Método PDBL e o Método da FBM para o sistema de 14 barras

\begin{tabular}{ccc}
\hline & Método PDBL & Método FBM \\
\hline$\alpha$ & 3,103 & 3,107 \\
Iteração & 13 & 10 \\
Barra crítica & 14 & 14 \\
Tensão da Barra crítica & 0,652 & 0,654 \\
\hline
\end{tabular}

A Tabela 2 e a Figura 41 mostram que a barra 14 apresenta a menor magnitude de tensão, assim como no Teste 1. 


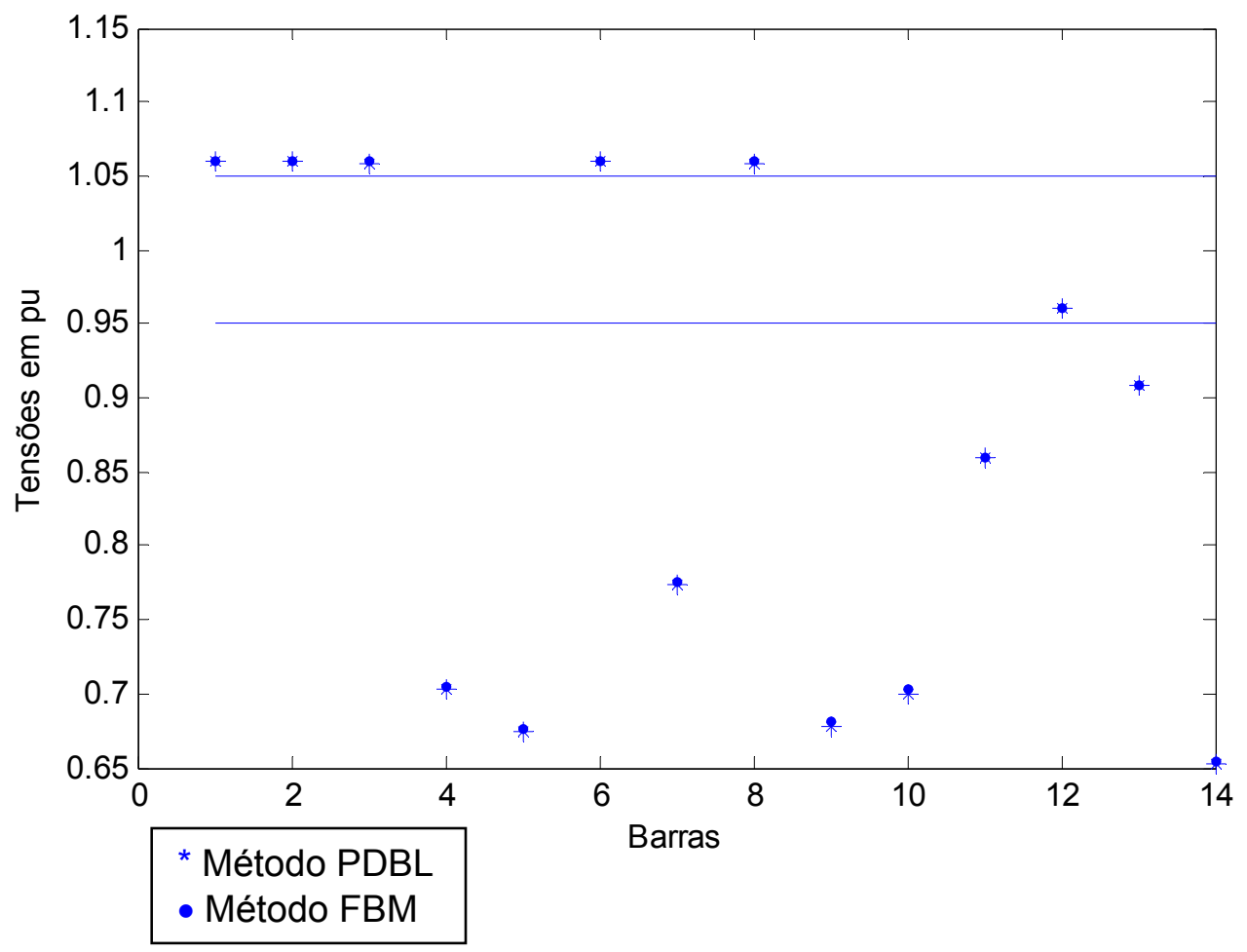

Figura 41 - Perfis de tensões para o sistema de 14 barras.

A convergência do Método da Função Lagrangiana Barreira Modificada foi mais rápida do que a do Método Primal-Dual Barreira Logarítmica, conforme mostrado na Tabela 2.

\subsection{SISTEMA DE 57 BARRAS}

O sistema de 57 barras, mostrado na Figura 41, tem as seguintes características: 
- 1 barra de geração (slack);

- 6 barras de controle de reativo;

- 50 barras de carga;

- 80 linhas de transmissão;

- 17 transformadores com o tap variável.

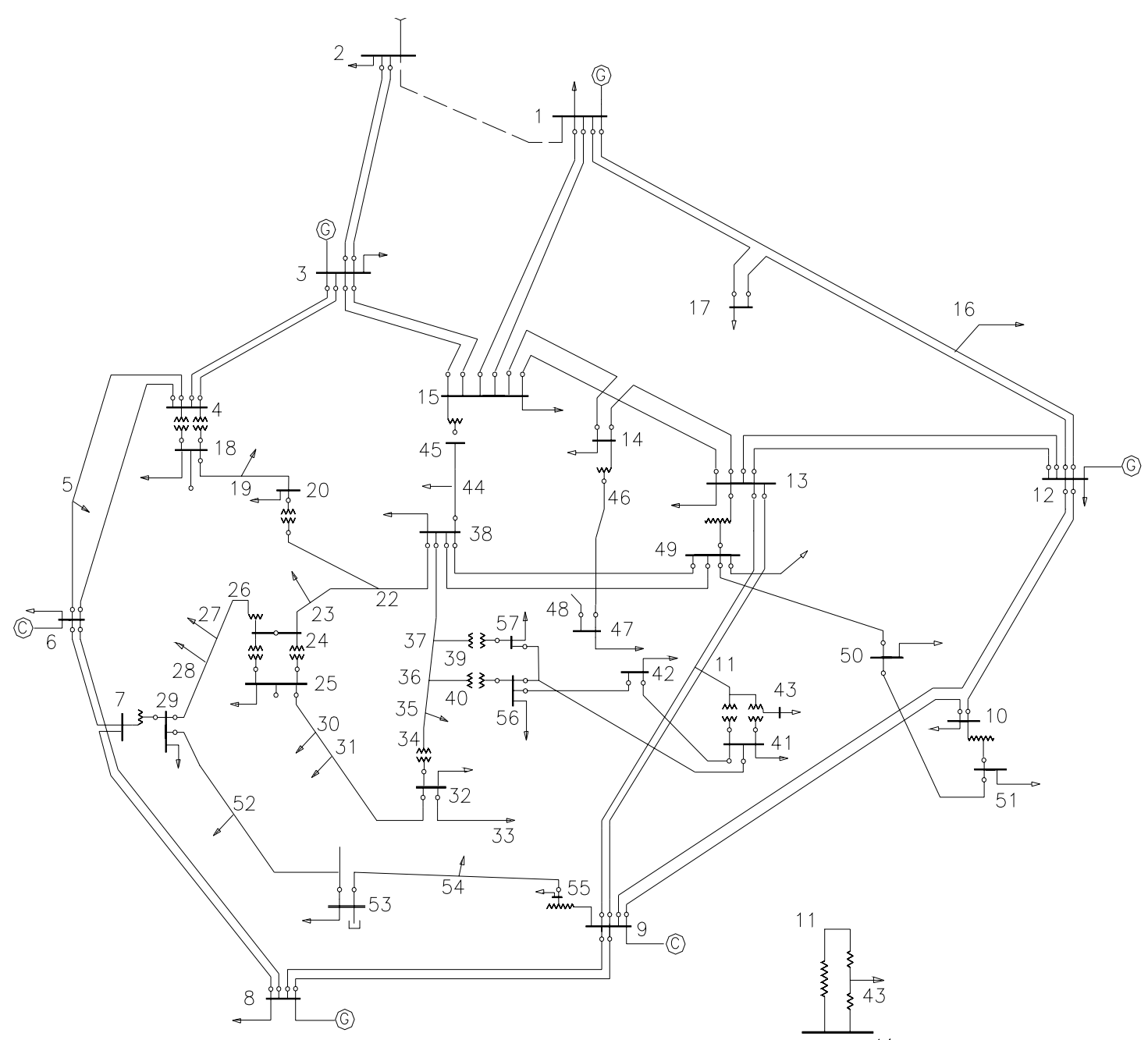

Figura 42 - O sistema de 57 barras. 


\subsubsection{Resultados do Teste 1}

Os resultados obtidos no teste 1 para o sistema IEEE 57 barras são apresentados na Tabela 3, para as duas metodologias implementadas o sistema apresenta resultados extremamente semelhantes em termos de ponto de máximo carregamento.

Tabela 3 - Comparativo entre o Método PDBL e o Método da FBM para o sistema de 57 barras

\begin{tabular}{ccc}
\hline & Método PDBL & Método FBM \\
\hline$\alpha$ & 0,542 & 0,556 \\
Iteração & 35 & 11 \\
Barra crítica & 31 & 31 \\
Tensão da Barra crítica & 0,757 & 0,750 \\
\hline
\end{tabular}

A distribuição das tensões ao longo do sistema, mostrada na Figura 43, é praticamente idêntica para os dois métodos, resultando na proximidade entre os pontos de máximo carregamento.

Quanto à convergência, o Método da Função Lagrangeana Barreira Modificada convergiu com um número de iterações menor do que o Método PrimalDual Barreira Logarítmica. 
Pode-se observar, tanto na Tabela 3 quanto na Figura 43, que a barra crítica do sistema é a barra 31.

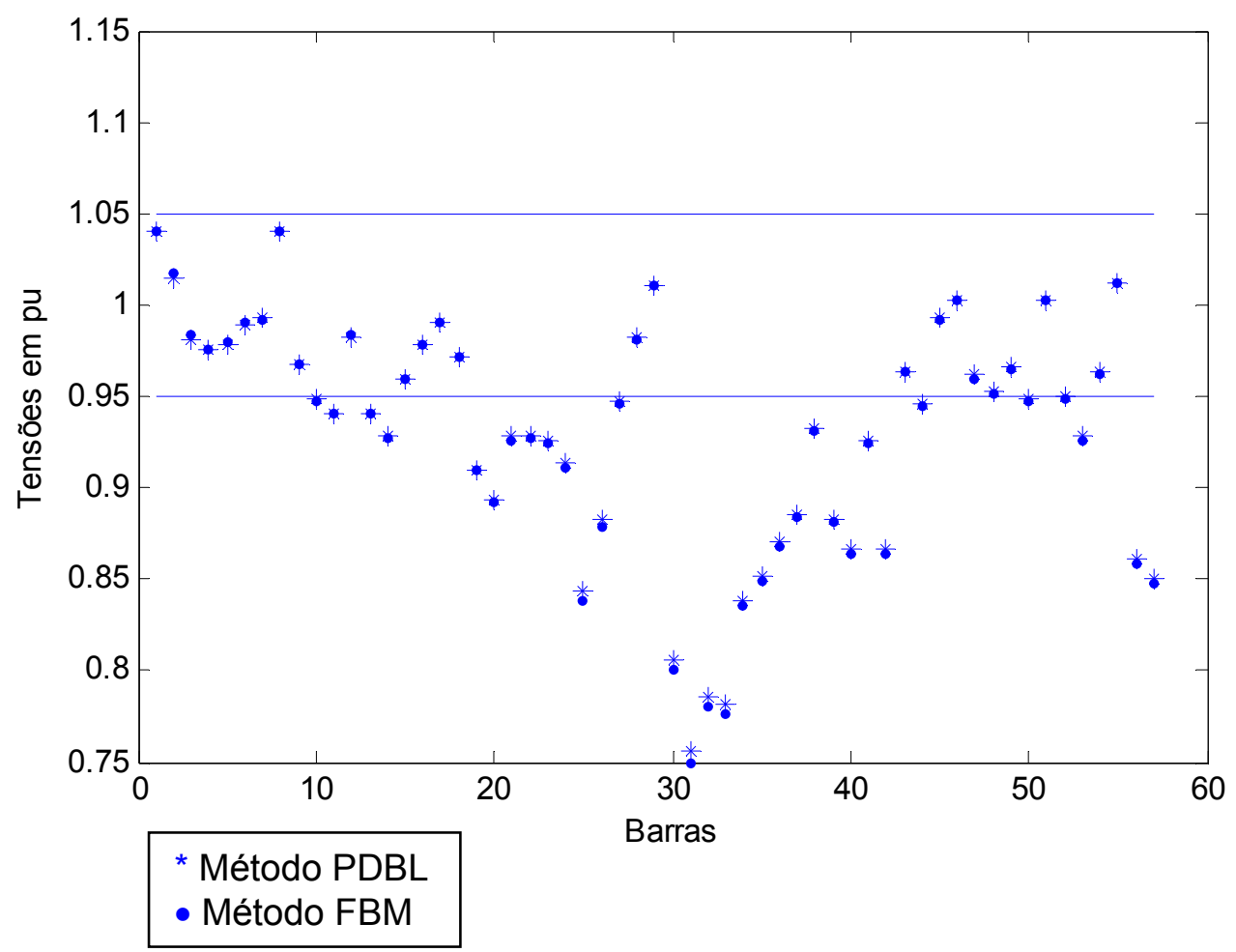

Figura 43. Perfis de tensões para o sistema de 57 barras

\subsubsection{Resultados do Teste 2}

Comparando a Tabela 3 à Tabela 4 percebe-se que há diferença entre os pontos de máximo carregamento, esta diferença entre os resultados obtidos com a aplicação dos Testes 1 e 2 justifica-se observando que no Teste 2 toda a geração de potência reativa do sistema foi liberada, e portanto os pontos de máximo carregamento foram ampliados. 
Tabela 4 - Comparativo entre o Método PDBL e o Método da FBM para o sistema de 57 barras

\begin{tabular}{ccc}
\hline$\alpha$ & 0,914 & 0,931 \\
Iteração & 94 & 20 \\
Barra crítica & 31 & 31 \\
Tensão da Barra crítica & 0,701 & 0,701 \\
\hline
\end{tabular}

A Tabela 4 e a Figura 44 mostra que a barra 31 apresenta a menor magnitude de tensão, assim como no Teste 1.

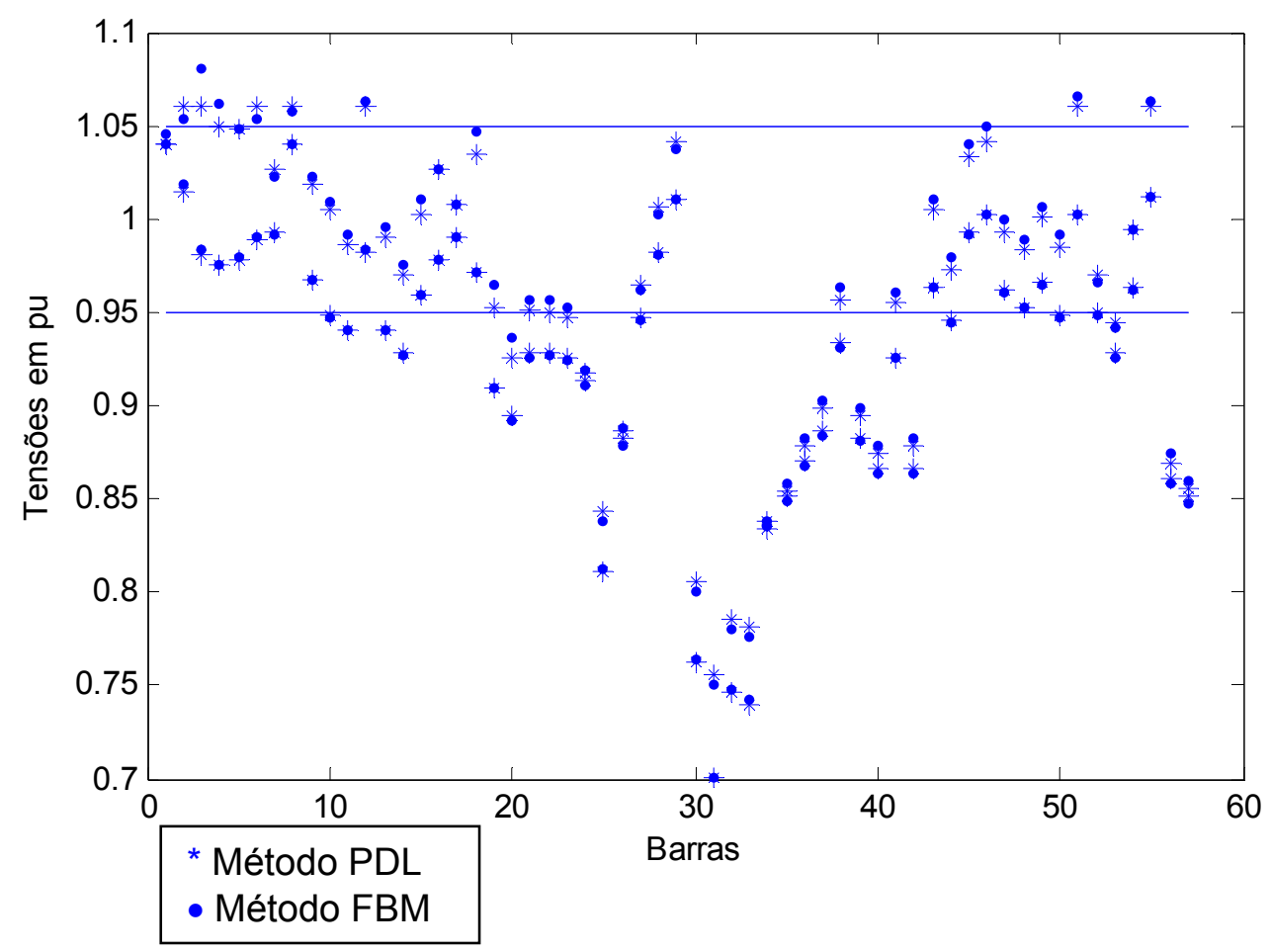

Figura 44. Perfis de tensões para o sistema de 57 barras 
A convergência do Método da Função Lagrangeana Barreira Modificada foi mais rápida do que a do Método Primal-Dual Barreira Logarítmica, conforme mostrado na Tabela 5.4 .

\subsection{SISTEMA DE 118 BARRAS}

O sistema de 118 barras, mostrado na Figura 5.7, tem as seguintes características:

- 1 barra de referência;

- 51 barras de controle de reativo;

- 66 barras de carga;

- 186 linhas de transmissão;

- 9 transformadores com tap variável. 
Capítulo 5 - Testes e Resultados

67

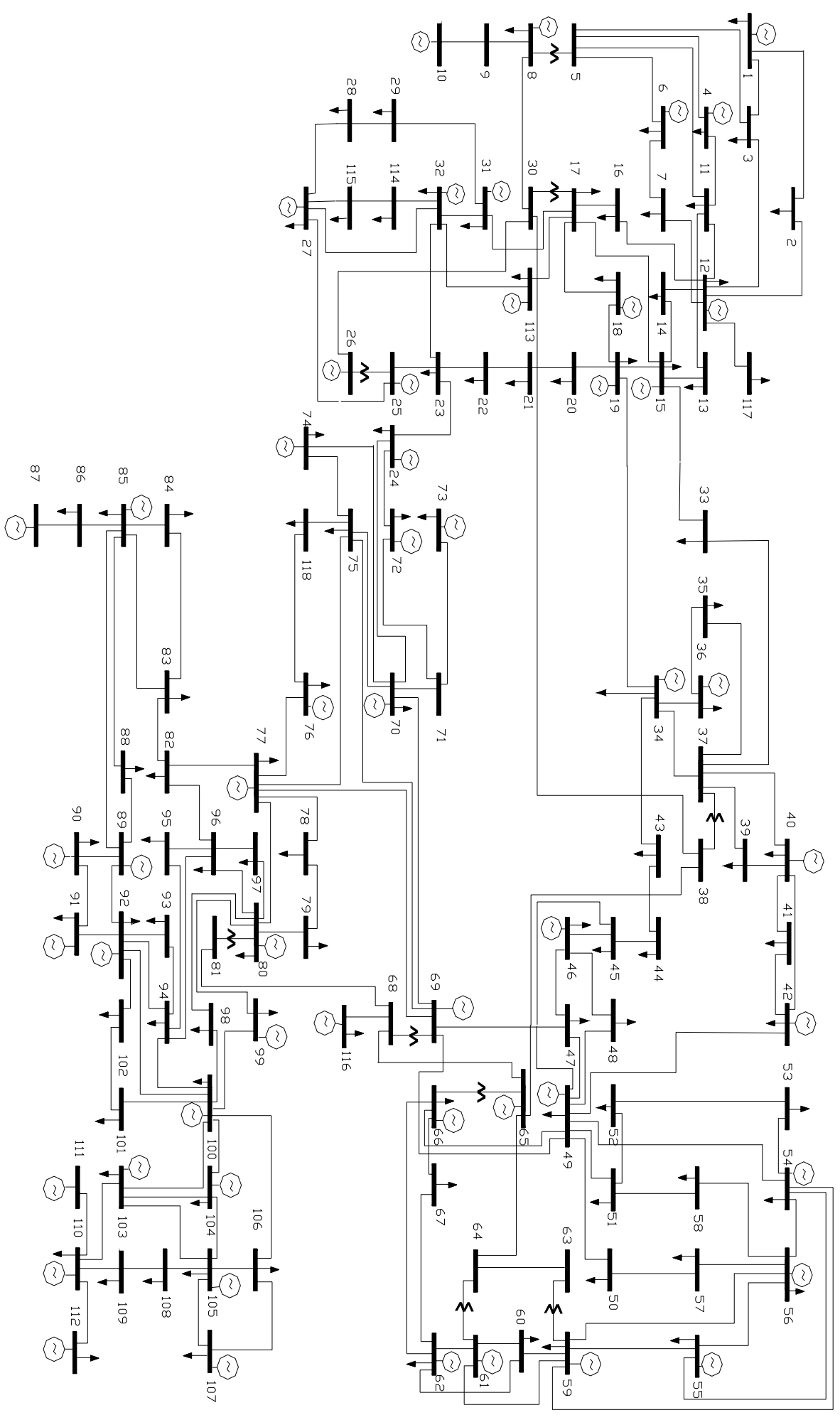

Figura 45 - O sistema de 118 barras. 


\subsubsection{Resultados do Teste 1}

Para o sistema IEEE 118 barras, os resultados obtidos no Teste 1, são apresentados na Tabela 5. O ponto de máximo carregamento difere um pouco de uma metodologia para a outra, isto pode ser constatado também na Figura 46, já que as distribuições das tensões ao longo do sistema apresentam diferenças.

Tabela 5 - Comparativo entre o Método PDBL e o Método da FBM para o sistema de 118 barras

\begin{tabular}{ccc}
\hline & Método PDBL & Método FBM \\
\hline$\alpha$ & 0,998 & 1,110 \\
Iteração & 50 & 47 \\
Barra crítica & 76 & 76 \\
Tensão da Barra crítica & 0,854 & 0,870 \\
\hline
\end{tabular}




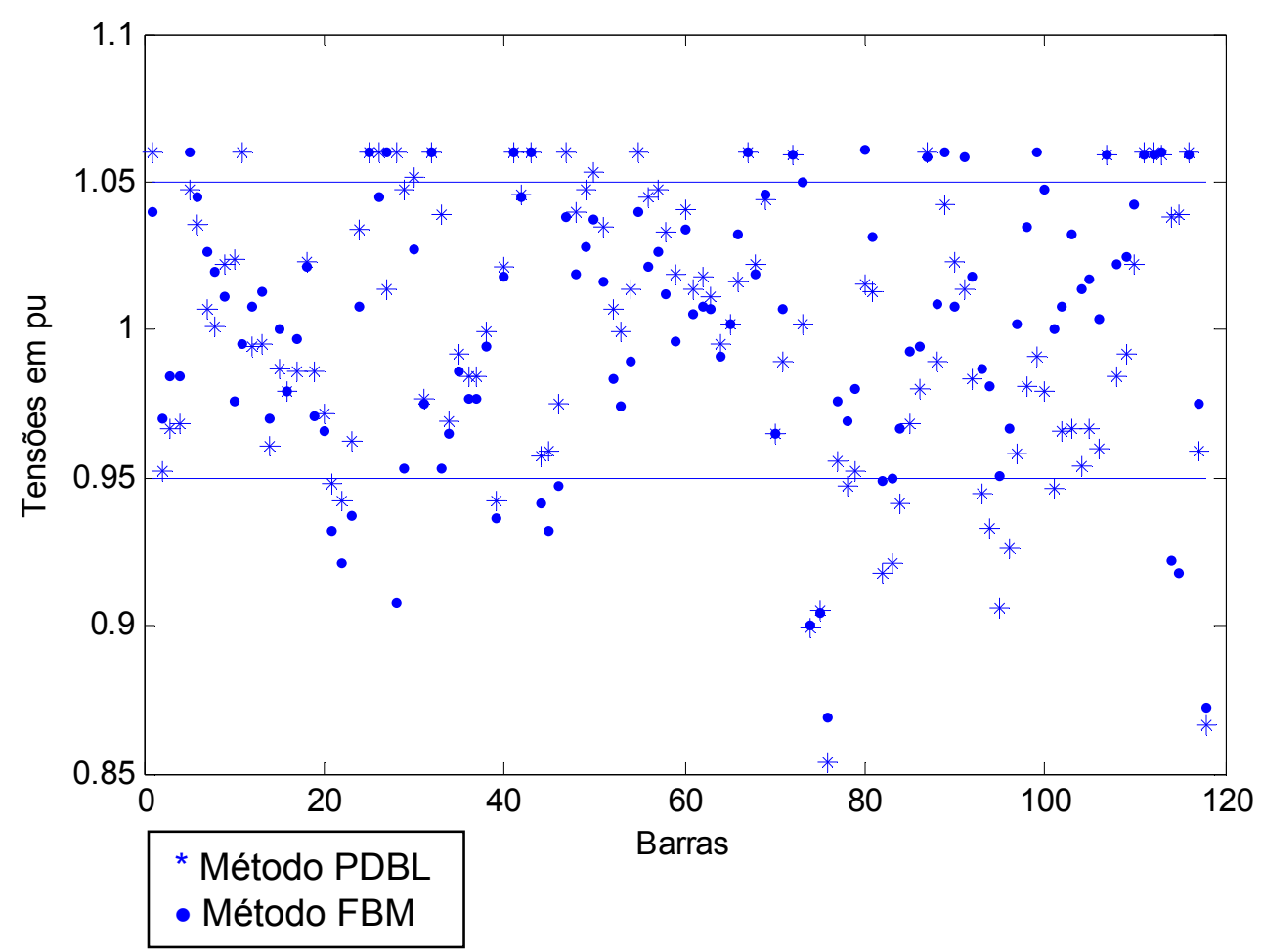

Figura 46. Perfis de tensões para o sistema de 118 barras

O Método da Função Lagrangeana Barreira Modificada convergiu com um número de iterações menor do que o Método Primal-Dual Barreira Logarítmica.

Para o Teste 1, a barra 76 apresenta a menor magnitude de tensão, ou seja, é a barra crítica do sistema, conforme pode-se observar na Tabela 5.5.

\subsubsection{Resultados do Teste 2}

A barra 44 apresenta a menor magnitude de tensão quando não é considerado o limite de geração de potência reativa, conforme a Tabela 6 . 
Tabela 6 - Comparativo entre o Método PDBL e o Método da FBM para o sistema de 118 barras

\begin{tabular}{ccc}
\hline & Método PDBL & Método FBM \\
\hline$\alpha$ & 2,436 & 2,394 \\
Iteração & 52 & 49 \\
Barra crítica & 44 & 44 \\
Tensão da Barra crítica & 0,800 & 0,800 \\
\hline
\end{tabular}

A Figura 47 apresenta os perfis de tensões para o sistema IEEE 118 barra. Nesta figura, constata-se que a distribuição das tensões ao longo do sistema apresenta certa diferença de um método para outro, o que resulta na diferença entre os pontos de máximo carregamento. 


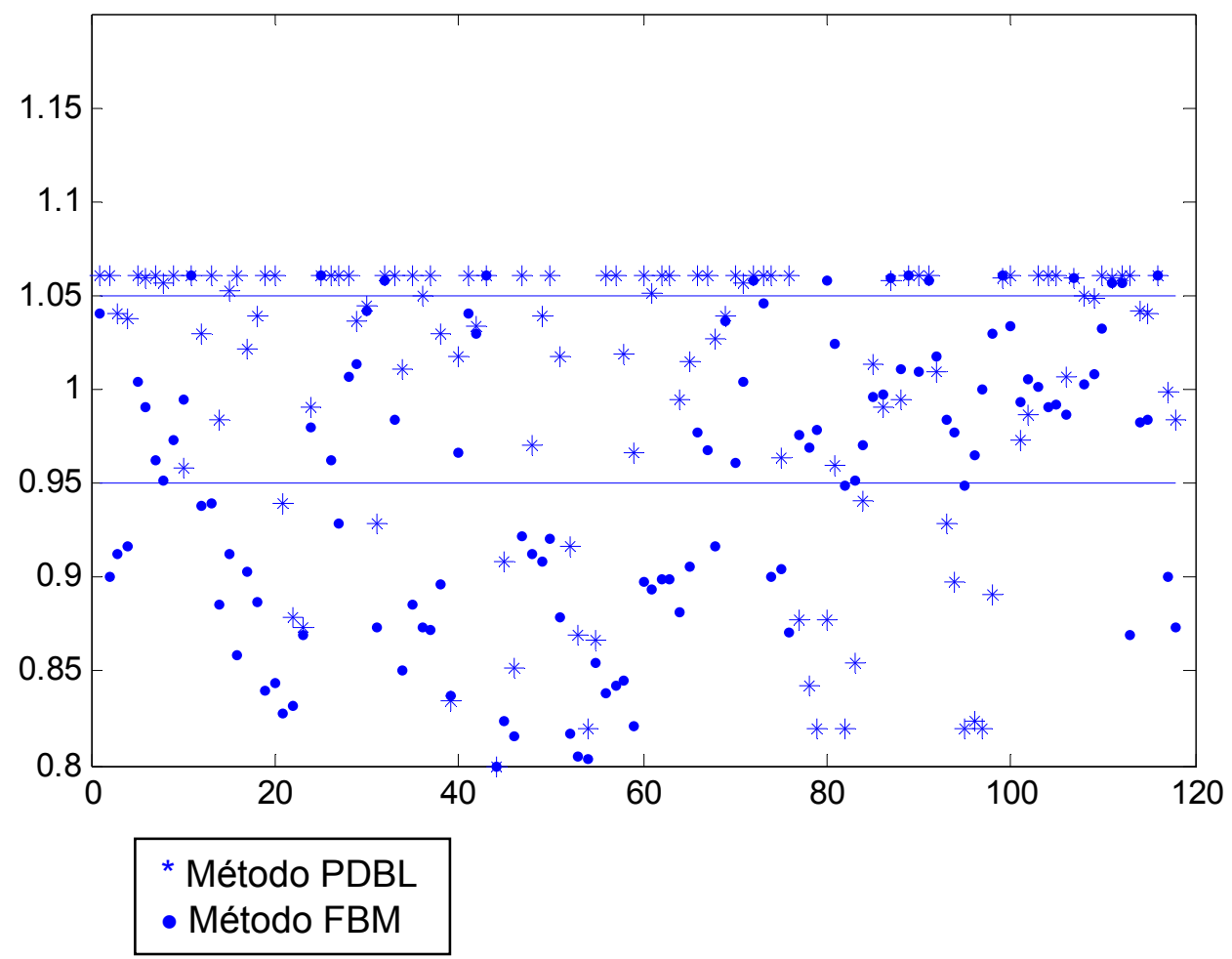

Figura 47. Perfis de tensões para o sistema de 118 barras

Quanto à convergência, o Método da Função Lagrangeana Barreira Modificada convergiu com um número de iterações menor do que o Método PrimalDual Barreira Logarítmica. 


\section{Capítulo 6}

\section{CONCLUSÕES}

Neste trabalho, o ponto de máximo carregamento foi determinado através de um problema de otimização utilizando uma variante do método de pontos interiores, o método da Função Lagrangeana Barreira Modificada. Este problema teve como restrições de igualdade as equações de balanço do sistema e como restrições de desigualdade os limites de tensões nas barras e os limites de geração de potência reativa gerada pelas barras $\mathrm{PV}$.

No método utilizado para resolver o problema de máximo carregamento, as restrições canalizadas foram desmembradas em duas desigualdades, nas quais acrescentou-se variáveis de folga ou de excesso, tornando essas desigualdades em igualdades. As variáveis de folga ou de excesso devem ser estritamente positivas, pois foram tratadas pela função barreira logarítmica e por um parâmetro de barreira. O valor inicial desse parâmetro é determinado pelo usuário. O método é dependente dos valores estimados para o parâmetro de barreira e para o parâmetro utilizado na atualização deste. Apesar dessa dependência, após o ajuste desses parâmetros a convergência é alcançada, isto é, um ponto de operação da rede elétrica é obtido, o qual satisfaz todas as restrições do problema. Verificou-se que o método é muito 
eficiente para parâmetros empíricos corretamente ajustados. As restrições infactíveis tornam-se factíveis durante o processo iterativo.

A propriedade de convergência do algoritmo da FLBM é finita ao invés de assintótica como no método da Função Barreira Clássica, o qual possibilita que a solução ótima encontrada no método da FLBM possa estar na fronteira da região factível, o que não acontece com a FBC, onde a solução somente pode estar próxima à fronteira, mas nunca alcançá-la. Conseqüentemente, as restrições tratadas pela FLBM podem ser nulas, diferentes da FBC. Uma característica interessante do método da FLBM é de não precisar de uma solução inicial factível, ao contrário dos métodos baseados na FBC que possuem essa desvantagem.

Nos testes realizados nos sistemas: IEEE 14, 57 e 118, observa-se que o algoritmo do método da Função Lagrangeana Barreira Modificada possui um desempenho satisfatório para determinação do ponto de máximo carregamento a que um sistema de energia elétrica pode ser submetido. Comparado a sua variante, o Método Primal-Dual Barreira Logarítmica, apresentou resultados semelhantes com a vantagem do número de iterações ser sempre menor.

\subsection{PERSPECTIVA PARA A CONTINUIDADE DESTE TRABALHO}

Como perspectiva para continuidade deste trabalho sugere-se alguns estudos: 
- Desenvolver uma nova abordagem para estimar, a partir do cálculo da margem de carregamento para parâmetros nominais, os efeitos sobre a alteração desta margem após uma perturbação no sistema.

- Ainda, pretende-se analisar os efeitos da perturbação da margem de carregamento nas variáveis de controle do sistema. Com o intuito de se obter informações para tomadas de ações corretivas antes que ocorra o colapso de tensão, isto é, esta estimativa pode ser usada para verificar o efeito quantitativo da ação das diversas variáveis de controle, a fim de se manter uma suficiente margem de carregamento para a operação do sistema.

- Através de análise de sensibilidade, estudar procedimentos de controle ou mesmo cortes de cargas ou outros, para manter o sistema operando em situações adversas após o cálculo da margem de carregamento para parâmetros nominais, 


\section{REFERÊNCIAS}

AJJARAPU, V; CHRISTY, C. (1992). The Continuation Power Flow: a tool for steady state voltage stability analysis. IEEE Transactions on Power Systems. Vol. 7, No 1. pp. 416-423.

ALMEIDA, K.C.; SALGADO, R. (2000). Optimal Power Flow Solutions Under variable Load Conditions. IEEE Transactions on Power Systems, Vol. 15, No. 4, nov. pp. 1204-1211.

ALVES, D. A. (2000). Obtenção do ponto de máximo carregamento em sistemas elétricos de potência utilizando novas técnicas de parametrização para o método de continuação. Tese Doutorado - Faculdade de Engenharia Elétrica e de Computação, Universidade Estadual de Campinas, São Paulo. $116 \mathrm{p}$.

Análise das Perturbações dos Dias 24 E 25/04/97 no Sistema Interligado S/SE/CO. Grupo Coordenador Para Operação Interligada - GCOI. Subcomitê de Estudos Elétricos - SCEL. Grupo de Trabalho de Proteção - GTP. Grupo de Trabalho de Planejamento da Operação - GTPO. Subcomitê de Operação SCO. Grupo de Trabalho de Análise da Operação - GTAO. Volume II. 1997.

BARBOSA L. V; SALGADO R; ALMEIDA K. C. (1998). Estudo do Máximo Carregamento de Sistemas de Potência via Algoritmos de Pontos Interiores. Proceedings of XII Brazilian Automatic Control Conference. Uberlândia - MG, vol. VI, pp.2005-2010.

CHOWDHURY, B. H.; TAYLOR, C. W. Voltage Stability Analysis: V-Q Power Flow Simulation Versus Dynamic Simulation. IEEE Transactions on Power Systems, vol.15, no 4, novembro 2000, p. 1354-1359.

CORTEZ, A. N. e VALE, M. H. M. (2001). Estabilidade de tensão: Impactos técnicos e econômicos decorrentes das metodologias utilizadas na determinação da margem de segurança. XVI SNPTEE, Campinas-SP.

DA SILVA L.C.P. (2001). Uma expansão dos métodos de curvas - PV e de análise modal estática para o estudo de estabilidade de tensão em sistemas de energia elétrica. Tese de doutorado, Universidade Estadual de Campinas UNICAMP.

ECHAVARREN, F.M., LOBATO E., ROUCO L. (2006). A corrective load shedding scheme to mitigate voltage collapse. Electrical Power and Energy Systems No. 28 pp. 58-64. 
GRANVILLE, S., "Optimal reactive dispatch through interior pointmethods", IEEE Transactions on Power Systems, Vol. 9, No 1, February, 1994.

HONG, Y. Y. \& Gau, C. H., 1994, "Voltage Stability Indicator for Identification of the Weakest Bus/Area in Power Systems", IEE Proc. Gener. Transm. Distrib., v. 141, n.4, pp 305-309.

IRISARRI, G. D; WANG, X; TONG, J; MOKHTARI, S. (1997). Maximum Loadability of Power Systems Using Interior Point Non-Linear Optimization Method. In: IEEE Transactions on Power Systems. Vol.12, n 1, pp. 162-172.

KUNDUR P; GAO, B. (1994a). Practical Consideration in Voltage Stability Assesment. In: Proceedings of IV SEPOPE- Symposium of Specialists in Electric Operational and Expansion Planning. Foz do Iguaçu. IV SEPOPE.

KUNDUR, P. Power System Stability and Control. New York: McGraw-Hill, 1994b. 1176 p., $24 \mathrm{~cm}$. (The EPRI Power System Engineering Series). Bibliografia: p. 990999.ISBN 0-07-035958-X.

KUNDUR, P., Morison, G. K., Gao, B., Danai, B. and Maratukulam, D., "Voltage Stability Analysis Program (VSTAB) - Application Guide", Ontario, Canada, November, 1993.

MELMAN, A.; POLYAK, R.A. (1996). The Newton Modified Barrier Method for QP Problems. Annals of Operations Research, v. 54, p. 465-519.

MOHAMED A., JASMON G.B. (1996). Determining the weak segment of a power system with voltage stability considerations. Electric Machines and Power Systems, 24:555-568.

MORISON, G. K., GAO, B. and KUNDUR, P. (1993). Voltage Stability Analysis Using Static and Dynamic Approaches. IEEE Transactions on Power Systems, Vol.8, No.3, pp.1159-1171.

NEMA O.M.S, CASTRO C.A.(1996). Índice de proximidade ao colapso de tensão baseado nas perdas de potência ativa - potencial de utilização na operação em tempo real. III SIMPASE, pp 1-7.

PAL, M. K. (1992). Voltage Stability Conditions Considering Load Characteristics. Transactions on Power Systems. Vol.01, No. 01, pp.243-249.

OVERBYE, T.; J. DOBSON, I.; DEMARCO, C. L. Q-V Curve Interpretations of Energy Measures for Voltage Security. IEEE Transactions on Power Systems, vol. 9, no 1 ,fevereiro 1994, p. 331-340.

POLYAK, R.A. (1992). Modified barrier functions. Mathematical Programming, v. 54, n. 2, p. 177-222.

QUINTANA, V.H., GOMEZ, A., MARTINEZ, J.L. (1995). Nonlinear Optimal Power Flows by Logarithmic-Barrier Primal-Dual Algorithm. IEEE NAPS Meeting. 
RIDER, M. J; CASTRO JUNIOR, C. A; BEDRIÑANA, M. F; GARCIA, A. V. (2004). Um método de pontos interiores para aplicações em otimização de sistemas de potência. In: Anais do XV CBA - Congresso Brasileiro de Automática, 2004, Gramado, RS. v. 1. p. 1-6.

SOUSA, V. A. (2006). Resolução do Problema de Fluxo de Potência Ótimo Reativo Via Método da Função Lagrangiana Barreira Modificada. Tese (Doutorado) - Escola de Engenharia de São Carlos, Universidade de São Paulo, São Carlos, 2006. 126 páginas.

WSCC REACTIVE POWER RESERVE WORK GROUP. (1998). Final Report, Voltage Stability Criteria, Undervoltage Load Shedding Strategy, and Reactive Power Reserve Monitoring Methodology, May, 1998, 154p., Disponível em: $<$ http://www.wscc.com>.

TAYLOR, C. (1994). Power System Voltage Stability. New York: McGraw-Hill.

TAYLOR, C. W. Power System Voltage Stability. New York: McGraw-Hill, 1994b. 274p., $23 \mathrm{~cm}$. (The EPRI Power System Engineering Series). Bibliografia: p. 1-6. ISBN 0-07-063184-0.

ZAMBRONI, A. C. S.; HONÓRIO, L. M; TORRES, G. L. (2004). Increasing the Loadability of Power Systems Through Optimal-Local-Control Actions. IEEE Transactions on Power Systems, Estados Unidos, v. 19, n. 1, p. 188-194. 


\section{ANEXO A - O MÉTODO DOS PONTOS INTERIORES}

\section{A.1 O PROBLEMA DE PROGRAMAÇÃO NÃO LINEAR}

Um típico problema de programação não linear (PNL) que freqüentemente surge em engenharia elétrica, tem a seguinte formulação matemática:

$\min f(x)$

$$
\begin{array}{lll}
\text { s.a } & g_{j}(x)=0, & j=1, \ldots, m<n \\
& h_{i}(x) \geq 0, & i=1, \ldots, p \\
& \underline{x}_{r} \leq x_{r} \leq \bar{x}_{r}, \quad r=1, \ldots, n
\end{array}
$$

em que:

- $\quad \mathrm{x} \in \mathrm{R}^{\mathrm{n}}$ é um vetor das variáveis do problema.

- $\quad f \in R^{n} \rightarrow R^{n}$ é uma função objetivo a ser minimizada.

- $g \in \mathrm{R}^{\mathrm{n}} \rightarrow \mathrm{R}^{\mathrm{m}}$ é um vetor das restrições de igualdade.

- $\mathrm{h} \in \mathrm{R}^{\mathrm{n}} \rightarrow \mathrm{R}^{\mathrm{p}}$ é um vetor das restrições de desigualdade.

Daqui em diante assume-se que $f(x), g_{j}(x)$ e $h_{i}(x)$ possuem derivadas contínuas de segunda ordem.

Qualquer ponto $\hat{x}$ que satisfaça todas as restrições em (A.1) é dito ser factível. O conjunto de todos os pontos factíveis define a região factível, e um ponto factível $x^{*}$ que atende as condições de mínimo desejado é chamado de ótimo local.

O problema não-linear (A.1) pode ser resolvido pelos MPI Primal-Dual de duas maneiras, (i) aplica-se os métodos diretamente ao problema não-linear, ou (ii) 
aplica-se os métodos para uma seqüência de aproximações (locais), como nas aproximações da Programação Linear Seqüencial (PLS) e uma abordagem de Programação Quadrática Seqüencial (PQS). Na sessão seguinte descrevem-se as idéias básicas que estão por trás da aproximação PLS.

\section{A.2 O MÉTODO DE PONTOS INTERIORES PRIMAL-DUAL PARA PNL}

Frisch foi o primeiro a considerar o MPI num manuscrito não publicado em 1955. Esta abordagem da função barreira logarítmica foi mais tarde estudada extensivamente por Fiacco e McCormick (1968), na solução de problemas com restrições de desigualdade genéricos, da seguinte forma:

$\min f(x)$

s.a $\quad h_{i}(x) \geq 0 \quad i=1,2, \ldots, p$

Assume-se que pelo menos um ponto $x^{0}$ (inicial) exista, onde $h_{i}\left(x^{0}\right)>0$, isto é, a região $\Omega:=\left\{x \in R^{n} \mid h_{i}(x) \geq 0\right\}$ é não vazia.

A abordagem de Fiacco e McCormick para resolver (A.2) considera uma abordagem de função barreira logarítmica ponderada para incorporar as restrições de desigualdade na função objetivo, transformando assim um problema com restrições de desigualdade (A.2) em uma seqüência de problemas modificados da forma: 


$$
\min \left\{f_{\mu}\left(x, \mu^{k}\right)=f(x)-\mu^{k} \sum_{i=1}^{p} \ln \left(h_{i}(x)\right)\right\}
$$

em que:

$\mu^{k}>0$ é o parâmetro de barreira.

O parâmetro de barreira monotonicamente decresce até zero com o avanço das iterações. Sob certas condições e $\mu^{k}$ suficientemente pequeno, conduzindo $\mu^{k}$ para zero, a seqüência $\left\{x\left(\mu^{k}\right)\right\}$ de minimização de (A.3) forma um caminho diferenciável continuamente convergindo para $x^{*}$, chamado de "trajetória de barreira", onde x é o minimizador de (A.2).

Várias dificuldades foram observadas com o uso do método de barreira logarítmica clássico para solução de (A.2), conforme segue abaixo:

- O primeiro problema foi a dificuldade de se determinar um ponto inicial factível, que pode ser tão difícil quanto resolver o problema propriamente dito.

- O segundo problema foram as várias dificuldades numéricas (com as técnicas numéricas disponíveis na época), até mesmo se o problema (A.2) fosse bem condicionado.

- Os multiplicadores de Lagrange estimados para as restrições ativas $\left(h_{i}(x)=0\right)$ são obtidos através das razões de duas quantidades tendendo a zero, o qual é instável.

- Ao longo da trajetória que aproxima-se da solução, a matriz Hessiana de $f_{\mu}\left(x, \mu^{k}\right)$ pode apresentar um mal condicionamento e, no limite $\left(\mu^{k} \rightarrow 0\right)$, é singular. 
- Outras dificuldades maiores são: a necessidade de um cuidadoso algoritmo de busca linear, a escolha do valor inicial $\mu^{0}$ e da maneira subseqüente de reduzir $\mu^{k}$ a cada iteração.

Embora os MPI tenham sido desenvolvidos para solucionar problemas de PL genéricos, um grande número de pesquisas com esses métodos para PNL vem recentemente sendo motivadas principalmente pelo bom desempenho dos MPI para PL e Programação Quadrática (PQ). Estas áreas de pesquisa desfrutam de um assombroso progresso nos últimos 10 anos. Descreve-se a seguir o desenvolvimento matemático do MPI Primal-Dual apropriado para resolver o problema de PNL (A.1).

\section{A.3 Problema Modificado e Condições de Otimalidade}

O método de pontos interiores, descrito aqui, inicialmente transforma as restrições canalizadas de (A.1) em duas restrições de desigualdades. Para este fim padroniza-se o sinal $\geq 0$ apenas por convenção e em seguida transformam-se todas as restrições de desigualdades em igualdade através da adição de vetores de excesso não negativos, como segue: 


$$
\begin{array}{ll}
\min & f(x) \\
\text { s.a } & g(x)=0 \\
& h(x)-s_{1 i}=0 \\
& -x_{r}-s_{2 r}+\bar{x}_{r}=0 \\
& x_{r}-s_{3 r}-x_{r}=0 \\
& s_{1 \mathrm{i}}, s_{2 r}, s_{3 r} \geq 0
\end{array}
$$

em que: $\mathbf{s}_{1 i}^{\top}=\left[\mathbf{s}_{11}, \mathbf{s}_{12}, \ldots, \mathbf{s}_{1 p}\right] \in R^{p}, \mathbf{s}_{2 r}^{\top}=\left[\mathbf{s}_{21}, \mathbf{s}_{22}, \ldots, \mathbf{s}_{2 n}\right] \in R^{n}, \mathbf{s}_{3 r}^{\top}=\left[\mathbf{s}_{31}, \mathbf{s}_{32}, \ldots, \mathbf{s}_{3 n}\right] \in R^{n}$ são os vetores da variáveis de excesso.

Como as condições de não negatividade $\left(s_{1 i}, s_{2 r}, s_{3 r}\right) \geq 0$ não podem crescer indefinidamente, serão controladas incorporando-as na função objetivo através da função barreira logarítmica, que impede a aproximação de um ponto factível à fronteira da região factível, ou seja, os termos logarítmicos garantem as condições das variáveis de folga serem estritamente positivas, as quais são tratadas implicitamente.

$\min f(x)-\mu \sum_{i=1}^{p} \ln \left(s_{1 i}\right)-\mu \sum_{r=1}^{n}\left[\ln \left(s_{2 r}\right)+\ln \left(s_{3 r}\right)\right]$

$$
\begin{array}{ll}
\text { s.a } & g_{j}(x)=0 \\
& h_{i}(x)-s_{1 i}=0 \\
& -x_{r}-s_{2 r}+\bar{x}_{r}=0 \\
& x_{r}-s_{3 r}-\underline{x}_{r}=0
\end{array}
$$

em que $\mu$ tende a zero durante o processo iterativo. 
Para resolver as restrições do problema (A.5), usa-se o método de NewtonLagrange. Associado ao problema (A.5) tem-se a função Lagrangiana que é dada por:

$$
\begin{aligned}
L= & f(x)-\mu \sum_{i=1}^{p} \ln \left(s_{1 i}\right)-\mu \sum_{r=1}^{n}\left[\ln \left(s_{2 r}\right)+\ln \left(s_{3 r}\right)\right]+ \\
& -\sum_{j=1}^{m} \lambda_{j} g_{j}(x)-\sum_{i=1}^{p} \pi_{1 i}\left[h_{i}(x)-s_{1 i}\right]+ \\
& -\sum_{r=1}^{n}\left[\pi_{2 r}\left(-x_{r}-s_{2 r}+\bar{x}_{r}\right)+\pi_{3 r}\left(x_{r}-s_{3 r}-\underline{x}_{r}\right)\right]
\end{aligned}
$$

em que:

$\lambda \in \mathrm{R}^{\mathrm{m}}, \pi_{1 \mathrm{i}} \in \mathrm{R}^{\mathrm{p}}, \pi_{2 \mathrm{r}} \in \mathrm{R}^{\mathrm{n}}, \pi_{3 \mathrm{r}} \in \mathrm{R}^{\mathrm{n}}$ são vetores dos multiplicadores de Lagrange, chamados de variáveis duais.

Quando o ponto factível $\bar{x}_{r}$ atinge o mínimo desejado $x_{r}^{*}$ é chamado de mínimo local de (A.6), sendo expresso em termos de um ponto satisfatório de (A.6), e que precisa satisfazer as condições necessárias de primeira-ordem de KarushKuhn-Tucker (KKT) encontrando-se assim os pontos extremos para achar um candidato ao ótimo.

$\nabla_{\mathrm{y}} \mathrm{L}=0$

sendo: 


$$
\nabla_{y} L=\left[\begin{array}{l}
\nabla_{x} f(x)^{\top}-J(x)^{\top} \lambda-J_{1}(x)^{\top}\left(\pi_{1 i}\right)+\left(\pi_{2 r}\right)^{\top} I-\left(\pi_{3 r}\right)^{\top} I \\
-\mu S_{1}^{-1} e+\pi_{1 i} \\
-\mu S_{2}^{-1} e+\pi_{2 r} \\
-\mu S_{3}^{-1} e+\pi_{3 r} \\
-g(x) \\
-\left(h(x)-S_{1 i}\right) \\
-\left(-x_{r}-S_{2 r}+\bar{x}_{r}\right) \\
-\left(x_{r}-S_{3 r}-\underline{x}_{r}\right)
\end{array}\right]
$$

em que: $y=\left(x_{r}, s_{1 i}, s_{2 r}, s_{3 r}, \lambda_{j}, \pi_{1 i}, \pi_{2 r}, \pi_{3 r}\right)$ é vetor das variáveis do problema, $J(x)^{\top}=\left(\nabla_{x} g_{1}(x), \ldots, \nabla_{x} g_{m}(x)\right), J_{1}(x)^{\top}=\left(\nabla_{x} h_{1}(x), \nabla_{x} h_{2}(x), \ldots, \nabla_{x} h_{p}(x)\right)$ são denominadas matrizes Jacobianas, I é a matriz identidade, $\mathrm{e}^{\top}=[1, \ldots, 1]$ e $\mathrm{S}_{1}, \mathrm{~S}_{2}, \mathrm{~S}_{3}$ são matrizes diagonais cujos elementos são: $s_{1 i}, s_{2 r}$ e $s_{3 r}$, respectivamente.

O algoritmo simplificado do MPI Primal-Dual é mostrado a seguir:

Passo 0: (Inicialização)

Faça $k=0$, defina $\mu^{\mathrm{k}}$ e escolha um ponto inicial $\mathrm{y}^{\mathrm{k}}$ que satisfaça as condições de positividade estrita das variáveis de excesso.

Passo 1: (Cálculo da Direção de Newton)

Formule o sistema de Newton no ponto atual e resolva para a direção de Newton.

Passo 2: (Atualização das Variáveis)

Calcule o tamanho do passo $(\Delta y)$ na direção de Newton e atualize as variáveis primais e duais. 
Passo 3: (Teste de Convergência)

Se o novo ponto calculado satisfizer o critério de convergência, pare. Caso contrário, faça $k=k+1$, atualize o parâmetro de barreira $\mu^{k}$, e retorne ao passo 1.

\section{Cálculo da Direção de Newton}

O sistema de equações não-lineares (A.7) é resolvido pelo método de Newton. Esse método utiliza a expansão em série de Taylor até primeira-ordem das equações do sistema, gerando um sistema do tipo $A x=b$; a solução desse sistema é vetor das direções de busca $(\Delta y)$, o qual será utilizado na atualização das variáveis.

$\nabla_{\mathrm{y}}^{2} \mathrm{~L} \cdot \Delta \mathrm{y}=-\nabla_{\mathrm{y}} \mathrm{L}$

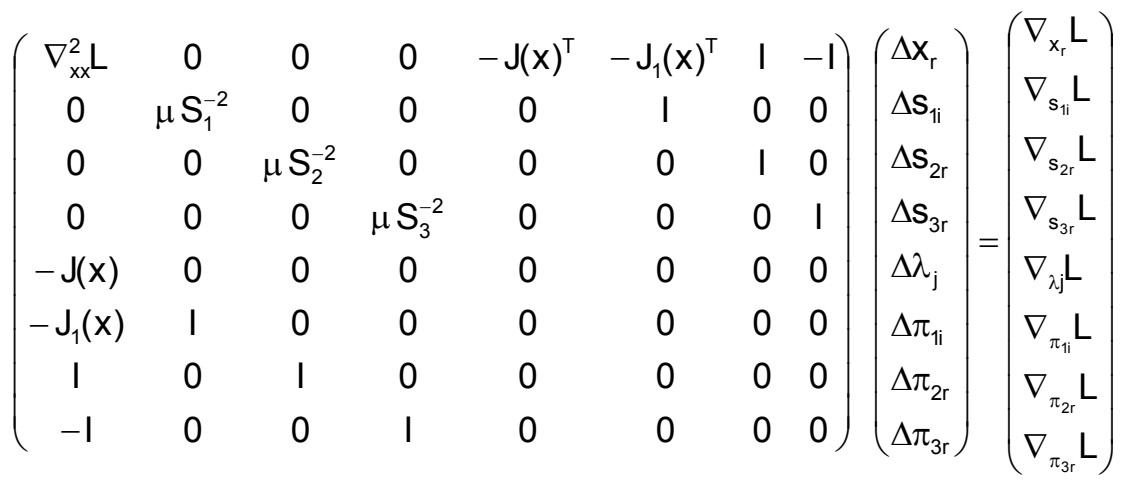

em que $\nabla_{x x}^{2} L=\nabla_{x x}^{2} f(x)-\nabla_{x x}^{2} J(x)^{\top} \lambda_{j}-\nabla_{x x}^{2} J_{1}(x)^{\top} \pi_{1 i}$. 


\subsection{3 - Atualização das Variáveis}

A direção de busca $\Delta y^{k}$ deve fornecer uma solução interior $y^{k+1}>0$ para que $\mathrm{y}^{\mathrm{k}+1}$ seja interior e o procedimento possa ser repetido.

Deve-se fazer uma escolha apropriada do tamanho do passo $\alpha^{k}>0$, de forma que:

$\mathrm{y}^{\mathrm{k}+1}=\mathrm{y}^{\mathrm{k}}+\alpha^{\mathrm{k}} \Delta \mathrm{y}>0$

Assim, as variáveis primais e duais são atualizadas por:

$$
\begin{array}{ll}
x_{r}^{k+1}=x_{r}^{k}+\alpha_{P}^{k} \Delta x & \lambda_{j}^{k+1}=\lambda_{j}^{k}+\alpha_{D}^{k} \Delta \lambda \\
s_{1 i}^{k+1}=s_{1 i}^{k}+\alpha_{P}^{k} \Delta s_{1 i} & \pi_{1 i}^{k+1}=\pi_{1 i}^{k}+\alpha_{D}^{k} \Delta \pi_{1 i} \\
s_{2 r}^{k+1}=s_{2 r}^{k}+\alpha_{P}^{k} \Delta s_{2 r} & \pi_{2 r}^{k+1}=\pi_{2 r}^{k}+\alpha_{D}^{k} \Delta \pi_{2 r} \\
s_{3 r}^{k+1}=s_{3 r}^{k}+\alpha_{P}^{k} \Delta s_{3 r} & \pi_{3 r}^{k+1}=\pi_{3 r}^{k}+\alpha_{D}^{k} \Delta \pi_{3 r}
\end{array}
$$

em que os escalares $\alpha_{P}^{k} \in(0,1]$ e $\alpha_{D}^{k} \in(0,1]$ são os tamanhos dos passos primais e duais respectivamente, e k é a iteração atual.

Caso tenha-se $\Delta y^{k} \geq 0$ então $\alpha^{k}$ pode ser qualquer número positivo de forma que sempre a condição (A.9) é satisfeita. Isto revela um ponto de descida e o problema não tem solução ótima finita. Portanto, o tamanho máximo do passo a ser tomado na direção de Newton é escolhido para preservar a positividade do vetor s e o sinal do vetor dos multiplicadores de Lagrange. Isto se traduz por: 


$$
\begin{aligned}
& \alpha_{\mathrm{P}}^{\mathrm{k}}=\gamma^{*} \min \left\{1, \min \left\{\frac{\mathrm{s}_{1 \mathrm{i}}^{\mathrm{k}}}{\left|\Delta \mathrm{s}_{1 \mathrm{i}}\right|}\left|\Delta \mathrm{s}_{1 \mathrm{i}}<0, \frac{\mathrm{s}_{2 \mathrm{r}}^{\mathrm{k}}}{\left|\Delta \mathrm{s}_{2 \mathrm{r}}\right|}\right| \Delta \mathrm{s}_{2 \mathrm{r}}<0, \frac{\mathrm{s}_{3 \mathrm{r}}^{\mathrm{k}}}{\left|\Delta \mathrm{s}_{3 \mathrm{r}}\right|} \mid \Delta \mathrm{s}_{3 \mathrm{r}}<0\right\}\right\}, \\
& \alpha_{\mathrm{D}}^{\mathrm{k}}=\gamma^{*} \min \left\{1, \min \left\{\frac{\pi_{1 \mathrm{i}}^{\mathrm{k}}}{\left|\Delta \pi_{1 \mathrm{i}}\right|} \mid \Delta \pi_{1 \mathrm{i}}<0, \frac{\left.\left.\pi_{2 \mathrm{r}}^{\mathrm{k}}\left|\Delta \pi_{2 \mathrm{r}}<0, \frac{\pi_{3 \mathrm{r}}^{\mathrm{k}}}{\left|\Delta \pi_{2 \mathrm{r}}\right|}\right| \Delta \pi_{3 \mathrm{r}}<0\right\}\right\}}{\left|\Delta \pi_{3 \mathrm{r}}\right|}\right)\right.
\end{aligned}
$$

em que $\gamma=0,9995$ é um valor determinado empiricamente, ou que pode ser calculado a partir da fórmula $1-1 /(9 \sqrt{z})$, segundo Wright (1995), sendo z o número de restrições de desigualdade do problema. Este escalar é um fator para assegurar que o próximo ponto irá satisfazer as condições de positividade estrita.

A equação (A.11) apresenta o cálculo para o tamanho dos passos primal e dual de forma separada, o que é uma vantagem para o MPI Primal-Dual para resolver problemas de $\mathrm{PL}$, e tem provado ser altamente eficiente na prática, pois acelera a convergência do método reduzindo o número de iterações de entre $10 \%$ a 20\% em problemas típicos. Em geral, nos problemas de PNL a interdependência das variáveis primais e duais presentes nas condições de factibilidade dual, não permite a separação do tamanho do passo no espaço primal e dual. Neste caso, um único tamanho do passo a para atualizar as variáveis primais e duais pode ser calculado por:

$$
\alpha=\min \left\{\alpha_{P}^{k}, \alpha_{D}^{k}\right\}
$$




\section{Redução do Parâmetro de Barreira}

O MPI Primal-Dual é muito sensível quanto ao parâmetro de barreira $\mu$. Para problemas de PL, a atualização deste parâmetro está geralmente baseada na redução do gap de dualidade. Dessa forma, Granville (1994) propõe a atualização de $\mu$ através da Equação (A.14), em que o numerador corresponde ao gap de dualidade.

$\mu=\frac{s_{1 i} \pi_{1 i}+s_{2 r} \pi_{2 r}+s_{3 r} \pi_{3 r}}{2 n \beta}$

em que n é o número de variáveis tratadas por barreira e $\beta>1$ é o fator de correção especificado pelo usuário.

Por se tratar de um dado empírico do método, uma forma mais simples de atualizar $\mu$ foi realizada por meio da equação (3.15).

$$
\mu^{k+1}=\frac{\mu^{k}}{\beta}
$$

em que $\beta>1$ é o fator de correção definido pelo usuário.

Um ponto inicial estritamente factível não é obrigatório, mas as condições de positividade estrita $\left(s_{1 i}>0, s_{2 r}>0, s_{3 r}>0, \pi_{1 i}>0, \pi_{2 r}>0\right.$ e $\left.\pi_{3 r}>0\right)$ devem ser satisfeitas em todos os pontos. O processo de otimização termina quando o valor da 
norma do vetor gradiente for menor do que uma tolerância de convergência $\xi$ preestabelecida e as condições de KKT estão satisfeitas. 